\title{
ESTIMATIVA DA EROSÃO DO SOLO EM UMA BACIA HIDROGRÁFICA NO MUNICÍPIO DE PIRACICABA (SP) UTILIZANDO OS MODELOS USLE E WEPP
}

\author{
SIMONE BeATRIz LIMA RANIERI \\ Engenheiro Agrônomo
}

Orientador: Prof. Dr. QUIRIJN DE JONG VAN LIER

\begin{abstract}
Tese apresentada à Escola Superior de Agricultura "Luiz de Queiroz", Universidade de São Paulo, para obtenção do título de Doutor em Agronomia, Área de Concentração: Solos e Nutrição de Plantas.
\end{abstract}

P I R A C I C A B A

Estado de São Paulo - Brasil

Outubro - 2000 


\section{ERRATA}

pág. 10: substituir eq. (2) por: $\mathrm{EI}=67,556\left(r^{2} / \mathrm{P}^{\prime}\right)^{0,85}$

págs. 8, $34 \mathrm{e} \mathrm{57:} \mathrm{substituir} \mathrm{unidade} \mathrm{do} \mathrm{fator} \mathrm{R}$ por $\mathrm{MJ} \mathrm{ha}^{-1} \mathrm{~mm} \mathrm{~h}^{-1} \mathrm{ano}^{-1}$ e unidade do fator $\mathrm{K}$ por $\mathrm{Mg} \mathrm{ha}^{-1}\left(\mathrm{MJ} \mathrm{ha}^{-1} \mathrm{~mm} \mathrm{~h}^{-1}\right)^{-1}$ 


\section{Dados Internacionais de Catalogaçāo na Publicaçāo (CIP) DIVISÃO DE BIBLIOTECA E DOCUMENTAÇĀO - Campus "Luiz de Queiroz"/USP}

Ranieri, Simone Beatriz Lima

Estimativa da erosão do solo em uma bacia hidrográfica no municipio de Piracicaba (SP) utilizando os modelos USLE e WEEP / Simone Beatriz Lima Ranieri. - - Piracicaba, 2000.

95 p. : il.

Tese (doutorado) - Escola Superior de Agricultura Luiz de Queiroz, 2000.

Bibliografia.

1. Bacia hidrográfica 2. Conservação do solo 3. Erosão 4. Geologia física 5.

Geoprocessamento 6. Manejo de solo 7. Modelo matemático 8. Proteção ambiental 9. SIG (Sistema de computador) I. Título

CDD 551.302

Permitida a conia total ou parcial deste documento. des de que citaila a fonte-0 - 6 utor 
"Verdade é uma coisa que o homem usa para dizer que os outros estão errados. Ela é parecida com a Lua e tem um monte de caras diferentes. Quando a verdade é verdadeira mesmo, todo mundo concorda com ela."

Patricia Gebrim - "Palavra de Criança" 
Dedico, com muito carinho, ao meu amor, Luís Fernando e ao meu filho Eduardo. 
Agradeço

à FAPESP, pela Bolsa de Estudos e demais recursos concedidos para a realização deste projeto,

ao Prof. Quirijn de Jong van Lier, pela orientação e presença constante no desenvolvimento do trabalho,

ao Prof. Gerd Sparovek, pelas idéias, discussões e incentivo ao aprimoramento deste estudo fora do país,

ao Dr. Dennis Flanagan, pela orientação do trabalho na Universidade de Purdue,

à pesquisadora Isabella $\mathrm{C}$. De Maria, pelo auxílio na aplicação dos modelos e pelas discussões, sugestões e críticas,

à toda equipe do Projeto Ceveiro: Mara de A. M. Weill, Enio F. da Silva, Roberta B. M. Sparovek, Daniele Focht e Peterson R. Fiorio, pela realização do trabalho de campo e por todo o aprendizado em conjunto,

aos queridos amigos brasileiros em Purdue, pelo apoio, infra-estrutura e calor humano, que tornaram nossa estadia tão alegre,

à Maria Lygia, pela base. 


\section{SUMÁRIO}

Página

ESTIMATIVA DA EROSÃO DO SOLO EM UMA BACIA HIDROGRÁFICA NO MUNICÍPIO DE PIRACICABA (SP) UTILIZANDO OS MODELOS USLE E WEPP...iii

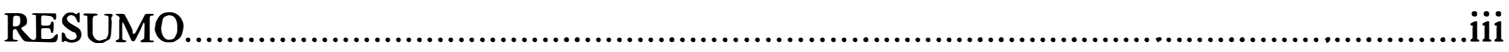

SUMMARY

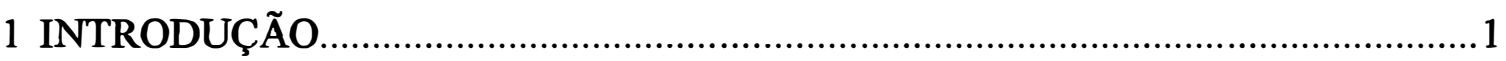

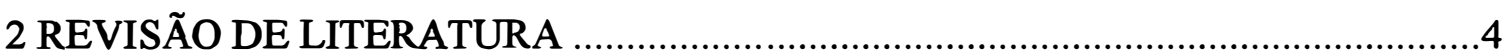

2.1 A bacia hidrográfica como unidade de estudo da erosão do solo...........................

2.2 Avaliação quantitativa da erosão do solo.............................................................

2.3 Evolução dos modelos de estimativa de erosão....................................................

2.4 USLE: histórico e apresentação do modelo.........................................................

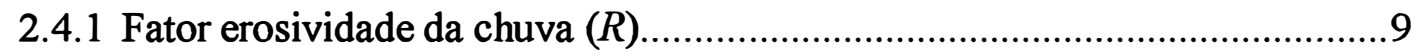

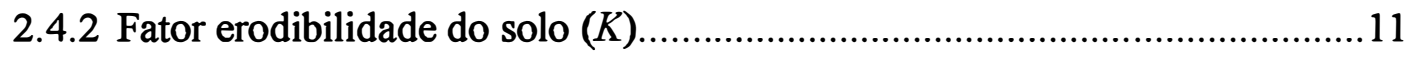

2.4.3 Fator comprimento de rampa e grau de declive $(L S) \ldots \ldots \ldots \ldots \ldots \ldots \ldots \ldots \ldots \ldots \ldots \ldots . . .12$

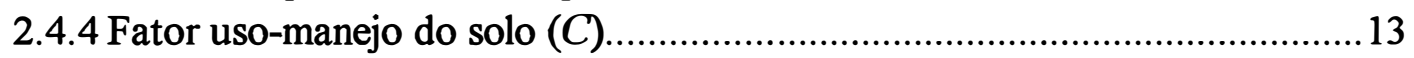

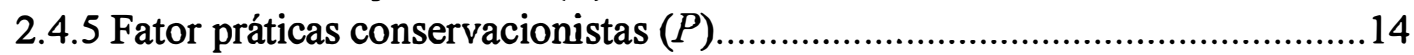

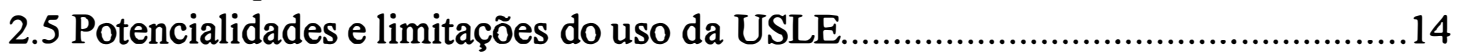

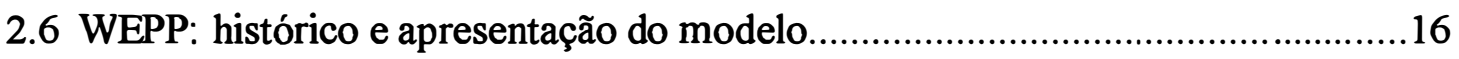

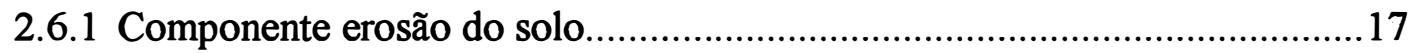

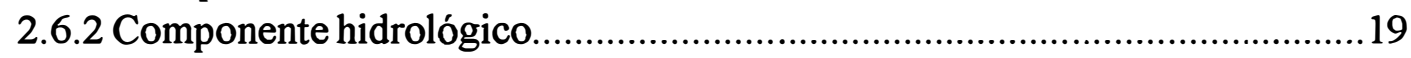

2.6.3 Componente crescimento vegetal e decomposição de resíduos......................21

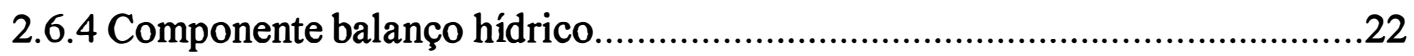

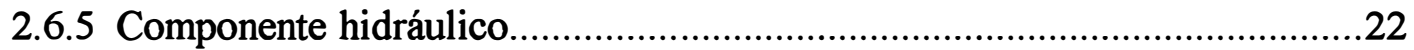

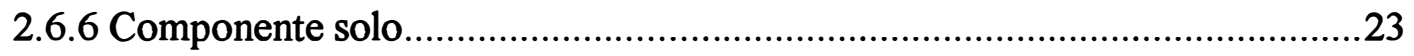

2.7 Potencialidades e limitações do uso do WEPP.................................................24

2.8 Compatibilidade dos modelos com Sistemas de Informações Geográficas..........25

3 DESENVOLVIMENTO DE UM PROGRAMA COMPUTACIONAL PARA APLICAÇÃO VETORIAL DE MOdELOS DE ESTIMATIVA DE EROSÃo

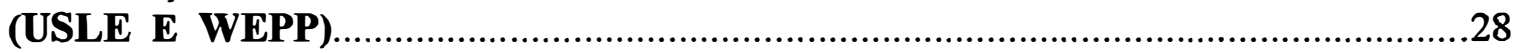

Resumo

Summary

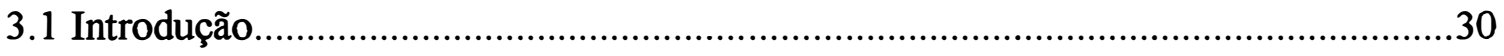

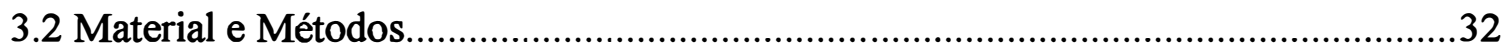




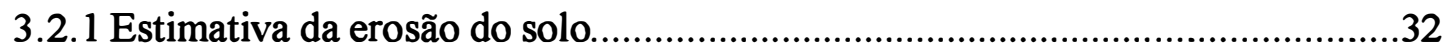

3.2.2 Dados de entrada necessários ao programa de interface..................................33

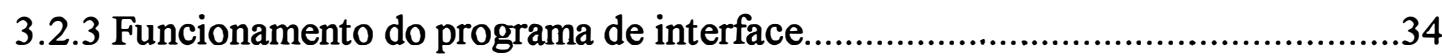

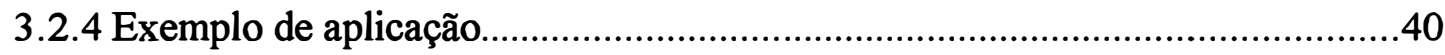

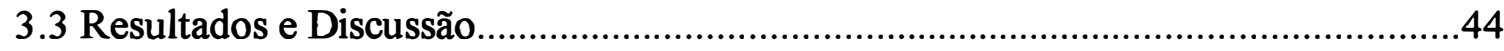

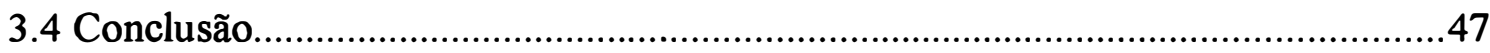

4 COMPARAÇ̃̃O GEORREFERENCIADA DOS MODELOS DE ESTIMATIVA

DE EROSÃO USLE E WEPP EM UMA BACIA HIDROGRÁFICA COM

PREDOMINÂNCIA DE CANA-DE-AÇÚCAR........................................................... 48

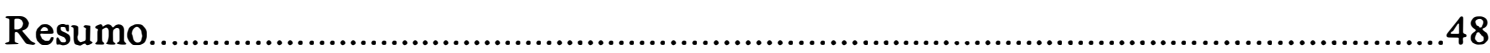

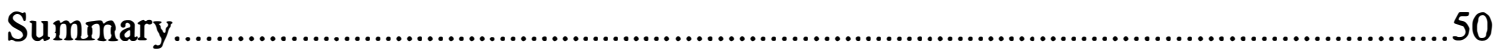

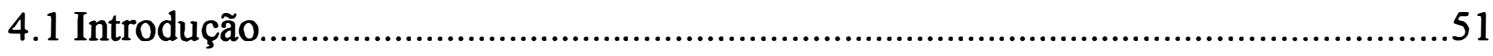

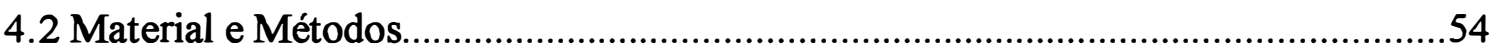

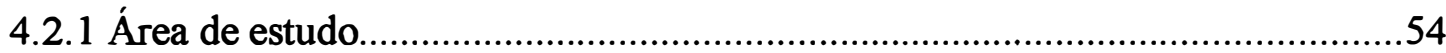

4.2.2 Obtenção e tratamento das informações do meio físico.....................................55

4.2.3 Levantamento de dados, ajuste dos parâmetros para o modelo

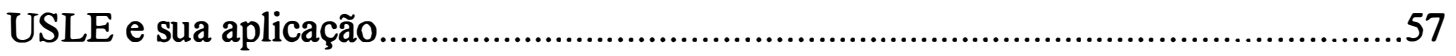

4.2.4 Levantamento de dados, ajuste dos parâmetros para o modelo WEPP e sua

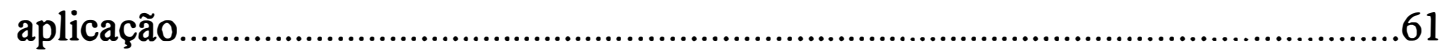

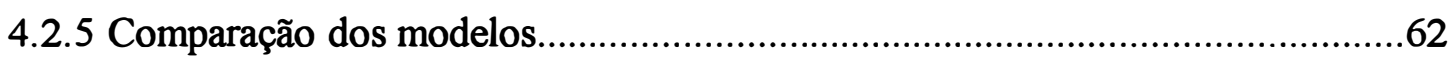

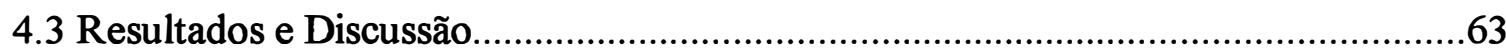

4.3.1 Comparação dos valores médios de erosão estimados pelos modelos................63

4.3.2 Comparação da distribuição espacial dos valores de erosão estimados

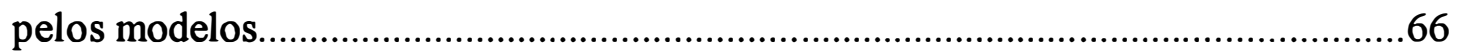

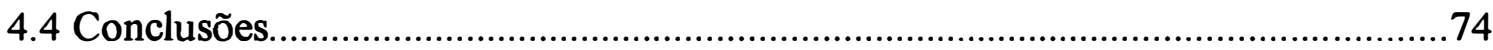

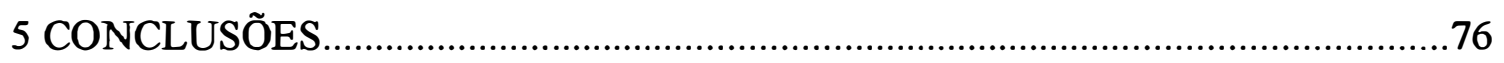

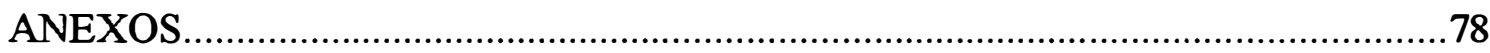

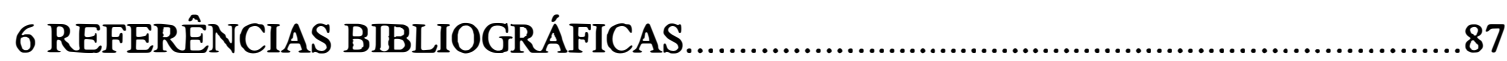




\title{
ESTIMATIVA DA EROSÃo DO SOLO EM UMA BACIA HIDROGRÁFICA NO MUNICÍPIO DE PIRACICABA (SP) UTILIZANDO OS MODELOS USLE E WEPP
}

\author{
Autora: Simone Beatriz Lima Ranieri \\ Orientador: Quirijn de Jong van Lier
}

\section{RESUMO}

O objetivo deste trabalho foi a aplicação de dois modelos de estimativa de erosão de concepções distintas em uma microbacia de 75,8 ha, com vários usos da terra, na região de Piracicaba - SP. Os modelos utilizados foram a Universal Soil Loss Equation (USLE) e o Water Erosion Prediction Project (WEPP). A aplicação dos modelos foi feita com o auxílio de um Sistema de Informações Geográficas (SIG), utilizando uma interface computacional desenvolvida para tornar possível o processamento georreferenciado dos resultados de perda e deposição de sedimentos. A definição das vertentes nas quais foram estimadas as perdas e deposições foi feita de forma vetorial, o que fez com que houvesse menor degradação das informações do relevo, com a diminuição de erros no cálculo da declividade e dos comprimentos de rampa, que freqüentemente ocorrem quando feitas pelo método matricial. A interface desenvolvida foi capaz de extrair as informações espaciais vindas do SIG, construir arquivos básicos para a aplicação dos modelos e georreferenciar novamente resultados pontuais de erosão para a sua releitura no SIG. Este processo automatizado permitiu que a avaliação da perda e deposição de sedimentos fosse feita espacialmente.

A USLE estimou perdas de solo, em média, 2,91 vezes superiores ao WEPP, independentemente do tipo de solo, comprimento da vertente ou uso da terra, exceção feita para as áreas de mata ciliar. Os valores médios de perda de solo obtidos para a bacia foram de 108,8 Mg.ha.ano ${ }^{-1}$ e 34,8 Mg.ha.ano ${ }^{-1}$ para a USLE e para o WEPP, respectivamente. A distribuição espacial da erosão na bacia foi diferente para os dois modelos, ocorrendo na USLE quebras abruptas nos valores de perda de solo devido ao peso do fator uso-manejo (C) dessa equação. Uma tendência de aumento das diferenças 
entre as estimativas dos dois modelos foi observada da parte superior para a inferior das vertentes, sendo que a relação USLE/WEPP aumentou neste sentido devido à consideração da deposição de sedimentos por parte do WEPP ao longo das encostas.

A necessidade de extrapolação das condições pelas quais a USLE foi concebida e a desconsideração das deposições de sedimentos nas encostas permitem afirmar que esta não deve ser utilizada em áreas como bacias hidrográficas. Por sua vez, diversas dificuldades na estimativa de erosão nesta escala foram superadas com o uso do WEPP devido à consideração das áreas de deposição de sedimentos e à possibilidade de aplicação em áreas irregulares e com diferentes seqüências de usos e solos. Tendo sido contornado o problema da variabilidade espacial das perdas e deposições pela atribuição de georreferência aos resultados, o principal desafio para a utilização deste modelo é o levantamento dos fatores aos quais o WEPP é mais sensível para as condições de estudo, com vistas a diminuir o número de experimentações necessárias para o levantamento dos parâmetros e tornar viável sua aplicação em planejamento agrícola e ambiental.

Palavras-chave: erosão; bacia hidrográfica; SIG; USLE; WEPP. 


\title{
Soil erosion prediction in a Watershed in Piracicaba (Brazil) USING THE MODELS USLE AND WEPP
}

\author{
Author: Simone Beatriz Lima Ranieri \\ Adviser: Quirijn de Jong van Lier
}

\section{SUMMARY}

The objective of this study was to compare two erosion models with different theoretical conceptions in a watershed of 75.8 ha with a series of land uses, in the region of Piracicaba - Brazil. The models used were the Universal Soil Loss Equation (USLE) and the Water Erosion Prediction Project (WEPP). The application of the models was done with the support of a Geographic Information System (GIS), using a computer interface developed to allow georeferenced processing of soil loss and sediment depositions. The definition of hillslopes for which the soil losses and depositions were estimated was done in a vector format, resulting in a lower loss of relief information due to the decrease of errors in the calculation of the slope length and steepness, that frequently occur when done in a raster format. The interface was capable to extract the spatial information from the GIS, to build basic files for the application of the models and to georeference punctual results of erosion for its entry in the GIS. This automated process allowed soil loss and sediment depositions to be treated as spatial variables.

With exception of the riparian forest, USLE estimated soil losses 2.91 times higher than WEPP, independently of the soil type, slope length or land use. The medium values of soil loss obtained for the watershed were 108.8 Mg.ha.year ${ }^{-1}$ and 34.8 Mg.ha.year ${ }^{-1}$ for USLE and WEPP respectively. The spatial distribution of erosion was different for the models, occurring abrupt changes in the values of soil loss for USLE due to the weight of the cover and management factor (C). The differences between the models increased from the top to the bottom of the hillslopes, and the ratio USLE/WEPP also increased due to the consideration of the deposition of sediments by WEPP along the hills. 
The need of extrapolation from the conditions that USLE was developed for and the disregard of sediment depositions allow to affirm that USLE should not be applied on watersheds scale. On the other hand, several difficulties in the erosion estimation at this scale were overcome using WEPP due to the consideration of sediment depositions and the possibility of application on irregular areas with different sequences of land use and soils. The main challenge for the use of this model is the identification of the factors for which WEPP is most sensitive, allowing reduction of the number of necessary experiments for the identification of parameters and making possible the application of WEPP in agricultural and environmental planning.

Key-words: erosion; watershed; GIS; USLE; WEPP. 


\section{INTRODUÇÃO}

A erosão acelerada do solo consiste num dos principais impactos ambientais causados pela atividade agrícola e, apesar da dificuldade de se calcular com precisão as perdas de solo, sabe-se que estas perdas têm causado sérias conseqüências econômicas e ambientais (Lal, 1988). Portanto, a estimativa das perdas de solo é essencial para se determinar a magnitude dos impactos da agricultura nos recursos naturais e para definir a sustentabilidade dos agroecossistemas (Matson et al., 1997), além de servir como guia para a seleção de melhores práticas de manejo. Diversos modelos matemáticos vêm sendo desenvolvidos e aperfeiçoados desde a década de 50 com o intuito de prever a magnitude das perdas de solo por erosão, afirmando a tendência mundial de se abordar problemas ambientais da forma quantitativa (Bouma, 1989). Duas concepções distintas de modelos de estimativa de erosão podem ser citadas: a dos modelos monoequacionários e a dos mecanísticos. Entre os modelos monoequacionários mais usados está a “Universal Soil Loss Equation"-USLE (Wischmeier \& Smith, 1978), que vem sendo extensivamente utilizada em trabalhos de planejamento agrícola desde sua publicação e, mais recentemente, como instrumento para avaliação de impactos ambientais pela agricultura. A ampla utilização da USLE deve-se, entre outros motivos, ao número relativamente reduzido de parâmetros necessários para sua aplicação e ao extenso banco de dados utilizado na sua fundamentação (Lane et al., 1992). A principal limitação da USLE está relacionada à sua natureza empírica e, portanto, à necessidade de experimentações para cada nova situação onde será aplicada (Laflen et al., 1991). Este modelo não considera a deposição de sedimentos ao longo das encostas uma vez que foi desenvolvido a partir de dados obtidos em parcelas pequenas e uniformes. Isto 
limita seu uso em áreas complexas como bacias hidrográficas, escala adotada na maioria dos trabalhos que visam planejamento e avaliação de impactos ambientais.

Entre os modelos mecanísticos mais usados está o Water Erosion Prediction Project - WEPP (Flanagan \& Nearing, 1995). Devido à sua natureza mecanística, seu uso dispensa extensivos experimentos de campo e calibrações, necessitando apenas dos dados básicos do sistema em estudo: dados do solo, do clima e do manejo agrícola. $\mathrm{O}$ WEPP é capaz de prever deposição de sedimentos ao longo das encostas e pode, portanto, ser aplicado na escala de bacias hidrográficas (Laflen et al., 1991). Como dificuldade de aplicação do WEPP em relação à USLE destaca-se sua maior necessidade de dados básicos de entrada. Esta limitação se acentua em regiões tropicais e subtropicais, onde a base cartográfica e de dados de solo, clima e de crescimento vegetal é escassa.

A comparação de modelos conceitualmente distintos e o entendimento das diferenças baseadas nas suposições dos mesmos são questões-chave que devem ser avaliadas nas tomadas de decisão do uso de um ou outro modelo de estimativa de erosão. Por outro lado, o tratamento da erosão do solo como uma variável espacial é outra questão que deve ser considerada A localização das áreas de perda ou acúmulo de sedimentos é um subsídio para apoiar decisões em planejamento. Tanto a USLE como o WEPP não são, em sua concepção, associados a um sistema de coordenadas geográficas, o que restringe sua comunicação com Sistemas de Informações Geográficas (SIG) e dificulta a sua análise conjunta com variáveis que normalmente são tratadas nestes sistemas. Desta forma, o desenvolvimento de um método que permita tratar as informações de erosão de forma georreferenciada se faz necessário.

O objetivo do trabalho foi verificar as seguintes hipóteses: 1) a USLE, em relação ao WEPP, superestima as perdas de solo em rampas muito longas, como as encontradas na área de estudo, por não considerar as deposições de sedimentos que ocorrem ao longo da vertente; 2) o WEPP é um modelo mais recomendável para a estimativa da erosão em bacias hidrográficas, onde freqüentemente existe variabilidade nos solos e usos da terra, pois possui rotinas de cálculo que permitem a estimativa das 
perdas e deposições de sedimentos nas encostas considerando as possíveis alterações nos elementos de fluxo. Para a verificação destas hipóteses, foi desenvolvida uma interface computacional entre os modelos e um SIG vetorial a fim de permitir que as estimativas de erosão fossem tratadas de forma georreferenciada. Utilizando esta interface, os modelos USLE e WEPP foram comparados na escala de bacia hidrográfica, quantificando suas diferenças espacialmente. Esta análise visou fornecer subsídio para a tomada de decisão quanto ao uso destes modelos em planejamento agrícola e ambiental.

O trabalho encontra-se dividido em duas partes. Na primeira parte (capítulo 3) é apresentada a metodologia desenvolvida para a automatização do processo de estimativa de perda de solo pelos dois modelos. Ela consiste em uma interface entre modelos de erosão e Sistemas de Informações Geográficas que operam em formato vetorial. Esta metodologia foi desenvolvida para a execução do trabalho e mostra-se como uma nova técnica, válida para permitir a aplicação de modelos de erosão de forma espacial, com a redução de erros freqüentemente cometidos com o uso de SIGs em formato matricial ou "raster". Na Segunda parte (capítulo 4) são apresentados os resultados da aplicação dos dois modelos na área de estudo e a comparação entre eles, com relação aos valores absolutos de erosão e à localização espacial das perdas e deposições de sedimentos. Neste capítulo também são discutidos os aspectos de compatibilidade dos modelos à escala de bacia hidrográfica. 


\section{REVISÃO DE LITERATURA}

\subsection{A bacia hidrográfica como unidade de estudo da erosão do solo}

Consolida-se o reconhecimento mundial de que a bacia hidrográfica é a unidade de estudo funcional que mais favorece ao desenvolvimento de muitos conceitos hidrológicos e a que mais se ajusta aos objetivos do planejamento ambiental (Prochnow, 1985). De acordo com Jenkins et al. (1994), a bacia hidrográfica é a unidade ecossistêmica e morfológica que melhor reflete os impactos das interferências antrópicas, como a ocupação das terras com atividades agrícolas. Em vista disto, no Brasil, a bacia hidrográfica é referenciada como área de influência a partir da Resolução de ${ }^{\circ}$ 001/86 do CONAMA (Conselho Nacional do Meio Ambiente), de 1981, sendo que esta unidade passou a ser considerada como área a ser analisada no estudo prévio de impacto ambiental (Mariano, 1996). Na Legislação do Estado de São Paulo, o Decreto $\mathrm{n}^{\circ}$ 36787, de 18 de maio de 1993, que regulamenta a lei $\mathrm{n}^{\circ} 7663$, discrimina grupos de bacias hidrográficas e esta divisão hidrográfica é aprovada pelo Conselho Estadual de Recursos Hídricos - CRH.

Jonys $^{1}$ (1973) citado por Santos (1993) afirma que uso e conservação do solo e da água são as essências do manejo de uma bacia hidrográfica. Solo e água atuam interativamente e qualquer ação que cause efeito adverso num destes elementos afetará o outro. Como exemplo, o autor cita que a estabilidade ecológica dos ambientes aquáticos é freqüentemente modificada pela ruptura das seqüências temporais de escoamento

\footnotetext{
${ }^{1}$ JONYS, G. K.. Impact of Erosion on Environmental Quality. Toronto, Conservation Council of Ontario, 1973. $13 \mathrm{p}$.
} 
superficial e de entrada de sedimentos. Esta entrada é causada pela erosão acelerada do solo na época chuvosa.

A determinação da perda de solo por erosão numa bacia hidrográfica possibilita a obtenção de dados objetivos sobre a magnitude do impacto ambiental causado pela atividade agrícola, sendo portanto um importante subsídio para o planejamento e recuperação da área, visando a minimização destes impactos.

Devido à grande complexidade das interações entre os diferentes fatores condicionantes da erosão, sua avaliação de forma quantitativa (isto é, com a utilização de modelos matemáticos), ainda é um desafio nesta escala de trabalho, mas deve ser a abordagem preferencial dos estudos de previsão de impactos ambientais e no direcionamento do planejamento agrícola.

\subsection{A valiação quantitativa da erosão do solo}

A erosão acelerada dos solos é um problema global e, apesar da dificuldade de se calcular com precisão as perdas de solo, sabe-se que a magnitude destas perdas têm causado sérias conseqüências econômicas e ambientais para os países (Lal, 1988). Desta maneira, a estimativa de perda de solo é um importante subsídio para o planejamento agrícola e ambiental (Lima et al., 1992). De acordo com Lane et al. (1992), a estimativa da erosão é essencial para a conservação do solo e o controle de sua perda, e útil para prever impactos antes mesmo de uma determinada cultura ou prática agrícola ser adotada na área. Isto vem a ser uma ferramenta de grande importância como suporte às tomadas de decisão, uma vez que as alternativas de manejo são numerosas, muitas vezes de alto custo, e os resultados de uma prática conservacionista pode levar anos ou décadas para exercer influência na erosão. Diversos modelos matemáticos vem sendo desenvolvidos e aperfeiçoados com o intuito de prever a magnitude das perdas de solo. Renard \& Mausbach (1990) apresentam um breve histórico da evolução destes modelos (Tabela 1). 
Além dos modelos mencionados, podem ser também citados o AGNPS "Agricultural Nonpoint Source" (Young et al., 1989), e o ILWIS - "Integrated Land and Watershed Management Information System" (Valenzuela ${ }^{2}$, 1988) citado por Pinto (1991). Todos os modelos da geração após a USLE foram elaborados a partir dela e contém parâmetros dessa equação.

Tabela 1. Modelos de estimativa de perda de solo por erosão hídrica e eólica.

\begin{tabular}{lll}
\hline Abreviação (Sigla) & \multicolumn{1}{c}{ Título } & Data \\
\hline USLE & Universal Soil Loss Equation & 1965,1978 \\
MUSLE & Modified Universal Soil Loss Equation & 1975 \\
Foster et al. & Runoff erosivity factor USLE & 1977 \\
ANSWERS & ANSWERS: A model for watershed planning & 1980 \\
CREAMS & Chemicals, Runoff, Erosion and Agricultural & 1981 \\
& Management Systems & \\
RUSLE & Revised Universal Soil Loss Equation & 1990 \\
WEPP & Water Erosion Prediction Project & 1989 \\
& Hillslope version & 1990 \\
& Watershed version & 1990 \\
OCP-WEPP & Grid version & 1990 \\
WEE & Wind Erosion Equation & 1968 \\
WEQ & Revision of Wind Erosion Equation & 1988 \\
WERM & Wind Erosion Research Model & 1991 \\
\hline
\end{tabular}

Fonte: adaptado de Renard \& Mausbach (1990). In: Larson et al. (coords.). Proceedings of Soil Erosion and Productivity Workshop. Minnesota, USA, 1990. p 55-64.

A aplicação de modelos vem afirmar a tendência mundial de se abordar problemas ambientais da forma quantitativa (Bouma, 1989). Este tipo de abordagem visa diminuir a subjetividade na tomada de decisão por parte do planejador. Os modelos de estimativa de perda de solo são, portanto, ferramentas de grande importância para fins de planejamento (Câmara, 1993).

A substituição de modelos empíricos por, modelos físicos busca torná-los de aplicação mais universal, uma vez que os processos que desencadeiam a erosão são explicitados. Com isso, diminui-se a subjetividade e em geral, eleva-se o número de

\footnotetext{
${ }^{2}$ VALENZUELA, C.R ILWIS overview. ITC Journal, Enschede. v.1, p. 3-14. 1988.
} 
informações geradas. Por outro lado, a entrada de dados se torna mais complexa, o que contribui para o aumento significativo no custo final do projeto.

De acordo com Jäger (1994), a USLE ainda é muito utilizada por ser um modelo extensivamente estudado e que exige um número de informações relativamente pequeno quando comparado a modelos determinísticos. Por este motivo, é considerada uma técnica válida para previsão de impactos causados pela erosão, principalmente na falta de bancos de dados mais completos.

Por outro lado, devido ao seu caráter menos subjetivo, é interessante que modelos determinísticos sejam aplicados e avaliados em condições tropicais, tanto para a compreensão do processo erosivo e seus impactos quanto para apontar pontos falhos que possam aparecer para estas condições.

\subsection{Evolucão dos modelos de estimativa de erosão}

O estudo da erosão do solo é muito recente se comparado à grande maioria das ciências agrícolas (Lane et al., 1992). Trabalhos que abordam quantitativamente esta questão começaram a ser desenvolvidos a partir da metade do século 20. Este tipo de abordagem foi possível em função da incorporação de novas tecnologias desenvolvidas nos últimos setenta anos à pesquisa da erosão, tais como novos procedimentos laboratoriais, equipamentos de medição de escoamento superficial em parcelas experimentais e pequenas bacias hidrográficas e avançadas técnicas computacionais.

De acordo com Nearing et al. (1990a), a preocupação em se compreender e controlar a erosão do solo apareceu no início de 1900 nos Estados Unidos e evoluiu para um grande impulso na década de 1930 para a pesquisa na área de controle de escoamento superficial e experimentos com erosão em parcelas. Este impulso culminou com o desenvolvimento da Equação Universal de Perda de Solo - USLE (Wischmeier \& Smith, 1965). 


\subsection{USLE: histórico e apresentação do modelo}

A Equação Universal de Perda de Solo (USLE) é a equação de estimativa de erosão mais conhecida e utilizada até os dias de hoje. Ela representou e representa, segundo Lane et al. (1992), uma tecnologia de simples entendimento e fácil aplicação, que vem desempenhando um importante papel no direcionamento das práticas de conservação do solo no planejamento do uso da terra. Deste modo, pode ser utilizada para diversas finalidades como previsão das perdas anuais médias de solo de uma área sujeita a determinadas práticas de utilização; orientação na seleção de práticas de cultivo, de manejo e conservação; previsão de alterações nas perdas de solo ocasionadas por mudança nas práticas de cultivo e conservação; determinação de modos de aplicação ou alteração das práticas agrícolas que permitam usos mais intensivos da terra; estimativa das perdas de solo para usos distintos na agricultura; estimativa das perdas de solo visando a determinação de práticas conservacionistas.

A USLE é uma equação empírica (Nearing et al., 1990a) utilizada para computar erosão laminar e linear em função de fatores que representam o clima, solo, topografia e uso da terra (Lane et al., 1992). Foi desenvolvida em 1954, no "National Runoff and Soil Loss Data Center", do Agricultural Research Service, na Universidade de Purdue, EUA. Após anos a equação evoluiu para o modelo revisado por Wischmeier \& Smith (1978) (eq.1):

$$
A=R . K . L . S . C . P
$$

Onde: $A=$ perda média anual de solo por unidade de área ( $\mathrm{Mg} \mathrm{ha}^{-1}$ ano); $R=$ erosividade das chuvas $\left(\mathrm{MJ} \mathrm{ha}^{-1} \mathrm{~mm} \mathrm{~h}^{-1}\right) ; K=$ erodibilidade do solo $\left(\mathrm{Mg} \mathrm{ha}^{-1}\left(\mathrm{MJ} \mathrm{ha}^{-1} \mathrm{~mm} \mathrm{~h}^{-1}\right)^{-1}\right) \cdot$ ano $^{-1} ; L$ e $S=$ fatores comprimento da encosta (adimensional) e declive (adimensional), respectivamente; $C=$ fator uso e manejo (adimensional); $P=$ fator práticas conservacionistas (adimensional). 
Os fatores $R, K, L$ e $S$ são dependentes das condições naturais e os fatores $\mathrm{C}$ e $\mathrm{P}$ são relacionados às formas de ocupação e uso das terras (fatores antrópicos).

A USLE deriva de mais de 10000 parcelas padrão de $1,8 \mathrm{~m}$ de largura, $22,1 \mathrm{~m}$ de comprimento $(0,004 \mathrm{ha})$ e $9 \%$ de declividade, distribuídas em todas as regiões dos Estados Unidos.

Os fatores que compõe a USLE são apresentados e discutidos a seguir.

\subsubsection{Fator erosividade da chuva ( $R)$}

O fator chuva ( $R$ ) expressa numericamente a capacidade da chuva, esperada em determinada localidade, de causar erosão em uma área sem proteção (Bertoni \& Lombardi Neto, 1990).

Estudos mostraram que, mantidos os outros fatores constantes, as perdas de solo pelas chuvas são diretamente proporcionais ao valor de um parâmetro de chuva identificado como "índice de erosão" (EI) (Wischmeier \& Smith, 1978). Esta relação representa o efeito da erosão por impacto das gotas de chuva, pelo salpicamento e pela turbulência combinados com a enxurrada para transportar as partículas de solo desprendidas. De acordo com Wischmeier \& Smith (1978), EI é definido como o produto da energia cinética da chuva $(\mathrm{E})$ pela sua intensidade máxima em 30 minutos $\left(I_{30}\right)$, e é um termo que reflete como a energia total e o pico de intensidade são combinados em cada evento de chuva particular.

A soma dos valores de EI de cada chuva, isoladamente, em determinado período, representa a erosividade da chuva dentro daquele período. A soma de todos os valores de EI das chuvas caídas em um ano num dado local, dará o valor anual de EI. O valor $\mathrm{R}$ da equação é a média dos valores anuais de $\mathrm{EI}$ de um período longo de tempo (vinte anos ou mais) (Wischmeier \& Smith, 1978).

A relação para a obtenção do índice de erosão é dada pela eq. 2 (Bertoni \& Lombardi Neto, 1990): 


$$
E I=6,886\left(r^{2} / P^{\prime}\right) 0,85
$$

onde: $E I=$ média mensal do índice de erosão $\left(\mathrm{MJ} \mathrm{ha}^{-1} \mathrm{~mm} \mathrm{~h}^{-1}\right) ; r=$ precipitação média mensal $(\mathrm{mm}) ; P^{\prime}=$ precipitação média anual, $(\mathrm{mm})$.

Lombardi Neto et al. (1981) 3 , citado por Bertoni \& Lombardi Neto (1990), utilizando a equação de $E I$, estabeleceram os valores de $E I_{30}$ para 115 locais escolhidos no Estado de São Paulo. Obtiveram então o mapa de isoerodentes - linhas que ligam pontos de igual potencial de erosão. Estas linhas mostram os valores médios anuais de erosividade $\mathrm{e}$ o fator $R$ da USLE (Figura 1).

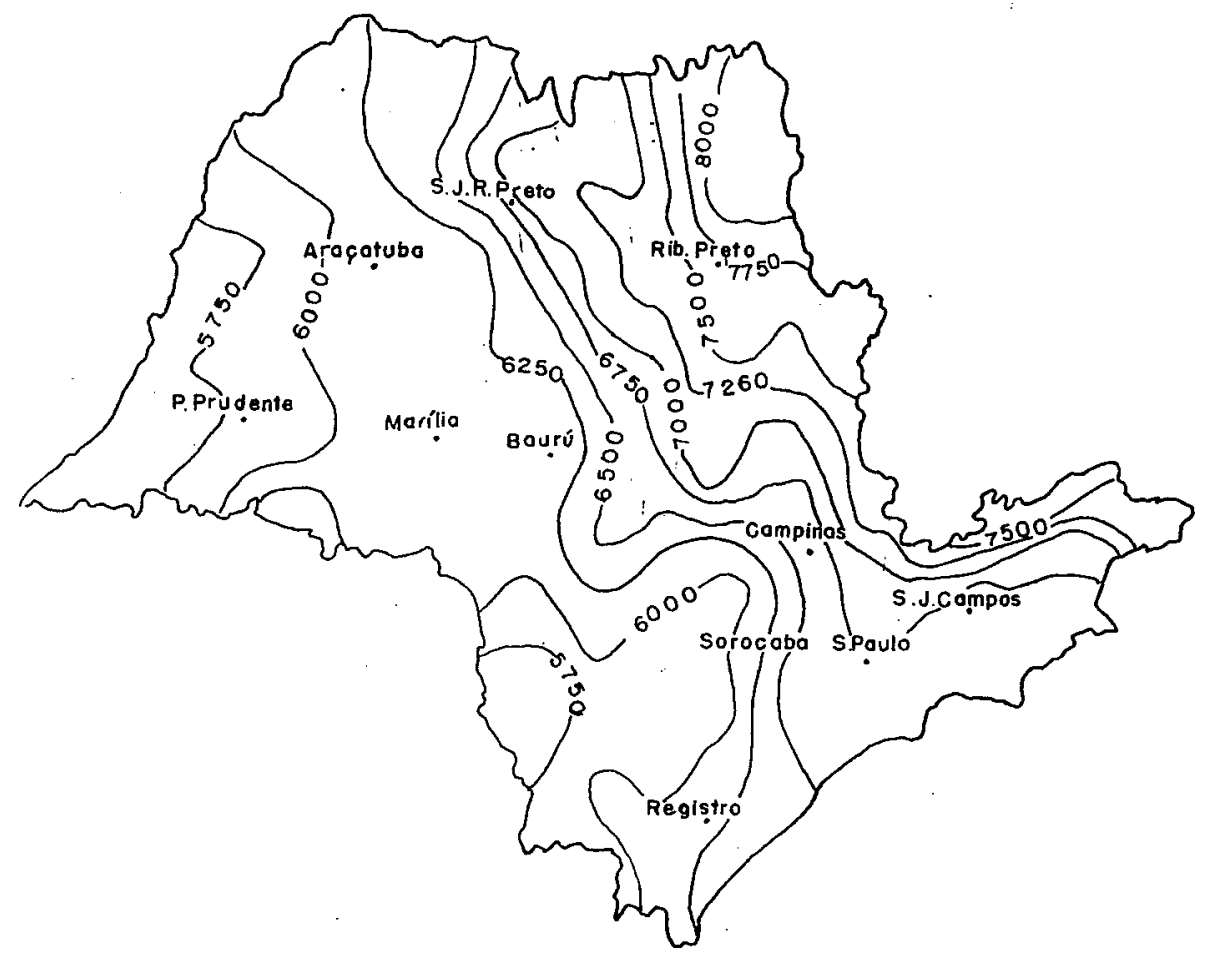

Figura 1. Valores médios anuais do índice de erosividade para o Estado de São Paulo. Fonte: Bertoni \& Lombardi Neto, 1990

\footnotetext{
${ }^{3}$ LOMBARDI NETO, F.; SILVA, I. R. \& CASTRO, O. M. Potencial de erosão das chuvas do Estado de São Paulo. In: ENCONTRO NACIONAL DE PESQUISA SOBRE CONSERVAÇÃO DO SOLO, 3., Recife. Anais...fl. 1981.
} 


\subsubsection{Fator erodibilidade do solo (K)}

Alguns solos são mais facilmente erodidos que outros, mesmo quando o declive, a precipitação, a cobertura vegetal e as práticas de controle da erosão são as mesmas. "Esta diferença, devido às propriedades inerentes ao solo, é conhecida como erodibilidade do solo $(K)^{\text {", }}$,(Wischmeier \& Smith, 1978).

$O$ fator $K$ na USLE é um valor quantitativo determinado experimentalmente. Ele consiste na taxa de perda de solo por unidade de índice de erosão medida numa parcela unitária (Lane et al. 1992). Dentro desta parcela os fatores $L S, C$ e $P$ são iguais a 1,0 e o fator $K$ é dados pela inclinação da linha de regressão entre o índice de erosão e a perda de solo. Através de experimentos conduzidos com chuva simulada em solos dos Estados Unidos, foi desenvolvido um método de estimativa de $K$ (Wischmeier et al., 1971) que se baseia na determinação de propriedades fisicas dos solos (porcentagem de silte e areia muito fina; porcentagem de areia, compreendida entre 2,0 e $0,1 \mathrm{~mm}$; estrutura e classe de permeabilidade) e a percentagem de matéria orgânica, através da combinação desses parâmetros graficamente em um nomograma. De acordo com Wischmeier et al. (1971), a erodibilidade tende a aumentar com o aumento no teor de silte.

Para solos brasileiros, porém, o método do nomograma apresenta algumas limitações, apontadas por diversos autores. Cogo (1978), trabalhando com o método nomográfico, afirma que este método não necessita de maiores esforços e recursos para a obtenção da erodibilidade, e sugere que seja utilizado para se ganhar tempo nas informações, mas observa que há necessidade de comparações entre este método e as medições diretas para uma melhor avaliação do nomograma. Outros autores também apontam para as limitações do uso do nomograma de Wischmeier et al. (1971) devido às diferenças texturais entre os solos usados na sua confecção e os solos brasileiros, principalmente no que se refere a solos com baixa porcentagem de silte e areia muito fina (Freire \& Pessoti, 1978; Henklain \& Freire, 1983; Angulo et al.,1985). Esta pode ser considerada uma das limitações do uso da USLE para solos tropicais. 


\subsubsection{Fator comprimento de rampa e grau de declive (LS)}

A influência do relevo na erosão do solo é substancial, sendo que o fator declividade $(S)$ e o fator comprimento de rampa $(L)$ são os que afetam a taxa de erosão hídrica. $\mathrm{O}$ fator $L S$ é a relação esperada de perda de solo por unidade de área em um declive qualquer em relação às perdas de solo correspondentes de uma parcela unitária padrão (Wischmeier \& Smith, 1978).

Algumas limitações do uso da USLE estão implícitas na própria concepção do fator $L S$. De acordo com Lane et al. (1992), a USLE foi originalmente aplicada para rampas uniformes. Porém, Foster \& Wischmeier (1974) desenvolveram métodos com base na equação de continuidade de sedimentos para aplicar a USLE em rampas desuniformes. Todavia, mesmo com o desenvolvimento deste método, não é aconselhável a aplicação da USLE para áreas muito irregulares, por não considerar a deposição de sedimentos ao longo das encostas. Esta é a grande limitação da utilização da USLE em bacias hidrográficas. $O$ uso de um gradiente médio de comprimento de rampa, considerando-o como uniforme, pode subestimar as perdas de solo em declives convexos e superestimar em declives côncavos. Neste sentido, Johnson (1988) alerta para o perigo de se utilizar a USLE sem considerar os efeitos de deposição, redestacamento e movimentação de partículas nas encostas. $\mathrm{O}$ autor discute que, na maior parte das condições reais de campo, a topografia do terreno é irregular, o que causa grandes variações no volume e na velocidade da enxurrada. Hamlet et al. (1992) apontam como problemática principal do uso da USLE em bacias hidrográficas o cálculo dos comprimentos de rampa. O mesmo problema é observado por Castro (1992), que demonstra o erro ocorrido na estimativa de perda de solo para bacias hidrográficas devido à USLE considerar este processo como sendo de caráter contínuo, não contemplando o fenômeno de deposição nas encostas. Mais recentemente, pesquisadores têm reconhecido que quando métodos concebidos para pequenas parcelas são usados para bacias hidrográficas complexas, a aplicabilidade de equações como a USLE fica reduzida. 
Da mesma forma, Risse et al. (1993) apontam para o fato da USLE ter sido concebida e avaliada para situações de declividade entre 3 a 20,7\% e para comprimentos de rampa entre 10,67 a 192,02 metros. Situações que ultrapassam estes limites apresentam problemas na estimativa da erosão pela USLE.

Mais uma limitação pode ser discutida ainda com relação à aplicação da USLE em rampas não homogêneas e bacias hidrográficas. Segundo a própria conceituação do fator $L S$, quanto maior o comprimento de rampa maior será a perda de solo. Quando se consideram rampas desuniformes pode ocorrer o inverso, isto é, quanto maior o comprimento de rampa maior a possibilidade de haver deposição de sedimentos ao longo dela, fato observado por Brown et al. (1981) e de Jong et al. (1983), estudando perdas de solo em bacias fechadas.

\subsubsection{Fator uso-manejo do solo (C)}

De acordo com Lane et al. (1992) o fator C advém da taxa de perda de solo durante um determinado estágio da cultura comparada à perda de solo na parcela padrão durante o mesmo período. Para a determinação deste fator são considerados estágios definidos de desenvolvimento das culturas e suas influências na erosão do solo. Os principais estágios considerados são: (a) período D - preparo do solo: desde o preparo até o plantio; (b) período 1 - plantio: do plantio a um mês após plantio; (c) período 2 estabelecimento: do fim do período 1 até dois meses após o plantio; (d) período 3 crescimento e maturação: de dois meses após o plantio até a colheita; (e) período 4 resíduo: da colheita até o preparo do solo.

Devido ao fato de a USLE não explicitar os termos "infiltração" e "escoamento superficial" nos cálculos, nas taxas de perda de solo estão implícitas as alterações destas variáveis de acordo com os estágios de cobertura e práticas de manejo (Lane et. al, 1992). Esta também constitui mais uma limitação do uso da USLE. Outra limitação da USLE deve-se ao fato de essa ser uma equação empírica e, portanto, todos os cálculos para o fator $\mathrm{C}$ serem válidos para condições específicas de cada região. 


\subsubsection{Fator práticas conservacionistas $(P)$}

$\mathrm{O}$ fator $\mathbf{P}$ representa $\mathrm{o}$ efeito das práticas conservacionistas, tais como plantio em nível, terraceamento e plantio em faixas na erosão do solo (Lane et al., 1992). Ele representa a relação entre a intensidade esperada de perdas de solo com determinada prática conservacionista e aquela quando a cultura está plantada no sentido do declive (morro abaixo). Na Tabela 2 estão alguns valores de $P$ para as práticas conservacionistas mais utilizadas contra a erosão, obtidas pela Seção de Conservação do Solo do Instituto Agronômico de Campinas.

Tabela 2. Valor de $P$ para algumas práticas conservacionistas

\begin{tabular}{lc}
\hline \multicolumn{1}{c}{ Práticas conservacionistas } & Valor de P \\
\hline Plantio morro abaixo & 1,0 \\
Plantio em contorno & 0,5 \\
Alternância de campinas + plantio em contorno & 0,4 \\
Cordões de vegetação permanente & 0,2 \\
\hline
\end{tabular}

Fonte: Bertoni \& Lombardi Neto, 1990

\subsection{Potencialidades e limitações do uso da USLE}

Como pôde ser visto anteriormente, devido ao fato de a USLE ser uma equação altamente empírica e concebida em parcelas unitárias, diversas limitações podem ser encontradas na sua aplicação. Dentre elas pode-se destacar: a) a necessidade de se trabalhar com áreas relativamente homogêneas com relação a solo, uso da terra e declividade; b) o fato de a equação deixar implícitos diversos parâmetros e seus efeitos; c) o fato de os cálculos para o fator $\mathrm{C}$ serem válidos para condições específicas de cada região; d) a não consideração de áreas de deposição; e) a não consideração da erosão linear. Todas estas limitações da USLE difícultam sua aplicação na escala de bacias hidrográficas, pois estas com freqüência possuem relevo complexo, áreas de perda e 
acúmulo de sedimentoss e erosão em sulcos (Foster \& Ferreira, $1981^{4}$, citado por Lane et al., 1992; Soileau et al., 1990; Kresnor et al., 1992).

Para Jäger (1994), apesar destas limitações, a USLE é considerada um bom instrumento para previsão de perdas de solo por erosão laminar, por exigir um número de informações relativamente pequeno quando comparado ao exigido por modelos mais complexos, e por ser uma equação bastante conhecida e estudada. E, embora não tenha sido concebida para a utilização em bacias hidrográficas, diversos autores têm aplicado a USLE para a estimativa de perda de solo utilizando esta escala como unidade de estudo (Chinnamani et al., 1982; Pelletier, 1985; Silva \& Freire, 1986; Stein et al., 1987; Figueiredo, 1988; Hession \& Shanholtz, 1988; Mitra et al., 1988; Castro, 1992; Hamlet et al., 1992; Santos, 1993; Jäger, 1994; Mellerowicz et al., 1994; Desmet \& Govers, 1996; Ranieri, 1996). Em condições como a brasileira, cuja base cartográfica e de dados em geral é escassa, a aplicação de outros modelos para a estimativa de perda de solo para fins de planejamento agrícola e ambiental é muito limitada.

Com relação à validação da USLE para as condições brasileiras, recentes experimentos têm sido desenvolvidos no Instituto Agronômico de Campinas (IAC) em parcelas unitárias. Foi observado que a USLE superestima os valores de perda de solo, indicando a necessidade de revisão dos parâmetros da equação (DeMaria \& Dechen, 1997). O mesmo resultado é apresentado por Johnson (1988), agora para a situação de bacia hidrográfica, que revisa diversos trabalhos desenvolvidos por uma série de autores em diversas partes do mundo, mostrando que em geral a USLE superestima as perdas de solo pelo fato de não considerar o fenômeno de deposição de sedimentos ao longo das encostas. Por outro lado, Soileau et al. (1990) mostraram que a USLE, por não considerar a formação de sulcos mais profundos ou voçorocas em bacias, acaba por subestimar as perdas por erosão. $\mathrm{O}$ autor afirma porém, que exceto em áreas onde houve erosão linear profunda, a USLE foi capaz de estimar perdas de solo em uma pequena

${ }^{4}$ FOSTER, G.R.; FERREIRA, V.A. Deposition in uniform grade terrace channels. In: Crop Production with Conservation in the 80's. p. 185-97. (ASCE: St. Joseph, MI.) 1981. 
bacia ( 3,8 ha) no norte do Alabama (USA) com resultados similares aos medidos na sua desembocadura, concordando também com as perdas estimadas por ${ }^{137} \mathrm{Cs}$.

\subsection{WEPP: histórico e apresentação do modelo}

De acordo com Laflen et al. (1991), a necessidade do desenvolvimento de uma nova técnica de estimar as perdas de solo por erosão surgiu a partir do reconhecimento de que a USLE apresentava diversas limitações. A mais importante era a impossibilidade de aplicá-la de forma satisfatória em situações diferentes àquelas nas quais ela foi desenvolvida, isto é, em outras regiões do mundo com características diversas de clima, solo, cobertura vegetal e práticas conservacionistas. Uma nova abordagem com relação às tecnologias de predição de perda de solo era requerida. Buscava-se a desenvolvimento de um modelo com base física (modelo determinístico), que pudesse contemplar todos os processos envolvidos na erosão do solo, desde o desprendimento de partículas, sua movimentação ao longo do terreno e sua deposição ou perda do sistema, sendo ele uma encosta ou uma bacia hidrográfica complexa. O WEPP (Water Erosion Prediction Project) foi resultado do trabalho desenvolvido a partir de um "workshop" ocorrido em Indiana (USA) em 1985, e de pesquisas conduzidas por quatro agências federais dos Estados Unidos (Agricultural Research Service, Soil Conservation Service, Forest Service and Bureau of Land Management), a partir de 1986.

O WEPP consiste em um modelo dinâmico de simulação que incorpora conceitos de erosão linear e areolar (Lane et al., 1992). Ele simula os processos que ocorrem em uma determinada área em função do estado atual do solo, cobertura vegetal, resíduos culturais e umidade. $\mathrm{O}$ estado atual destas características determinam a resposta da área a um determinado evento hidrológico, sendo ele derivado de chuva, derretimento de neve ou irrigação. Para cada dia, as características do solo e da cobertura vegetal são atualizadas. Quando o evento de chuva ocorre, as características atuais do terreno determinam se haverá produção de escoamento superficial. Se houver, o modelo determina desprendimento de partículas, transporte e deposição ao longo da encosta, em 
canais ou pequenos reservatórios (Laflen et al., 1991). O modelo não contempla, porém, erosões em grandes voçorocas e cursos d'água perenes (Lane et al., 1992).

O WEPP é apresentado em três versões: encosta (vertente), malha (célula) ou bacia hidrográfica (Laflen et al., 1991). A versão para encostas é uma direta substituição da USLE, acrescentando-se a capacidade de estimar a deposição de sedimentos ao longo do terreno. A versão para bacias hidrográficas determina o desprendimento, transporte e deposição de sedimentos ao longo das diversas encostas até os cursos d'água. A versão malha é aplicável para áreas nas quais os limites não coincidem com os limites de uma bacia.

Para as três versões, o WEPP é dividido em diversos componentes que consistem na parametrização dos processos que regulam o fenômeno erosivo, descritos resumidamente a seguir.

\subsubsection{Componente erosão do solo}

A erosão do solo é um processo que envolve desprendimento, transporte e deposição de partículas. A quantificação destes três processos ocorre no componente erosão do solo do WEPP (Nicks et al., 1989). Para tanto, o modelo leva em consideração tanto a erosão areolar como a linear.

De acordo com Foster et al. (1995), o WEPP usa a equação de continuidade de equilíbrio dinâmico de sedimentos para descrever o movimento das partículas em uma vertente (eq. 3).

$$
d G / d x=D_{f}+D_{i}
$$

Onde: $x=$ distância do topo da vertente $(m)$;

$G=$ descarga de sedimentos $\left(\mathrm{kg} \mathrm{s}^{-1} \mathrm{~m}^{-1}\right)$;

$D_{i}=$ descarga de sedimentos de áreas de erosão areolar para o sulco $\left(\mathrm{kg} \mathrm{s}^{-1} \mathrm{~m}^{-2}\right)$;

$D_{f}=$ taxa de erosão linear $\left(\mathrm{kg} \mathrm{s}^{-1} \mathrm{~m}^{-2}\right)$ 
O sedimento advindo de erosão areolar é considerado independente de $x$ e é sempre positivo. No caso da erosão linear, $D_{f}$ pode ser positivo se houver desprendimento e negativo se houver deposição.

A erosão areolar é considerada como sendo o desprendimento e o transporte por ação do impacto das gotas de chuva. Ela também pode ser conceituada como um processo de descarga de sedimentos até canais de fluxo ou sulcos, vindos de áreas entresulcos (Foster et al., 1995). Estes sedimentos podem então serem depositados nos sulcos ou carregados para fora da vertente. Ela é modelada como uma função do fator "erodibilidade areolar" do solo, da declividade e do quadrado da intensidade da chuva (Lane et al., 1992). A erodibilidade é uma função da granulometria do solo e da sua cobertura vegetal. Os períodos nos quais a capacidade de infiltração é maior que a intensidade da chuva não são considerados na contribuição para o desprendimento de partículas no processo de erosão areolar (Nicks et al., 1989).

A erosão linear em solo descoberto é estimada como uma função linear do excesso de cisalhamento hidráulico. A inclinação desta função linear é definida como "erodibilidade linear" e o cisalhamento hidráulico que deve ser excedido antes que o desprendimento linear ocorra é definido como "cisalhamento hidráulico crítico" (Lane et al., 1992). As taxas de erosão linear são afetadas pelos sedimentos na água de escoamento superficial e pela cobertura vegetal e/ou resíduos culturais. De acordo com Lane \& Nearing (1989), o desprendimento e transporte nos sulcos de erosão ocorrem quando a tensão de cisalhamento hidráulico excede o cisalhamento crítico e quando o sedimento carregado é menor que a capacidade de transporte de sedimentos da enxurrada (eq. 4 e 5 ).

$$
D_{f}=D_{c}\left(1-G / T_{c}\right)
$$

Onde: $D_{c}=$ capacidade de desprendimento pelo fluxo no sulco $\left(\mathrm{kg} \mathrm{s}^{-1} \mathrm{~m}^{-2}\right)$; $T_{c}=$ capacidade de transporte de sedimentos no sulco $\left(\mathrm{kg} \mathrm{s}^{-1} \mathrm{~m}^{-1}\right)$

$$
D_{c}=K_{r}\left(\tau_{f}-\tau_{c}\right)
$$


Onde: $K_{r}=$ erodibilidade no sulco $\left(s m^{-1}\right)$;

$\tau_{f}=$ tensão de cisalhamento do fluxo agindo nas partículas do solo $(P a)$;

$\tau_{c}=$ tensão de cisalhamento crítico do solo $(P a)$

$K_{r}$ e $\tau_{c}$ são parâmetros de entrada exigidos pelo WEPP e são calculados com base em atributos do solo como granulometria e matéria orgânica.

Já a deposição ocorre quando o sedimento a ser carregado é maior que a capacidade de transporte da enxurrada (eq. 6).

$$
D f=\frac{\beta V_{f}}{q}\left(T_{c}-G\right)
$$

Onde: $V_{f}=$ velocidade efetiva de queda (deposição) para o sedimento $\left(m s^{-1}\right)$;

$q=$ descarga do fluxo por unidade de largura $\left(m^{2} s^{-1}\right)$

$\beta=$ constante empírica (no WEPP: $\beta=0,5 \mathrm{~m}$ )

De acordo com Nearing et al., (1990b), dentre os parâmetros relacionados ao componente erosão do solo aos quais o modelo é mais sensível destaca-se a erodibilidade no sulco. Segundo os autores, parâmetros de sensibilidade moderada são a condutividade hidráulica saturada e a erodibilidade entre-sulcos. A condutividade mostra-se mais importante quando as chuvas são menos intensas. Em geral, no caso de chuvas muito intensas, ocorrerá enxurrada independentemente da condutividade hidráulica do solo, exceto para áreas de florestas. Já a textura do solo mostra-se importante pois afeta o cálculo da erodibilidade do solo entre-sulcos e no sulco e da fricção hidráulica, afetando com isto a formação e largura dos sulcos de erosão e a capacidade de transporte de sedimentos da enxurrada.

\subsubsection{Componente hidrológico}


"O processo de erosão é o resultado direto das forças e energias envolvidas nos processos hidrológicos" (Laflen et al., 1991). O impacto e a magnitude destas forças são afetados pelas características da cultura acima e abaixo da superficie do solo, pelas condições do solo em superficie e subsuperficie e pela topografia do terreno. $\mathrm{O}$ componente hidrológico do WEPP é composto de três outros componentes, sendo eles: clima, inverno e hidrologia de superfície e de subsuperfície.

O componente clima usa tanto variáveis fornecidas e simula o clima da região usando o gerador de clima CLIGEN (Nicks et al., 1995). Este, por sua vez, baseia-se nos métodos de geração de clima utilizados no modelo EPIC (Williams et al., 1984) ${ }^{5} \mathrm{e}$ SWRRB (Williams et al., 1985) ${ }^{6}$, citados por Nicks et al. (1995). Os parâmetros de entrada do CLIGEN são utilizados para estimar a duração, pico e quantidade total de enxurrada, que por sua vez também são afetadas pelo estado atual de cobertura vegetal, biomassa em decomposição e umidade das diversas camadas do solo (Laflen et al., 1991). De acordo com Nearing et al. (1990b), a precipitação é um dos parâmetros do componente hidrológico ao qual o WEPP é mais sensível.

O componente hidrologia de superficie e subsuperfície possui uma seqüência de cálculos que incluem infiltração, excesso de precipitação, acúmulo de água em depressões e pico de descarga. $\mathrm{O}$ componente infiltração do solo engloba dois estágios: a) quando não ocorre acúmulo de água na superfície e a infiltração é considerada igual à intensidade da precipitação; b) quando ocorre acúmulo de água na superfície, e a infiltração é considerada como uma função do potencial matricial, da infiltração cumulativa e da condutividade hidráulica saturada. $O$ excesso de precipitação é a diferença entre a intensidade da precipitação a infiltração, representado pela equação de onda cinemática (eq. 7). A partir deste excesso determina-se a enxurrada.

\footnotetext{
${ }^{5}$ Williams, J.R., Jones, C.A .,Dyke, P.T. 1984. A modeling approach to determining the relationship between erosion and soil productivity. Trans. ASAE 21 (1): 129-144p.

${ }^{6}$ Williams, J.R., Nicks, A. D.; Amold, J.G. 1985. Simulator of water resources in rural basins. ASAE Hydraulics J. 111(6):970-986.
} 


$$
\partial h / \partial t+\partial q / \partial x=r-f=v
$$

Onde: $h=$ profundidade do fluxo $(m)$;

$t=$ tempo $(s)$;

$q=$ descarga por unidade de largura $\left(m^{2} s^{-1}\right)$;

$x=$ distância do plano $(m)$;

$r=$ intensidade da precipitação $\left(m s^{-1}\right)$;

$f=$ taxa de infiltração $\left(m s^{-1}\right)$;

$v=$ excesso de chuva $\left(m s^{-1}\right)$

O componente inverno engloba congelamento do solo, acumulação e derretimanto de neve. Este componente não foi levado em consideração no presente trabalho devido às condições climáticas locais.

\subsubsection{Componente crescimento vegetal e decomposição de resíduos}

As condições de cobertura vegetal e de resíduos culturais são vitais para a estimativa do desprendimento e transporte de partículas do solo. O WEPP estima diariamente o crescimento de plantas usando o modelo EPIC, acrescentando neste cômputo a acumulação e a decomposição dos resíduos.

Diversos são os parâmetros de entrada exigidos pelo WEPP na determinação deste componente. Assim como para outros componentes, o modelo apresenta maior ou menor sensibilidade a alguns destes parâmetros. De acordo com Nearing et al. (1990b), o parâmetro cobertura morta no sulco foi considerado o mais sensível em relação aos resultados de erosão e produção de sedimentos. Este comportamento pode ser explicado pela grande influência da biomassa viva ou morta na estabilidade dos agregados, o que afeta sensivelmente a resistência do solo à erosão (Nearing et al., 1990b). Já a porcentagem de cobertura oferecida pelo dossel influencia mais o desprendimento de partículas em áreas entre-sulcos. 


\subsubsection{Componente balanço hídrico}

A determinação do balanço hídrico é crucial para a estimativa da infiltração, a enxurrada e da força de desprendimento pelo fluxo d'água em sulcos e canais. $\mathrm{O}$ componente balanço hídrico e percolação quantifica estes processos (Laflen et al., 1991).

Este componente se utiliza de informações dos componentes clima, crescimento vegetal e infiltração para a estimativa de evapotranspiração potencial e evaporação do solo e transpiração da planta (Sabavi \& Williams, 1995). A partir destas informações o componente balanço hídrico determina a quantidade e o estado da água no solo a cada 24 horas para cada horizonte e calcula a percolação em profundidade, utilizando a eq. 8 .

$$
\Theta=\Theta_{i n}+(P-I) \pm S-Q-E T-D-Q_{d}
$$

Onde: $\Theta=$ armazenagem de água na zona radicular do solo em um determinado dia $(m)$;

$\Theta_{i n}=$ armazenagem de água inicial na zona radicular $(m)$;

$P=$ precipitação cumulativa no dia $(m)$;

$I=$ interceptação da precipitação pela vegetação $(m)$;

$S$ = conteúdo de água em forma de neve $(m)$;

$Q=$ quantidade de enxurrada cumulativa na superficie $(m)$;

$E T=$ evapotranspiração cumulativa no dia $(m)$;

$D=$ perda de água cumulativa diária por percolação abaixo da zona radicular $(m)$;

$Q_{d}=$ fluxo subsuperficial lateral $(m)$.

\subsubsection{Componente hidráulico}

O componente hidráulico calcula as forças hidráulicas de cisalhamento requeridas para ocorrer erosão linear (Lane et al., 1992). A tensão de cisalhamento em sulcos é dividida em duas partes; uma que age no solo para causar desprendimento e outra que age nos resíduos expostos na superficie e que não é ativa no desprendimento de partículas. A porção da tensão de cisalhamento que age no solo e causa erosão é 
proporcional à taxa do coeficiente de fricção para o solo em relação ao coeficiente total de friç̧ão (solo mais cobertura) (Gilley \& Weltz, 1995).

De acordo com Laflen et al. (1991), um problema particular da aplicação deste componente é a representação de várias faixas de cobertura e solo diferentes ao longo da encosta e seus efeitos. É possível que haja enxurrada em uma determinada faixa da encosta e em outra haja deposição. Esta possível alternância de locais com perda e acúmulo exige muitas aproximações das equações de onda cinemática.

Mais uma vez o parâmetro de resíduos culturais é um dos mais importantes neste componente. De acordo com Nearing et al. (1990b), o efeito dos resíduos de culturas nas erosões lineares e no transporte de sedimentos são refletidos primeiramente no coeficiente de rugosidade, diminuindo o valor do número de Reynolds e provocando redução da energia do fluxo da enxurrada. Embora a rugosidade da superficie seja um parâmetro de entrada, o modelo a ajusta diariamente de acordo com a decomposição dos resíduos.

\subsubsection{Componente solo}

As propriedades do solo influenciam nos processos básicos de erosão do solo como infiltração, enxurrada, desprendimento de partículas pelo impacto das gotas de chuva e pelo fluxo concentrado e transporte de sedimentos. $\mathrm{O}$ componente solo do WEPP trata das mudanças temporais nas propriedades dos solos devido ao impacto de diversos fatores, incluindo as atividades antrópicas (Laflen et al., 1991). Este componente requer diversas variáveis do componente hidrológico importantes para a estimativa do volume e taxa de enxurrada, infiltração e percolação. Diariamente são atualizadas as condições do solo e das variáveis de superfície. Estas variáveis incluem rugosidade (altura e orientação), densidade, condutividade hidráulica saturada, erodibilidade linear e areolar e cisalhamento hidráulico crítico. 


\subsection{Potencialidades e limitações do uso do WEPP}

Dado o vasto número de informações geradas, o WEPP oferece diversas aplicações (Lane et al., 1992) além das oferecidas pelo uso da USLE, incluindo entre outras: (1) localização do desprendimento de sedimentos nas encostas, tanto para eventos de precipitação isolados quanto para médias anuais; (2) avaliação dos diversos sistemas de produção e práticas agrícolas; (3) estudo do efeito da rugosidade do terreno na distribuição de sedimentos; (4) possibilidade de avaliar em tempo real a estimativa de perda de solo, sendo esta uma das maiores vantagens do uso do WEPP para planejamento. Para Laflen \& Flanagan (1992), através do uso do WEPP é possível responder diversas questões, dentre elas: (1) qual o melhor manejo da terra para o controle eficiente da erosão; (2) em que local da encosta podem ser instaladas práticas permanentes para uma determinada condição de clima, solo e topografia; (3) qual seria o impacto da conservação do solo fora da propriedade agrícola, isto é, impactos ambientais (como a perda de solo do sistema para cursos d'água e reservatórios). Este último pode ser considerado como o avanço que pode dar o impulso ao início de uma nova visão com relação aos objetivos da conservação do solo. As tomadas de decisão em planejamento deverão então levar em consideração não somente os efeitos da erosão na produção agrícola, mas também na quantidade e qualidade da água superficial.

Além das aplicações citadas pelos autores, pode-se incluir outras importantes contribuições e avanços do WEPP em relação à USLE, como a inclusão da versão aplicável para bacias hidrográficas e a inserção do cálculo da erosão linear na sua rotina.

Dentro das limitações do modelo, Laflen et al. (1991) levantam a necessidade de extenso levantamento de dados para que seja aplicável e de treinamento intenso de pessoal para a efetiva implementação do WEPP. De acordo com Nearing et al. (1990b), os processos naturais são extremamente variáveis e nem sempre um modelo determinístico pode fornecer resultados confiáveis, sendo necessário o estabelecimento de limites de confiança para as estimativas de erosão. 


\subsection{Compatibilidade dos modelos com Sistemas de Informações Geográficas}

Para o planejamento e análise ambiental, uma técnica de grande utilidade é o Sistema de Informações Geográficas (SIG). Crestana (1994), discutindo técnicas recentes de avaliação ambiental, afirma que é possível observar, modelar, avaliar e simular o comportamento local de variáveis edafo-ambientais via SIG.

Um SIG é um sistema de informações desenvolvido para trabalhar com dados referenciados por coordenadas espaciais ou geográficas (Star \& Estes, 1990). De acordo com Eastman (1997), a representação de dados espaciais em um SIG pode ser feita de maneiras distintas. Duas representações fundamentais podem ser usadas: a vetorial e a matricial ou "raster". Na vetorial, os limites das feições são definidos por uma série de pontos que se agrupam formando linhas. Os pontos possuem coordenadas geográficas ( $\mathrm{X}$ e $\mathrm{Y}$ ) e os atributos das feições são armazenados separadamente no programa. A ligação das feições e atributos pode ser feita através de um número identificador para cada feição no mapa. Na matricial, a representação gráfica das feições e atributos é unificada. A área de estudo é dividida em uma malha de células ou pixels que armazenam os atributos daquela localidade. A cada célula é dado um valor numérico que pode representar tanto o identificador da feição, quanto atributos qualitativos e quantitativos. As vantagens do uso de um SIG que opera em formato matricial está no reduzido espaço requerido para o armazenamento de dados, na facilidade de executar operações matemáticas através da sobreposição de mapas, e na rapidez de alteração de cenários. Já os SIGs que operam em formato vetorial têm as vantagens da eficiência na representação dos limites das feições de mapas e na precisão de cálculos que dependem de orientação, como distâncias entre feições. Seja qual o formato do SIG escolhido, a função de um sistema de informações é aumentar a velocidade de um indivíduo tomar decisões, o que é interessante para trabalhos de planejamento.

Mellerowicz et al. (1994) enfatizam a importância do SIG para o planejamento do solo e da água. Os autores mostram ter havido um aumento da aplicação do SIG para este fim devido a diversos fatores como a melhora da qualidade, disponibilidade e facilidade de manipulação dos sistemas, o aumento da disponibilidade de informações 
básicas para alimentar o sistema, e o aumento da demanda por trabalhos de planejamento que exijam menor gasto de tempo.

Em trabalhos de planejamento ou previsão de impactos cujo enfoque é a erosão do solo, percebe-se o crescente uso de ferramentas como os SIGs. Além da rapidez na manipulação dos dados, os SIGs permitem um diagnóstico mais criterioso da situação da área, por tratar as informações de forma espacializada. No caso da erosão, a posição geográfica das áreas de maior perda ou acúmulo de terra, principalmente na escala de bacias hidrográficas, é uma informação de suma importância para apoiar decisões de intervenção na área. Portanto, cresce cada vez mais a demanda pela criação de interfaces computacionais entre modelos de erosão e SIGs.

A aplicação da USLE em bacias hidrográficas com o auxílio de SIG pode ser vista em diversos trabalhos (Chinnamani et al., 1982; Pelletier, 1985; Silva \& Freire, 1986; Stein et al., 1987; Figueiredo, 1988; Hession \& Shanholtz, 1988; Mitra et al., 1988; Castro, 1992; Hamlet et al., 1992; Santos, 1993; Jäger, 1994; Mellerowicz et al., 1994; Hamada et al., 1995; Rocha et al., 1995; Desmet \& Govers, 1996; Ranieri, 1996; Sparovek et al. 1997; Fiorio, 1998; Weill, 1999), todos eles utilizando SIGs "raster". Quanto ao modelo WEPP, alguns trabalhos na escala de bacias podem ser citados, como os de Sabavi et al. (1995) e Cochrane \& Flanagan (1999), também utilizando SIG matricial.

A automatização do processo de estimativa de erosão através de SIG "raster" apresenta uma série de limitações relacionadas principalmente à construção do relevo e ao cálculo dos comprimentos de rampa (Brown et al., 1981; de Jong et al., 1983; Johnson, 1988; Castro, 1992; Hamlet et al., 1992). Pelo fato de o comprimento de rampa ser um dado vetorial, diversas adaptações são necessárias para sua determinação num sistema "raster", sempre limitando os cálculos em função do tamanho do pixel ou célula determinada. $\mathrm{O}$ acúmulo de erros relacionados à construção do relevo de forma "raster" acaba sendo prejudicial à estimativa da erosão, pois este constitui-se de um dos mais importantes parâmetros dos modelos. Em áreas como as bacias, cuja topografia em geral é complexa, a utilização de SIGs vetoriais vem a proporcionar uma redução na perda das 
informações e uma maior veracidade na reprodução do relevo. Porém, nenhum trabalho foi encontrado sobre estimativa de erosão associados a SIGs vetoriais. Portanto, o desenvolvimento de uma interface entre modelos de erosão e SIGs vetoriais se mostra como uma alternativa para subsidiar trabalhos de conservação do solo e planejamento do uso da terra. 


\title{
3 Desenvolvimento de um programa computacional para aplicação vetorial de modelos de estimativa de erosão (USLE e WEPP).
}

\author{
Autora: Simone Beatriz Lima Ranieri \\ Orientador: Quirijn de Jong van Lier
}

\section{Resumo}

Uma interface computacional para aplicação de modelos de estimativa de erosão de forma vetorial foi desenvolvida. A interface, denominada Interface Vetorial de Erosão (EVI), foi testada em uma bacia hidrográfica de 75,8 ha, localizada no município de Piracicaba - SP. Considerando a erosão hídrica como um processo vetorial, ocorrendo em linhas com direção e sentido de fluxo da enxurrada, as vertentes nas quais foram aplicados os modelos USLE (Universal Soil Loss Equation) e WEPP (Water Erosion Prediction Project) foram consideradas segmentos de reta e definidas de forma manual ou assistida. Isto fez com que houvesse menor degradação das informações do relevo, com a diminuição de erros nos cálculos das declividades e dos comprimentos de rampa, que freqüentemente ocorrem quando feitos pelo método matricial. A EVI foi capaz de extrair as informações espaciais da área de estudo, construir arquivos básicos para a aplicação dos modelos e georreferenciar novamente resultados pontuais de erosão do solo com rapidez. Este processo automatizado permitiu que os resultados de perda e deposição de sedimentos fossem espacializados. Desta forma, a EVI mostrou-se como uma ferramenta útil para o planejamento agrícola e ambiental.

Palavras-chave: erosão; interface; vetor; USLE; WEPP. 


\section{Development of a computer program for vector application of erosion prediction models (USLE and WEPP)}

Author: Simone Beatriz Lima Ranieri

Adviser: Quirijn de Jong van Lier

\section{Summary}

A computer interface for application of erosion models in a vector format was developed. The Erosion Vector Interface (EVI) was tested in watershed of 75.8 ha, located in Piracicaba - Brazil. Erosion was defined as a vector process described by runoff lines under unidirectional flow. For application of the models USLE (Universal Soil Loss Equation) and WEPP (Water Erosion Prediction Project) hillslopes were considered to be line segments and their coordinates defined in a manual procedure. This procedure resulted in a lower degradation of the relief information when compared to a raster procedure due to the decrease of errors in the calculation of the slope length and steepness. The interface was capable to extract the spatial information from the GIS, to build basic files for the application of the models and to georreference punctual results of erosion estimation for its entry in the GIS. This automated process allowed soil loss results and sediment depositions to be spatially distributed. Consequently, EVI was considered a useful tool for agricultural and environmental planning.

Key-words: erosion; interface; vector; USLE; WEPP. 


\subsection{Introdução}

A previsão da magnitude das perdas de solo e da redistribuição de sedimentos é um subsídio de grande importância para o planejamento agrícola e ambiental (Lima et al., 1992). Desta forma, o tratamento da erosão do solo como uma variável espacial é importante, pois a localização das áreas de perda ou acúmulo de sedimentos é um subsídio para apoiar decisões em planejamento. Modelos de estimativa de erosão, em geral, não prevêem a espacialização dos resultados de perda de solo pois não são associados a um sistema de coordenadas geográficas. Este é o caso de modelos muito utilizados como a "Universal Soil Loss Equation"-USLE (Wischmeier \& Smith, 1978) ou de modelos relativamente novos como o Water Erosion Prediction Project - WEPP (Flanagan \& Nearing, 1995). A conseqüente restrição de comunicação destes modelos com Sistemas de Informações Geográficas (SIG) dificulta a sua análise conjunta com variáveis que normalmente são tratadas nestes sistemas.

Outra particularidade destes modelos é que eles tratam a erosão como um processo vetorial, isto é, que ocorre em vertentes, representadas por linhas ou segmentos de reta com direção e sentido de fluxo da enxurrada. Isto é evidenciado pelo fato de um dos principais parâmetros dos modelos de erosão ser o comprimento de rampa (Foster \& Wischmeier, 1974; Wischmeier \& Smith, 1978; Srinivasan \& Engel, 1991; Risse et al., 1993; Nearing et al., 1990a).

Em geral, a representação de dados espaciais em um SIG pode ser feita de duas maneiras: a vetorial e a matricial ou "raster". Na vetorial, linhas, pontos ou polígonos definem as feições. Na matricial, a representação de todas as feições é feita através de células ou pixels (Eastman, 1997). Observa-se um grande número de trabalhos de 
aplicação de modelos de erosão usando SIGs que operam exclusivamente em formato matricial (Johnson, 1988; Hamlet et al., 1992; Mellerowicz et al., 1994; Sabavi et al., 1995; Sparovek et al., 1997), seja pelo fato destes exigirem espaço reduzido para o armazenamento de dados, seja pelo menor custo em relação aos SIGs vetoriais. A automatização do processo de estimativa de erosão através de métodos matriciais apresenta limitações relacionadas principalmente ao cálculo da declividade do terreno e dos comprimentos de rampa (Brown et al., 1981; de Jong et al., 1983; Johnson, 1988; Srinivasan \& Engel, 1991; Hamlet et al., 1992). Isto se deve a dois fatores principais, que estão interligados. $O$ primeiro é o nível de detalhamento do terreno, definido pelo tamanho do pixel e o segundo é a necessidade da geração de um Modelo de Elevação de Terreno (MET), o que pode degradar os valores das declividades pela interpolação das curvas de nível, principalmente em áreas de declividade acentuada ou em topos de morros (Srinivasan \& Engel, 1991). Em outras palavras, a necessidade de "rasterizar" as informações planialtimétricas (geralmente apresentadas em formato vetorial) para em seguida "vetorizá-las" para o cálculo dos comprimentos de rampa, faz com que haja degradação do relevo, afetando a estimativa de erosão. Este problema seria reduzido se a descrição das vertentes e os cálculos de seus comprimentos e declividades fossem feitas diretamente através de um método vetorial. Porém, a falta de uma interface computacional compatível com SIGs vetoriais (informações georreferenciadas) e os modelos de estimativa de erosão (informações não georreferenciadas) impede esse procedimento.

O objetivo deste trabalho é descrever uma interface computacional (Interface Vetorial de Erosão-EVI) desenvolvida para a aplicação dos modelos de estimativa de erosão (USLE e WEPP) de forma vetorial e mostrar seu desempenho por meio de um exemplo de aplicação em uma bacia hidrográfica. 


\subsection{Material e Métodos}

\subsubsection{Estimativa da erosão do solo}

Os modelos de estimativa de erosão usados para a aplicação da EVI foram a USLE e o WEPP, este último na sua versão para vertentes (Hillsope, v.99.5). Embora o WEPP possua uma versão aplicável para a escala de bacia hidrográfica, esta simplifica o formato das encostas, dividindo cada face de contribuição de sedimentos em parcelas de formato poligonal, tratando-as como rampas unitárias (Figura 1). Com isso, há perda de detalhes sobre o relevo, que podem ser importantes na estimativa da erosão.

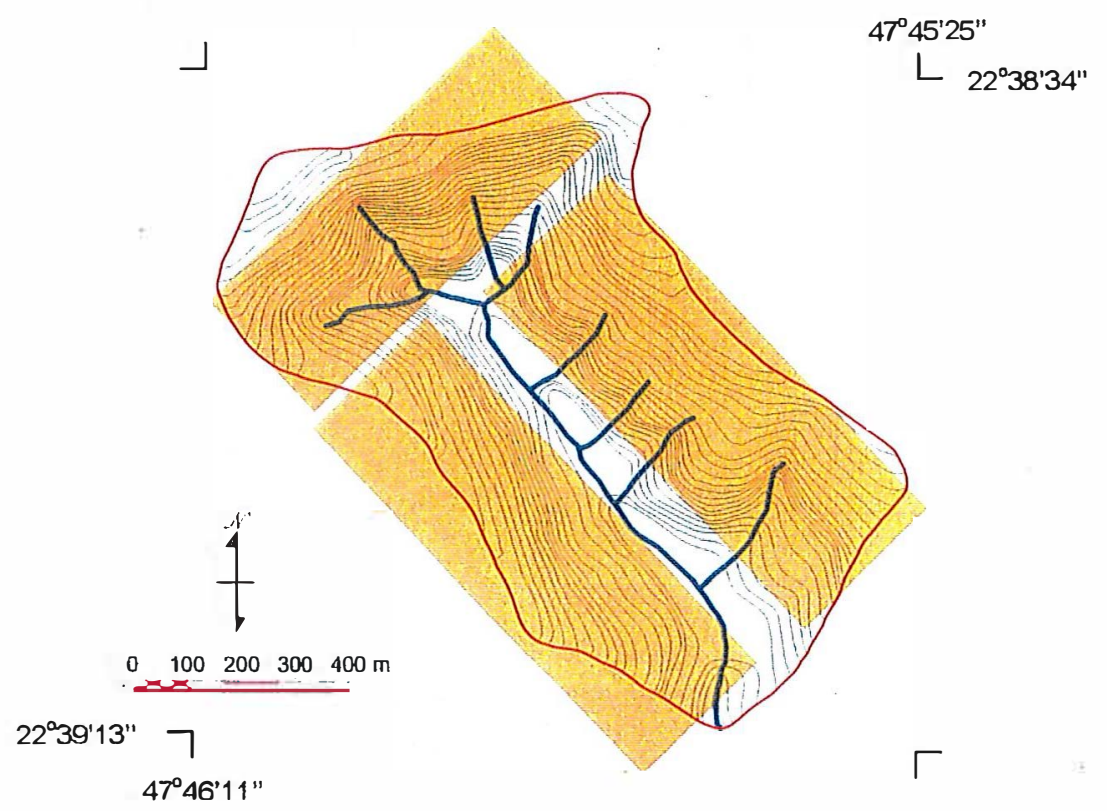

Figura 1. Exemplo da divisão da bacia em polígonos produzida pelo modelo WEPP na versão para bacias hidrográficas, resultando na simplificação do relevo. 


\subsubsection{Dados de entrada necessários ao programa de interface}

A localização das vertentes às quais serão aplicados os modelos deve ser definida por segmentos de reta, com direção e sentido. Cada vertente é representada por pontos num sistema de coordenadas cartesianas tridimensional $(\mathrm{x}, \mathrm{y}, \mathrm{z})$, onde $\mathrm{x}$ e $\mathrm{y}$ representam a distância horizontal e vertical (em metros) de uma origem e $z$ a elevação (em metros) do plano definido pelos eixos $\mathrm{x}$ e y. Estes dados podem ser extraídos, por exemplo, de mapas de curvas de nível, definindo-se as vertentes perpendicularmente às curvas. Neste caso, cada ponto corresponderá a uma interseção entre as curvas de nível e as vertentes (nó). A definição das vertentes de forma manual ou assistida, além de ser um procedimento relativamente rápido e permitir o controle desejado no detalhamento do relevo, evita possíveis erros que poderiam ocorrer se este processo fosse automatizado, como a não consideração de interrupções no relevo devido à presença de estradas, construções, terraços, etc.

Cada nó é associado a um código numérico para o uso da terra e tipo de solo, do qual se tenham todas as informações que os modelo de estimativa de erosão necessitam em relação a estes objetos. Estes dados básicos podem ser gerados com auxílio de SIG ou não. Os dados climáticos exigidos pelos modelos são considerados uniformes para a área. As informações planialtimétricas $(\mathrm{x}, \mathrm{y}, \mathrm{z})$, código de solo, código de uso da terra $\mathrm{e}$ número da vertente de cada nó são organizadas em uma planilha, como na Tabela 1.

Tabela 1. Exemplo de dados contidos no arquivo de entrada de dados georreferenciados.

\begin{tabular}{cccccc}
\hline X & Y & Z & Solo & uso & vertente \\
\hline---15972 & 7492358 & 500 & 4 & 1 & 1 \\
215990 & 7492351 & 498 & 4 & 1 & 1 \\
216012 & 7492344 & 496 & 3 & 1 & 1 \\
216037 & 7492335 & 494 & 3 & 2 & 1 \\
216064 & 7492326 & 492 & 3 & 2 & 1 \\
215935 & 7492381 & 501 & 4 & 1 & 2 \\
215971 & 7492377 & 500 & 4 & 1 & 2 \\
215989 & 7492376 & 498 & 1 & 1 & 2 \\
216006 & 7492374 & 496 & 1 & 3 & 2 \\
216027 & 7492372 & 494 & 3 & 3 & 2 \\
216051 & 7492369 & 492 & 3 & 3 & 2 \\
215930 & 7492393 & 501 & 4 & 1 & 3 \\
215967 & 7492395 & 500 & 4 & 1 & 3 \\
215997 & 7492396 & 496 & 4 & 3 & 3 \\
\hline
\end{tabular}




\subsubsection{Funcionamento do programa de interface}

\section{Processamento do arquivo de entrada}

O arquivo de entrada de dados georreferenciados (Tabela 1) é importado pelo programa que, num primeiro passo, ajusta os nós de cada vertente a uma linha reta obtida por regressão linear, projetando-os perpendicularmente sobre ela. Os dados destas regressões são armazenados em um arquivo para possibilitar posterior georreferenciamento.

\section{Utilizando USLE}

A USLE é apresentada da seguinte forma matemática (eq.1) (Wischmeier \& Smith, 1978):

$$
A=R \text { K.L.S.C.P }
$$

onde: $A=$ perda média anual de solo por unidade de área $\left(\mathrm{Mg} \mathrm{ha}^{-1}\right.$ ano); $R=$ erosividade das chuvas $\left(\mathrm{MJ} \mathrm{ha}^{-1} \mathrm{~mm} \mathrm{~h}^{-1}\right) ; K=$ erodibilidade do solo $\left(\mathrm{Mg} \mathrm{ha}^{-1}\left(\mathrm{MJ} \mathrm{ha}^{-1} \mathrm{~mm} \mathrm{~h}^{-1}\right)^{-1}\right)$ ano ${ }^{-1} ; L$ e $S=$ fatores comprimento da encosta (adimensional) e grau de declive (adimensional); $C=$ fator uso e manejo (adimensional); $P=$ fator práticas conservacionistas (adimensional).

Para uso como interface para a USLE é necessário conhecer a erodibilidade (K) para cada unidade de mapeamento de solos, e os fatores uso-manejo (C) e práticas conservacionistas $(\mathrm{P})$ para cada unidade de mapeamento de uso da terra considerados. Estes dados devem estar contidos em arquivos de entrada para a EVI com os códigos de solo e suas respectivas erodibilidades e os códigos de uso e seus respectivos valores de $\mathrm{C}$ e $P$ multiplicados (exemplos nas Tabelas 2 e 3). A erosividade da chuva (R) da área deve ser conhecida e seu valor fornecido ao programa.

Tabela 2. Exemplo de planilha com valores de $\mathrm{K}$ associados aos códigos de solo

\begin{tabular}{cc}
\hline Código de solo & $\begin{array}{c}\text { Erodibilidade } \\
\left(\mathrm{Mg} \mathrm{ha}^{-1}\left(\mathrm{MJ} \mathrm{ha}^{-1} \mathrm{~mm} \mathrm{~h}^{-1}\right)^{-1}\right) \cdot \mathrm{ano}^{-1}\end{array}$ \\
\hline 1 & 0,028 \\
2 & 0,025 \\
3 & 0,037 \\
4 & 0,052 \\
\hline
\end{tabular}


Tabela 3. Exemplo de planilha com valores de CP associados aos códigos de uso da terra

\begin{tabular}{cc} 
Código de uso da terra & CP \\
\hline 1 & 0,1533 \\
2 & 0,0080 \\
3 & 0,0001 \\
\hline
\end{tabular}

Com base nos arquivos de entrada de dados georreferenciados (Tabela 1), o programa calcula o fator comprimento de rampa e grau de declive (LS) de metro em metro ao longo de cada vertente. Numa vertente de $n$ metros de comprimento, o fator LS é estimado a cada metro através do método adaptado de Foster $\&$ Wischmeier (1974) e Wischmeier \& Smith (1978). Para isto, a vertente é dividida em $\boldsymbol{n}$ segmentos de 1 metro (Figura 2). Calcula-se inicialmente o fator comprimento do trecho $i\left(L_{i}, 1 \leq i \leq n\right)$ (eq.2):

$$
L_{i}=\left(\frac{i}{22,13}\right)^{0,5}
$$

Em seguida, calcula-se o fator declividade de cada segmento até o segmento $i_{j}$ $S_{j}(1 \leq j \leq i)$, com base na declividade de cada segmento $\left(\sigma_{j}, \mathrm{~m} / \mathrm{m}\right)$, esta calculada a partir das coordenadas $x, y, z$ de entrada (eq.3):

$$
S_{i}=65,41 \frac{\sigma_{i}^{2}}{1+\sigma_{i}^{2}}+4,56 \frac{\sigma_{i}}{\sqrt{1+\sigma_{i}^{2}}}+0,065
$$

O fator LS ao fim do trecho $i\left(L S_{i}\right)$ é então calculado por (eq.4):

$$
L S_{i}=L_{i} \sum_{i=1}^{i} P_{i} S_{i}
$$

onde $P_{j}$ é o fator de ponderação, calculado por (eq.5):

$$
P_{i}=\frac{j^{m+1}-(j-1)^{m+1}}{i^{m+1}}
$$


onde $m$ eqüivale a 0,5 para declives maiores ou iguais a $0,05 \mathrm{~m} \mathrm{~m}^{-1}$, a 0,3 para declives menores ou iguais a $0,03 \mathrm{~m} \mathrm{~m}^{-1} \mathrm{e}$, para declives entre 0,03 e $0,05 \mathrm{~m} \mathrm{~m}^{-1}$, é calculado por (eq.6):

$$
m=10 . \sigma
$$

Em seguida a erosão é calculada para a USLE ao longo de cada vertente, utilizando os valores de K, LS e CP de cada ponto e o valor de R da área.

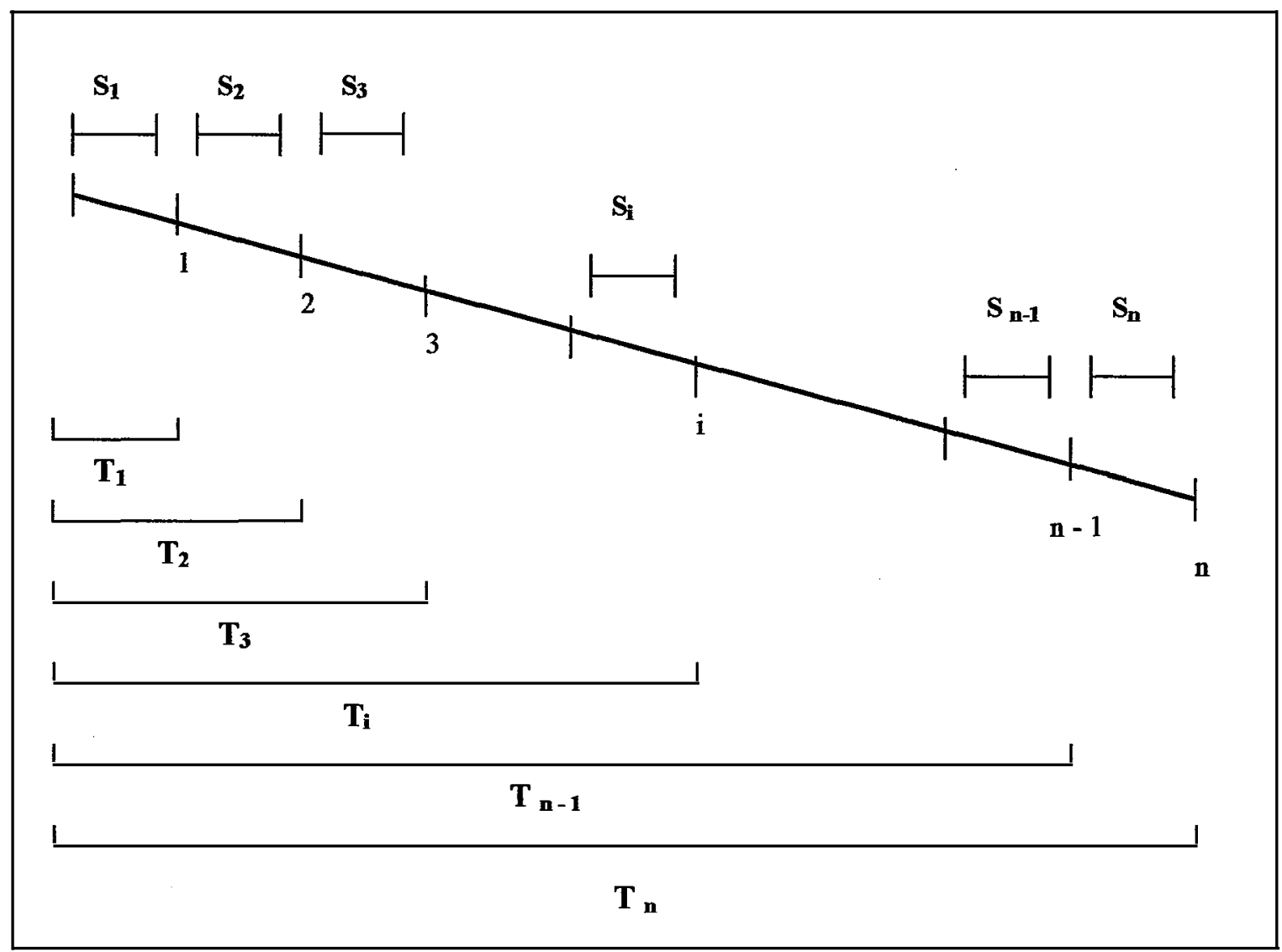

Figura 2. Representação de uma vertente e seus respectivos segmentos (S) e trechos (T) utilizados no cálculo do fator LS.

O programa gera arquivos que contêm a longitude $(X)$, latitude $(Y)$, perda de solo ( $\mathrm{kg} \mathrm{m}^{-2}$ e $\mathrm{Mg} \mathrm{ha}^{-1}$ ) e número da vertente para três opções de saída: 1) para os mesmos pontos dos arquivos de entrada; 2) para intervalos eqüidistantes ao longo das 
vertentes ou 3) para 100 pontos de perda de solo por Elemento de Fluxo (combinação entre solo e uso da terra ao longo da vertente). $\mathrm{O}$ valor da erosão para os pontos do arquivo de saída é estimado baseando-se na erosão calculada para os dois pontos vizinhos mais próximos. As informações de perda de solo são georreferenciadas com base no arquivo com os dados das regressões das vertentes, e podem ser utilizadas em outras aplicações. A representação esquemática das operações de aquisição de dados e funcionamento da EVI para a USLE pode ser vista na Figura 3.

\section{Utilizando WEPP}

Para cada solo e uso da terra existentes, constroem-se os arquivos de manejo (.man) e de solo (.sol) isoladamente, ou seja, considerando apenas um Elemento de Fluxo (EF) (ou "Overland Flow Element" (OFE)), no formato aceito pelo WEPP na versão para vertentes. Assim como para a USLE, constrói-se o arquivo de entrada com as informações geográficas de cada vertente (Tabela 1). O programa EVI associa cada código de solo e uso com os respectivos arquivos de solo e uso isolados do WEPP. Em seguida, constrói um arquivo de solo (.sol), uso/manejo (.man) e relevo (.slp) para cada vertente, no formato aceito pelo WEPP, contendo a seqüência de OFEs. A interface gera um arquivo de execução automática dos cálculos para cada vertente e outro que seqüencia a operação automática do programa WEPP para todas as vertentes. Com isto, os cálculos no WEPP dependem exclusivamente do arquivo executável do programa e todas as vertentes são calculadas em seqüência sem necessidade de assistência do usuário. A vantagem do uso da EVI nesta fase é a rapidez com que são construídos os arquivos de relevo com seus respectivos OFEs, o que, manualmente, demandaria muito tempo, principalmente se existir um grande número de vertentes.

Usando os arquivos gerados pela EVI, o cálculo das perdas e deposições de sedimentos para cada vertente é feito no WEPP. Após as operações de estimativa de erosão, os arquivos de saída do WEPP (.sum) são interpretados. Arquivos de saída georreferenciados são criados da mesma forma que a descrita para a USLE. 
A representação esquemática das operações de aquisição de dados e funcionamento da EVI para o WEPP pode ser vista na Figura 4.

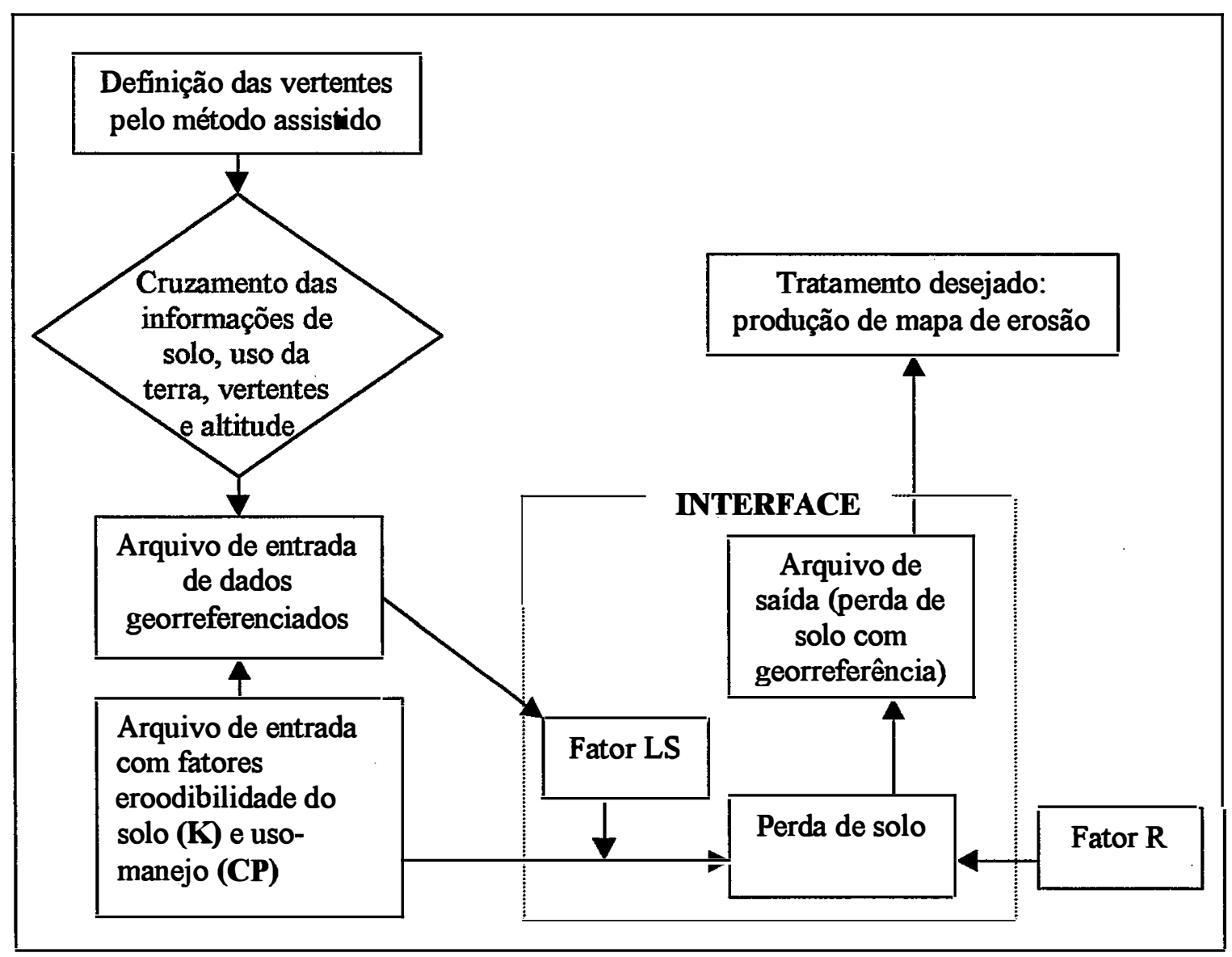

Figura 3. Representação esquemática das operações para uso da EVI com USLE. 


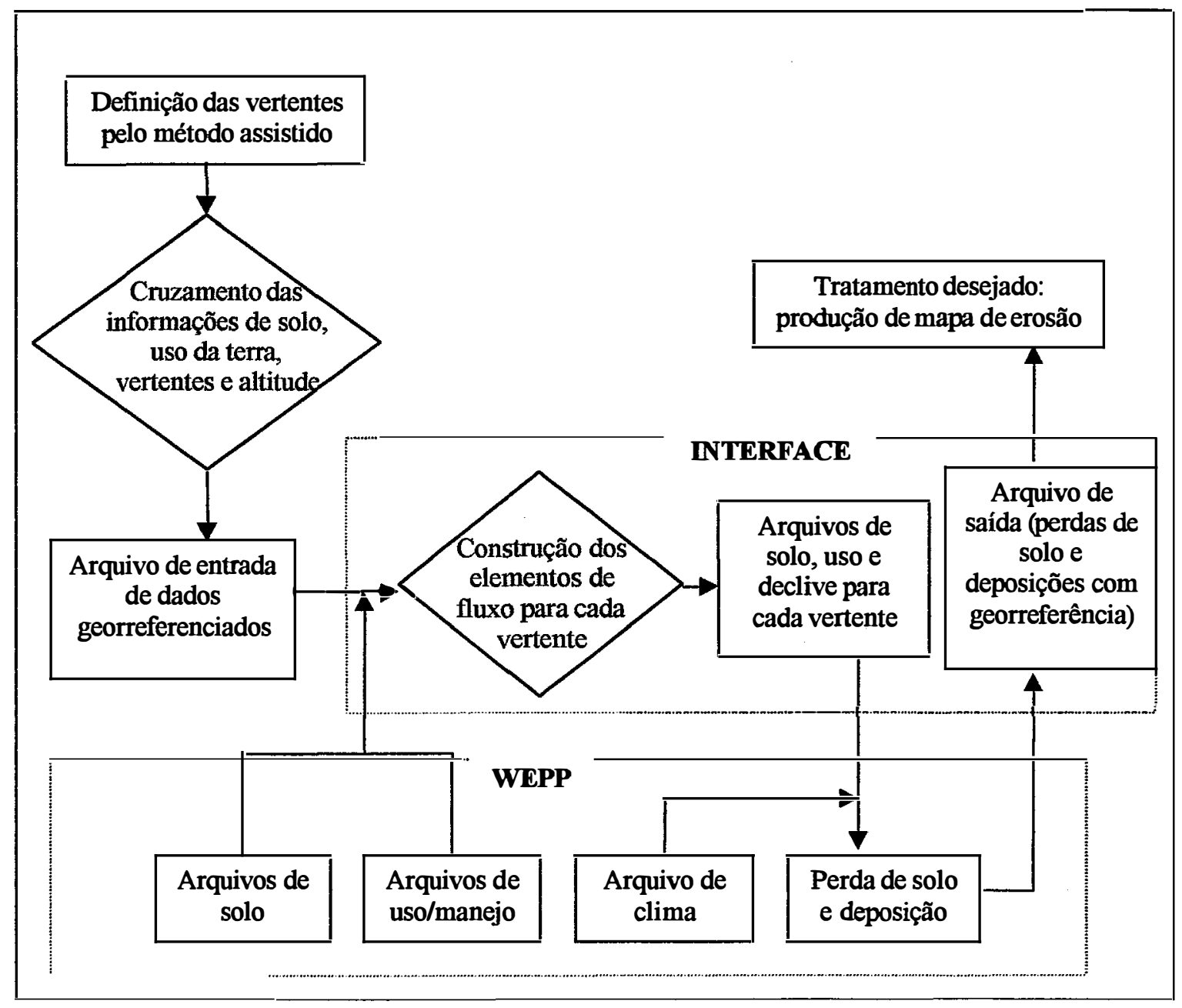

Figura 4. Representação esquemática das operações para uso da EVI com WEPP. 


\subsubsection{Exemplo de aplicação}

\section{Área de estudo}

Como exemplo de aplicação da EVI foi utilizada uma bacia hidrográfica de 75,8 ha, localizada na região de Piracicaba - SP (Figura 5). A bacia situa-se no entorno das coordenadas $22^{\circ} 38^{\prime} 54^{\prime \prime}$ de latitude Sul e $47^{\circ} 45^{\prime} 40^{\prime \prime}$ de longitude Oeste. O clima, segundo a classificação de Koeppen, é do tipo mesotérmico, Cwa, isto é, subtropical úmido com estiagem no inverno, cujas chuvas do mês mais seco não atingem $30 \mathrm{~mm}$ e a temperatura do mês mais quente é superior a $22^{\circ} \mathrm{C}$, enquanto a do mês mais frio é inferior a $18^{\circ} \mathrm{C}$. $\mathrm{O}$ relevo predominante é o suave ondulado a ondulado, com uma declividade média de $0,14 \mathrm{~m} \mathrm{~m}^{-1}$, com $75 \%$ do declive variando entre $0,02 \mathrm{~m} \mathrm{~m}^{-1} \mathrm{e} 0,20$ $\mathrm{m} \mathrm{m}^{-1}$. Entre os solos, predominam os ALISSOLOS CRÔMICOS e ARGISSOLOS VERMELHO-AMARELOS (83\%), com presença também de CAMBISSOLOS HÁPLICOS (10\%) e NEOSSOLOS LITÓLICOS (7\%), todos com camada superfícial arenosa ou média. Grande parte da sub-bacia encontra-se ocupada com cana-de-açúcar $(69 \%)$, sendo o restante pastagens $(8 \%)$ e mata ciliar $(23 \%)$.

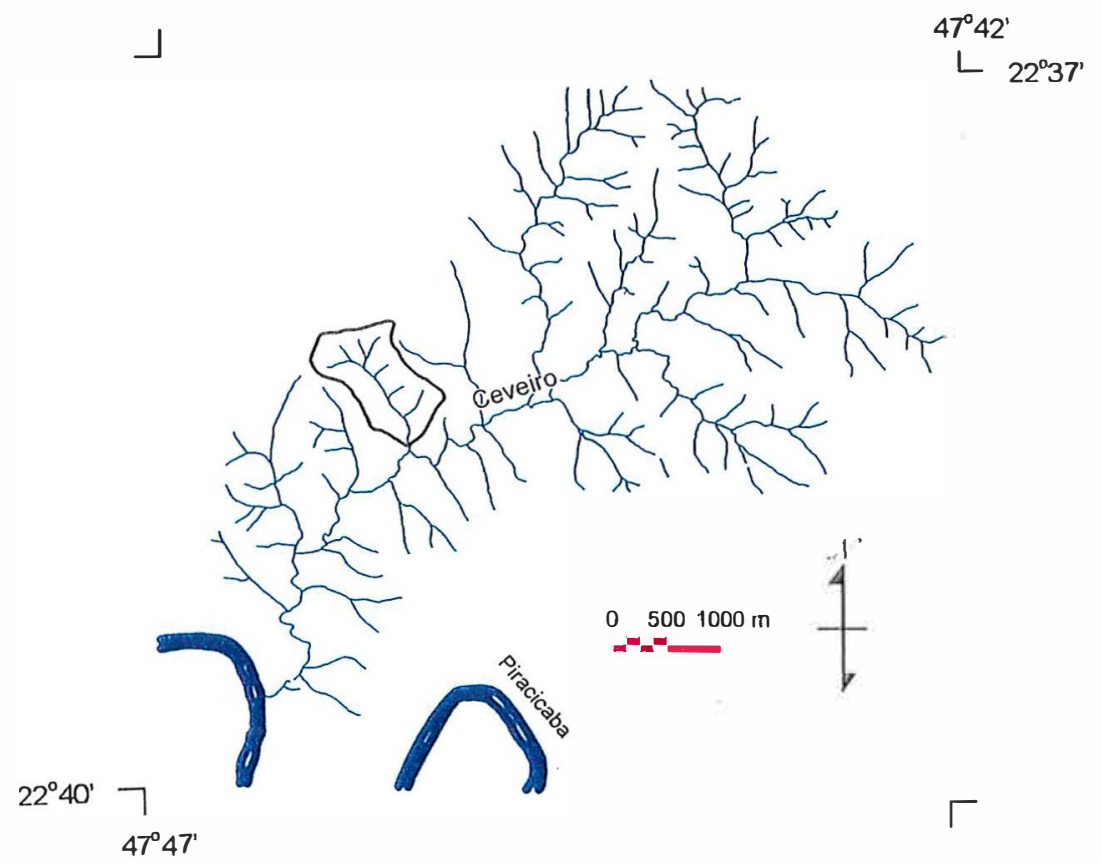

Figura 5. Bacia hidrográfica de estudo (em destaque). 


\section{Obtenção das informaçōes do meio físico}

Todas as informações espaciais do meio físico foram processadas no SIG TNTMips ${ }^{\circledR}$, operando em formato vetorial. A caracterização do relevo da bacia foi obtida através da carta topográfica do Plano Cartográfico do Estado de São Paulo, na escala 1:10.000, com curvas de nível de 5 em 5 metros, do ano de 1979. Esta carta foi digitalizada em mesa digitalizadora, com o auxílio do programa computacional AUTOCAD (Censi et al., 1994), utilizando-se como base a projeção linear de coordenadas "Universal Transversa de Mercador" (UTM). As curvas de nível originais foram interpoladas por triangulação, obtendo-se um mapa com curvas de nível espaçadas de 2 em 2 metros. Como informação básica de solos foi utilizado o mapa pedológico existente para a área, na escala 1:10.000. Este mapa também foi digitalizado e georreferenciado no SIG. O mapa de uso da terra foi obtido através de fotointerpretação de pares estereoscópicos da área, na escala 1:25.000, de julho de 1995, aferido a campo, sendo depois digitalizado e georreferenciado no SIG.

\section{Aplicação da USLE}

Os fatores C e P da USLE foram obtidos em literatura regional (Menk, 1993; DeMaria (comunicação pessoal ${ }^{7}$ )), com pequenos ajustes para melhor representar as condições de manejo locais. $\mathrm{O}$ fator $\mathrm{K}$ foi calculado pelo método descrito por Denardin (1990), baseado no nomograma de Wischmeier et al. (1971), a partir dos resultados granulométricos e químicos das amostras de solo coletadas em 31 pontos ao longo da área, de $0,20 \mathrm{em} 0,20 \mathrm{~m}$ de profundidade. Um arquivo com os códigos de solo e seus valores de $\mathrm{K}$ e um de uso da terra e seus valores de $\mathrm{C}$ e $\mathrm{P}$ foram construídos, como descritos nas Tabelas 2 e 3 . O fator erosividade da chuva $(R)$ foi considerado igual para toda a área estudada, e calculado com base nos registros de 30 anos do Posto Meteorológico da ESALQ/USP (Piracicaba - SP), localizado a 22 $42^{\prime} 30^{\prime \prime}$ de latitude sul, $47^{\circ} 38^{\prime} 00^{\prime \prime}$ longitude oeste e 546 metros de altitude, distante $14,7 \mathrm{~km}$ da área de estudo.

\footnotetext{
${ }^{7}$ Isabella C. DeMaria - Pesquisadora do Instituto Agronômico de Campinas, Seção de Conservação do Solo (Campinas - SP)
} 
O mapa digital de curvas de nível serviu como base para a obtenção do mapa de vertentes. Foram desenhadas 87 vertentes (segmentos de reta) na tela do SIG seguindo a direção e sentido preferenciais do fluxo da enxurrada (Figura 6).

Os mapas de solos, uso da terra, curvas de nível e vertentes foram sobrepostos no SIG. Após este cruzamento, cada nó passou a possuir as informações de solo e uso da terra, associadas às suas respectivas coordenadas geográficas. Estas informações (como na Tabela 1) foram exportadas para a EVI, que calculou as perdas de solo para pontos de 20 em 20 metros ao longo de cada vertente. Este arquivo de saída foi importado pelo SIG, sendo obtido um mapa de pontos de perda de solo para a bacia. Estes pontos foram interpolados pelo método do Inverso do Quadrado das Distâncias, gerando um mapa em formato matricial, com resolução espacial (pixel) de $5 \times 5 \mathrm{~m}$, contendo os valores de erosão para toda a área.

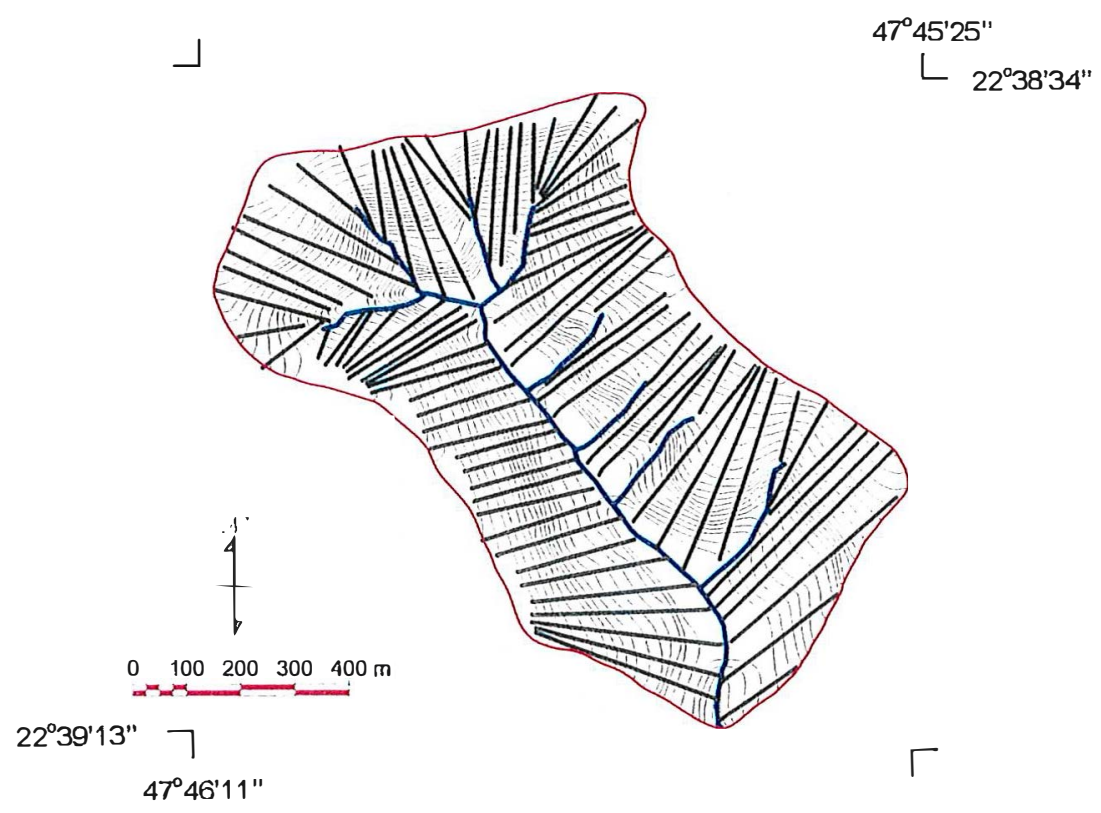

Figura 6. Vertentes definidas para a estimativa da erosão. 


\section{Aplicação do WEPP}

A simulação do clima de Piracicaba foi obtida através do modelo CLIGEN (Nicks et al., 1995) a partir de dados dos últimos 30 anos da base de dados da Estação Meteorológica da ESALQ/USP. A construção dos arquivos de solos foi feita com base nos resultados analíticos dos 31 pontos de amostragem descritos anteriormente. Os parâmetros necessários para a construção dos arquivos de uso/manejo do WEPP para as culturas da cana-de-açúcar, pastagem e mata ciliar (Apêndices 1 e 2) foram obtidos via literatura ou via consulta a pesquisadores, a partir de dados da região ou a partir de adaptações de dados obtidos em locais e culturas semelhantes (Doorenbos \& Kassan, 1979; Berish, 1982; Machado et al., 1982; van Heemst, 1988; Zimmer et al., 1988; Casagrande, 1991; Szott et al., 1994; Australian Agronomy Conference, 1996; Castro \& Kauffman, 1998; Didham, 1998; Vasconcelos, 1998).

As mesmas 87 vertentes descritas no item anterior foram utilizadas para os cálculos de erosão pelo modelo WEPP. As informações do cruzamento dos nós das vertentes com as curvas de nível foram fornecidas à EVI, que então construiu arquivos de relevo com seus respectivos OFEs, associando-os aos arquivos e de solo e uso/manejo construídos no WEPP. A estimativa das perdas de solo e deposições foi feita no WEPP e os resultados foram lidos pela EVI, que os georreferenciou novamente. Este arquivo de saída foi exportado para o SIG. Como descrito para a USLE, os resultados pontuais de erosão foram interpolados pelo método do Inverso do Quadrado das Distâncias no SIG, obtendo-se um mapa de erosão em formato matricial, com resolução espacial de $5 \times 5 \mathrm{~m}$. 


\subsection{Resultados e Discussão}

A EVI foi capaz de estimar as perdas de solo para a USLE, construir arquivos de entrada para serem lidos pelo WEPP e georreferenciar as informações de erosão produzidas pelos dois modelos. Os mapas matriciais produzidos podem ser vistos nas Figuras 7 e 8.

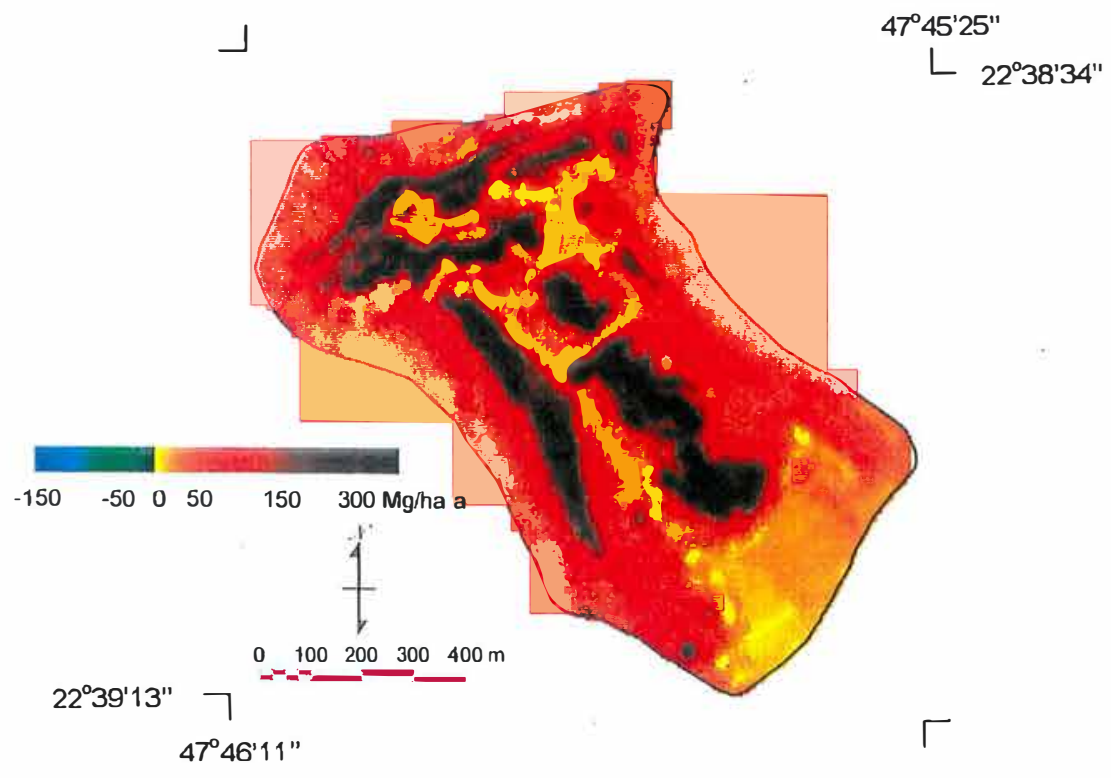

Figura 7. Distribuição espacial da erosão estimada pelo modelo USLE, em formato matricial. 


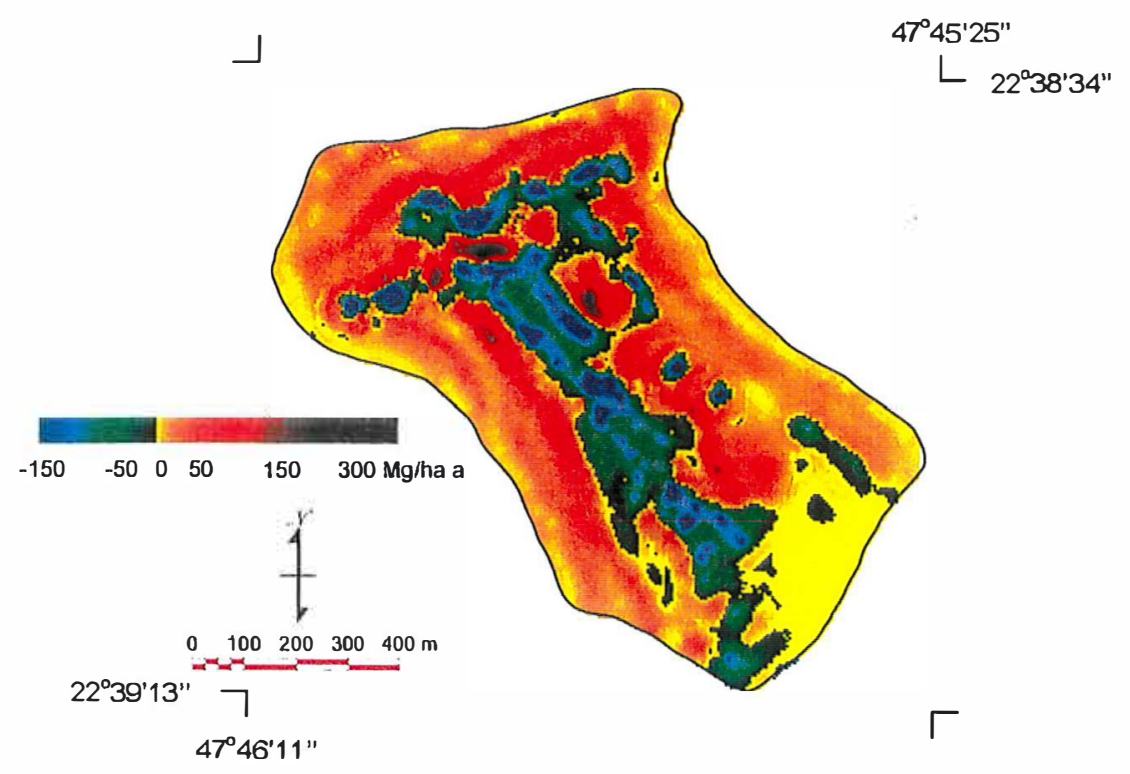

Figura 8. Distribuição espacial da erosão estimada pelo modelo WEPP, em formato matricial.

Como as vertentes foram definidas de forma vetorial, as possíveis distorções das informações (como a interpolação dos dados de erosão) ocorreram somente no final do processo e não na caracterização do relevo e no cálculo do fator LS da USLE. Assim, diminuíram-se as fontes de erros associadas ao cálculo da declividade e do comprimento de rampa com base no MET (método matricial), como as encontradas por diversos autores (Brown et al., 1981; de Jong et al., 1983; Johnson, 1988; Srinivasan \& Engel, 1991; Hamlet et al., 1992).

Outra vantagem do uso da EVI foi a rapidez com que puderam ser aplicados os modelos, mesmo com um número grande de vertentes. No caso do modelo WEPP, os arquivos de entrada com toda sua seqüência de OFEs foram construídos automaticamente. O processamento global das 87 vertentes (considerando que todos os 
dados de entrada estão disponíveis) envolvendo a geração do arquivo de entrada da EVI, processamento inicial dos arquivos pela EVI visando a aplicação automática do WEPP, processamento final pela EVI dos dados gerados pelo WEPP georreferenciando os valores de perda de solo ou deposições e a reimportação no SIG demanda aproximadamente 30 minutos. Caso as mesmas informações tivessem que ser processadas sem a EVI, provavelmente o tempo estimado seria de dois dias.

Por último, a EVI torna-se uma ferramenta útil em planejamento uma vez que possibilita fazer de forma automática com que modelos de erosão que não prevêem a espacialização dos dados trabalhem em ambiente georreferenciado, o que significa um avanço no estudo da erosão e confere uma nova dimensão ao uso dos modelos. 


\subsection{Conclusão}

A EVI mostrou-se como uma ferramenta útil no auxílio do mapeamento da erosão do solo e no planejamento de áreas como bacias hidrográficas, possibilitando a representação espacial das áreas de perda e deposição de sedimentos sem a degradação das informações de relevo. 


\title{
4 Comparação georreferenciada dos modelos de estimativa de erosão USLE e WEPP em uma bacia hidrográfica com predominância de cana-de-açúcar
}

\author{
Autora: Simone Beatriz Lima Ranieri \\ Orientador: Quirijn de Jong van Lier
}

\section{Resumo}

O objetivo deste trabalho foi a comparação de dois modelos de estimativa de erosão de concepções distintas (um monoequacionário e um mecanístico), visando fornecer subsídio para a escolha destes modelos para fins de planejamento agrícola e ambiental. Os modelos Universal Soil Loss Equation - USLE e Water Erosion Prediction Project - WEPP foram aplicados em uma bacia hidrográfica de 75,8 ha com diferentes solos e usos da terra, localizada na região de Piracicaba - SP e comparados quanto aos valores absolutos de perda de solo e à sua distribuição espacial. A USLE estimou valores de erosão 2,91 vezes superiores ao WEPP independentemente do tipo de solo, comprimento de vertente ou uso da terra, exceto para áreas de mata ciliar. Os valores médios de perda de solo obtidos para a bacia foram de $108,8 \mathrm{Mg} \mathrm{ha}^{-1} \mathrm{ano}^{-1}$ para a USLE e 34,8 $\mathrm{Mg} \mathrm{ha}^{-1} \mathrm{ano}^{-1}$ para o WEPP, sendo esse resultado muito influenciado pela presença expressiva da cultura da cana-de-açúcar, representando $69 \%$ da área total. A distribuição espacial dos resultados de erosão na bacia foi diferenciada para os dois modelos, havendo na USLE quebras abruptas nos valores de perda de solo devido ao peso do fator uso-manejo (C). Foi observada uma tendência de maior estimativa da USLE em relação ao WEPP, da parte superior das vertentes para a inferior, pois este último considera deposição de sedimentos ao longo das encostas. A necessidade de extrapolação das condições pelas quais a USLE foi desenvolvida e a desconsideração das deposições de sedimentos afetou significativamente as diferenças entre os dois modelos e permitiu afirmar que o uso da USLE em bacias hidrográficas não é recomendável. Por outro lado, o modelo WEPP, por estimar deposição de sedimentos e ajustar a estimativa das perdas 
e deposições à cada alteração de solo e/ou uso da terra, mostrou-se como uma ferramenta promissora para a utilização na escala de bacia.

Palavras-chave: erosão; USLE; WEPP; bacia hidrográfica; cana-de-açúcar. 


\title{
4 Georeferenced comparison of the erosion models USLE and WEPP in a watershed predominantly cropped with sugarcane
}

\author{
Author: Simone Beatriz Lima Ranieri \\ Adviser: Quirijn de Jong van Lier
}

\section{Summary}

The objective of this study was to compare two erosion models of different conceptions (one empirical and one mechanistic), aiming to supply information on the choice of these models for agricultural and environmental planning. The Universal Soil Loss Equation (USLE) and the Water Erosion Prediction Project (WEPP) were applied in a watershed of 75.8 ha with different soils and land uses, located in Piracicaba-Brazil. The absolute values of estimated soil loss and their spatial distribution were compared. With exception of the riparian forest, USLE estimated erosion values 2.91 times higher than WEPP independently of the soil type, slope length or land use. The medium values of soil loss obtained for the watershed were $108.8 \mathrm{Mg} \mathrm{ha}^{-1} \mathrm{year}^{-1}$ for USLE and $34.8 \mathrm{Mg} \mathrm{ha}^{-1}$ year $^{-1}$ for WEPP. The results were strongly influenced by the presence of sugar-cane, which represent $69 \%$ of the total area. The spatial distribution of erosion was different for the models, occurring abrupt changes in the values of soil loss for USLE due to the weight of its cover and management factor (C). The differences between the models increased from the top to the bottom of the hillslopes, and the ratio USLE/WEPP also increased due to the consideration of the deposition of sediments by WEPP along the hillslopes. The need of extrapolation of the conditions that USLE was developed for and the disregard of sediment depositions affected strongly the differences between the models and allow to affirm that USLE should not be applied in watersheds. On the other hand, WEPP estimates sediment depositions and adjusts the estimation of losses and depositions for each change of soil and/or land use. It is shown that WEPP is a promising tool for use in watershed scale.

Key-words: erosion; USLE; WEPP; watershed; sugarcane. 


\subsection{Introdução}

A erosão do solo é um dos principais impactos decorrentes da atividade agrícola (Lal, 1988). Por essa razão, a estimativa das perdas de solo é essencial para determinar a magnitude desses impactos nos recursos naturais e para definir a sustentabilidade dos agroecossistemas (Matson et al., 1997), assim como serve de guia para a seleção de melhores práticas de manejo.

Modelos de estimativa de erosão vêm sendo desenvolvidos desde a década de 50 para determinar valores de erosão e, principalmente, para serem utilizados como instrumentos auxiliares de planejamento (Renard \& Mausbach, 1990). Duas concepções distintas de modelos podem ser citadas: a dos modelos monoequacionários, baseados em uma única equação, e a dos mecanísticos, compostos de algoritmos de equações. Devido à variabilidade dos fatores que desencadeiam o processo de erosão, ela pode ser considerada como um fenômeno complexo onde diversas suposições, simplificações e constantes experimentalmente determinadas prestam papel importante nos resultados dos modelos, sejam eles monoequacionários ou mecanísticos. A comparação de modelos conceitualmente distintos aplicados para os mesmos dados e o entendimento das diferenças baseadas nas suposições e hipóteses dos modelos é uma questão chave para a seleção de métodos mais adequados para se trabalhar com problemas práticos (Hilborn \& Mangel, 1997).

Outra questão a ser considerada nos estudos de erosão diz respeito à sua variabilidade espacial. No caso de bacias hidrográficas, a unidade ecossistêmica mais utilizada em trabalhos de planejamento agrícola e ambiental (Prochnow, 1985), esta variabilidade é expressiva, exigindo o tratamento dos resultados quantitativos de perda 
de solo de forma georreferenciada. Porém, a maioria dos modelos de estimativa de erosão não foi concebida para estimar erosão desta forma.

Entre os modelos monoequacionários mais usados está a Universal Soil Loss Equation - USLE (Wischmeier \& Smith, 1978). A USLE vem sendo extensivamente utilizada em trabalhos de planejamento agrícola desde sua publicação e, mais recentemente, como instrumento para avaliação de impactos ambientais pela agricultura. A ampla utilização da USLE deve-se, entre outros motivos, ao número relativamente reduzido de parâmetros necessários para sua aplicação e ao extenso banco de dados utilizado na sua fundamentação (Lane et al., 1992). A principal limitação da USLE está relacionada à sua natureza empírica e, portanto, à necessidade de experimentações para cada nova situação onde será aplicada (Laflen et al., 1991). Este modelo também não considera a deposição de sedimentos ao longo das encostas uma vez que foi desenvolvido a partir de dados obtidos em parcelas pequenas e uniformes, o que limita seu uso em áreas complexas como bacias hidrográficas. A aplicação da USLE nessa escala apresenta problemas relacionados aos comprimentos das rampas, freqüentemente muito maiores que aqueles para os quais a equação foi desenvolvida (Brown et al., 1981; de Jong et al., 1983; Johnson, 1988; Hamlet et al., 1992) e à complexidade de relações entre solos e usos da terra encontrada em áreas extensas. Apesar destas restrições, têm-se encontrado diversas aplicações da USLE em bacias hidrográficas (Johnson, 1988; Mitra et al., 1988; Hamlet et al., 1992; Mellerowicz et al., 1994; Sparovek et al., 1997), todas elas com o auxílio de Sistemas de Informações Geográficas (SIG).

Entre os modelos mecanisticos mais usados está o Water Erosion Prediction Project - WEPP (Flanagan \& Nearing, 1995). Devido à sua natureza mecanística, seu uso dispensa extensivos experimentos de campo e calibrações, necessitando em vez disto de dados básicos do sistema em estudo: dados do solo, do clima, do manejo agrícola. O WEPP estima, para cada local considerado, a perda e a deposição de sedimentos. $\mathrm{O}$ saldo dos dois resulta em perda ou deposição líquida. Dessa forma, o WEPP é capaz de prever deposição de sedimentos ao longo das encostas e pode, portanto, ser aplicado em bacias hidrográficas (Laflen et al., 1991). Alguns trabalhos 
com uso do WEPP em bacias hidrográficas com auxílio de SIG podem ser encontrados em Sabavi et al. (1995) e Cochrane \& Flanagan (1999).

Por outro lado, a utilização do WEPP fica limitada em áreas cuja base cartográfica e de dados de solo, clima e crescimento vegetal é escassa, como em muitas regiões tropicais e sub-tropicais. Além disto, a confiabilidade na aplicação deste modelo nestas regiões também depende de ajustes em algoritmos de equações utilizadas em diversos dos seus componentes, uma vez que estas equações foram calibradas em condições diferentes (Nearing et al., 1990b). Contornadas estas limitações, a aplicação de modelos mecanísticos como o WEPP nestas regiões seria de grande relevância, tanto para a compreensão do processo erosivo e seus impactos, quanto para a redução do número de experimentações necessárias para a aplicação dos modelos como a USLE, com conseqüente redução no custo e tempo despendidos em trabalhos deste tipo.

O objetivo deste trabalho foi comparar a aplicação dos modelos USLE e WEPP para a estimativa da erosão em uma bacia hidrográfica quantificando suas diferenças espacialmente, visando, através desta análise, fornecer subsídio para a tomada de decisão do uso destes modelos em planejamento agrícola e ambiental. 


\subsection{Material e Métodos}

\subsection{1 Área de estudo}

A área escolhida para este estudo foi uma bacia hidrográfica de 75,8 ha, localizada no município de Piracicaba, Estado de São Paulo (Figura 1). A bacia situa-se no entorno das coordenadas $22^{\circ} 38^{\prime} 54^{\prime \prime}$ de latitude Sul e $47^{\circ} 45^{\prime} 40^{\prime \prime}$ de longitude Oeste. O clima, segundo a classificação de Koeppen, é do tipo mesotérmico, Cwa, isto é, subtropical úmido com estiagem no inverno. $\mathrm{O}$ relevo predominante é o suave ondulado a ondulado, com uma declividade média de $0,14 \mathrm{~m} \mathrm{~m}^{-1}$, variando entre $0,02 \mathrm{~m} \mathrm{~m}^{-1} \mathrm{e}$ $0,20 \mathrm{~m} \mathrm{~m}^{-1} \mathrm{em} 75 \%$ da área. Os solos, classificados de acordo com Embrapa (1999) são: $\mathrm{ACt}=$ ALISSOLOS CRÔMICOS Argilúvicos abrúpticos, A moderado, textura arenosa/média e ACtq + PVAaq = Associação de ALISSOLOS CRÔMICOS Argilúvicos abrúpticos arênicos + ARGISSOLOS VERMELHO-AMARELOS Alumínicos arênicos, ambos A moderado, textura arenosa/média ( $83 \%$ da área); $\mathrm{CXa}=$ CAMBISSOLOS HÁPLICOS Alumínicos típicos, Ta, A moderado, textura média (10\% da área); RLe = Associação de NEOSSOLOS LITÓLICOS Eutróficos típicos, A moderado + NEOSSOLOS LITÓLICOS Eutróficos chernossólicos, ambos Ta ou Tb, textura média, substrato siltitos da Formação Corumbataí e RLd = NEOSSOLOS LITÓLICOS Distróficos típicos, A moderado, textura média, substrato arenitos da Formação Pirambóia (7\% da área). O solo RLd não foi considerado neste estudo devido à sua pequena área de ocorrência.

A maior parte da área encontra-se ocupada com cana-de-açúcar (69\%), sendo o restante ocupado com pastagem (8\%) e matas ciliares perturbadas (em fase inicial de sucessão) (23\%). A bacia faz parte da bacia do Rio Piracicaba, que recentemente vem sendo objeto de estudo devido à contaminação de suas águas com agroquímicos 
provenientes principalmente da lavoura de cana-de-açúcar, resíduos industriais e efluentes urbanos. A grande movimentação de terra durante a reforma do canavial deixa o solo bastante suscetível à erosão e a conseqüente degradação da área pode ser observada pela situação crítica em que se encontra a represa de captação à jusante da bacia em relação à qualidade e disponibilidade de água.

\subsubsection{Obtenção e tratamento das informações do meio físico}

As informações espaciais foram processadas no SIG TNT-Mips ${ }^{\circledR}$, operando em formato vetorial. A caracterização do relevo da bacia foi obtida através da carta topográfica do Plano Cartográfico do Estado de São Paulo, na escala 1:10.000, com curvas de nível de 5 em 5 metros, de 1979. Esta carta foi digitalizada em mesa digitalizadora, com o auxílio do programa computacional AUTOCAD (Censi et al., 1994), utilizando-se como base a projeção linear de coordenadas "Universal Transversa de Mercador" (UTM). As curvas de nível originais foram interpoladas por triangulação, obtendo-se um mapa com curvas de nível espaçadas de 2 em 2 metros. Como informação básica de solos foi utilizado o mapa pedológico existente para a área, na escala 1:10.000. Este mapa também foi digitalizado e georreferenciado no SIG (Figura 2). O mapa de uso da terra foi obtido através de fotointerpretação de pares estereoscópicos da área, na escala 1:25.000, de julho de 1995, aferido a campo, sendo depois digitalizado e georreferenciado no SIG (Figura 3). 
provenientes principalmente da lavoura de cana-de-açúcar, resíduos industriais e efluentes urbanos. A grande movimentação de terra durante a reforma do canavial deixa o solo bastante suscetível à erosão e a conseqüente degradação da área pode ser observada pela situação crítica em que se encontra a represa de captação à jusante da bacia em relação à qualidade e disponibilidade de água.

\subsubsection{Obtenção e tratamento das informações do meio físico}

As informações espaciais foram processadas no SIG TNT-Mips ${ }^{\circledR}$, operando em formato vetorial. A caracterização do relevo da bacia foi obtida através da carta topográfica do Plano Cartográfico do Estado de São Paulo, na escala 1:10.000, com curvas de nível de 5 em 5 metros, de 1979. Esta carta foi digitalizada em mesa digitalizadora, com o auxílio do programa computacional AUTOCAD (Censi et al., 1994), utilizando-se como base a projeção linear de coordenadas "Universal Transversa de Mercador" (UTM). As curvas de nível originais foram interpoladas por triangulação, obtendo-se um mapa com curvas de nível espaçadas de 2 em 2 metros. Como informação básica de solos foi utilizado o mapa pedológico existente para a área, na escala 1:10.000. Este mapa também foi digitalizado e georreferenciado no SIG (Figura 2). O mapa de uso da terra foi obtido através de fotointerpretação de pares estereoscópicos da área, na escala 1:25.000, de julho de 1995, aferido a campo, sendo depois digitalizado e georreferenciado no SIG (Figura 3). 


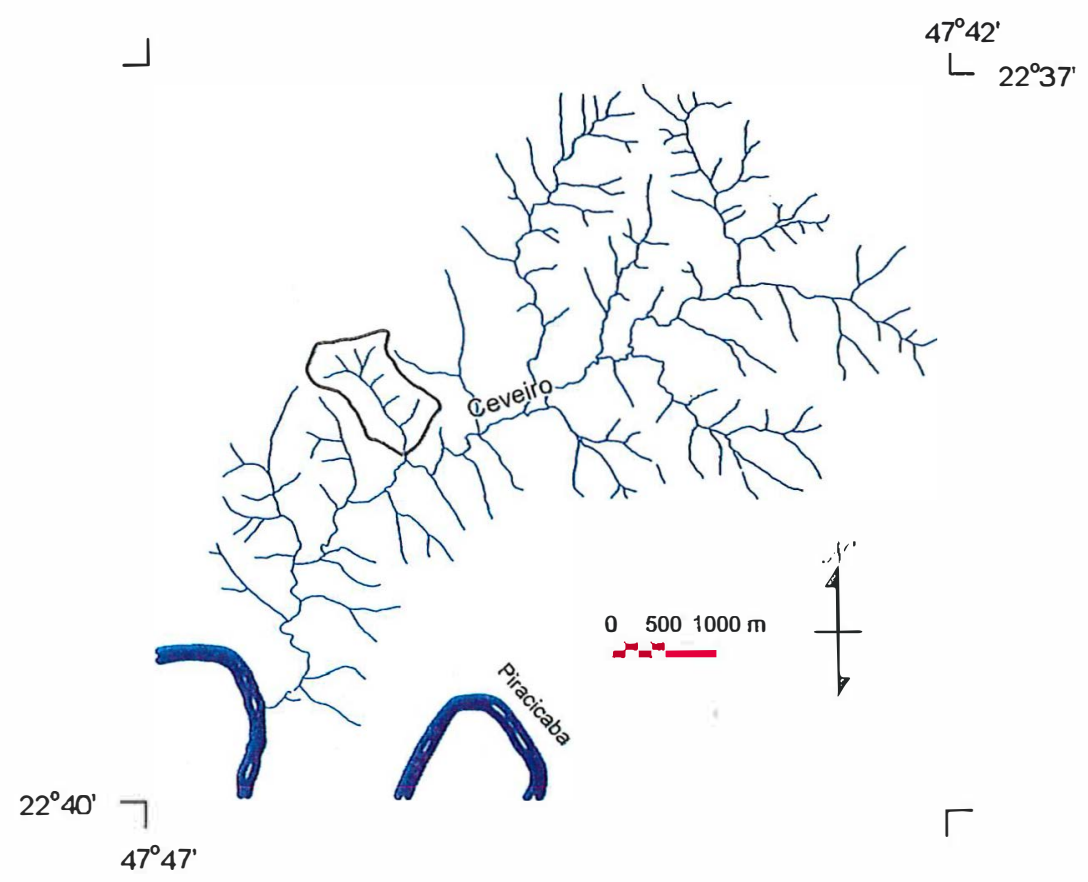

Figura 1. Bacia hidrográfica de estudo (em destaque).

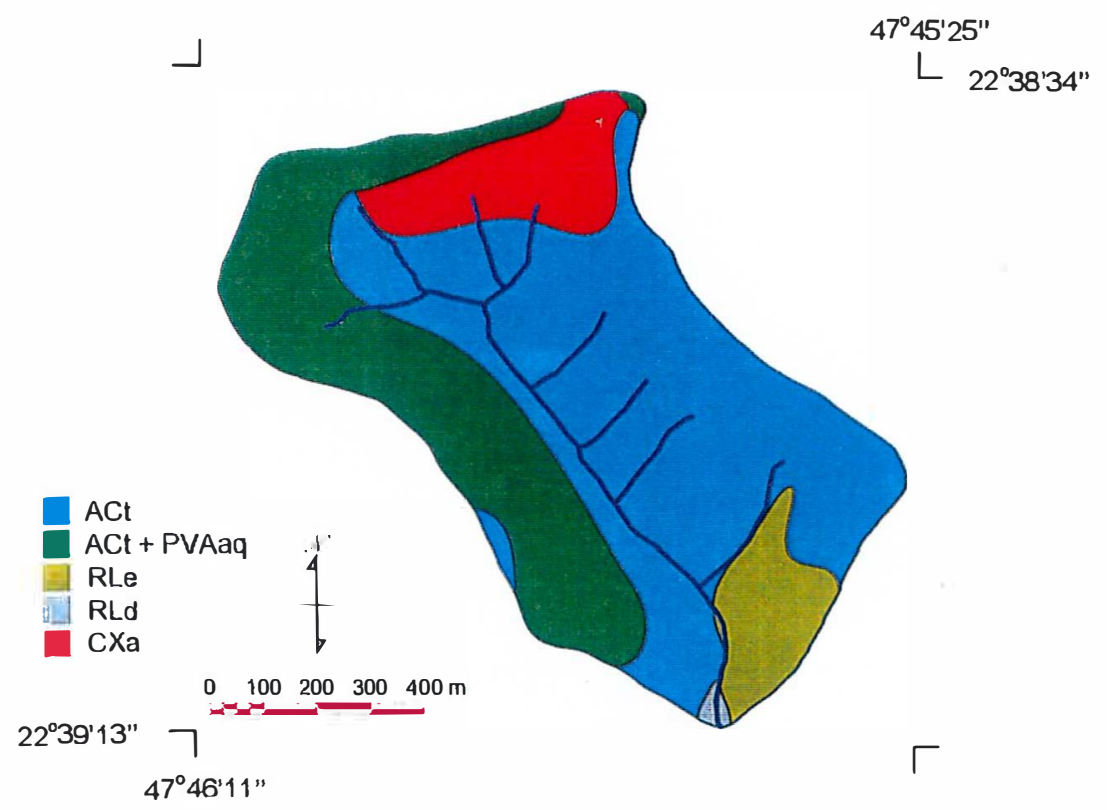

Figura 2. Mapa pedológico da bacia de estudo (levantamento feito por Sparovek (1991) e legenda reclassificada de acordo com Embrapa (1999)). 


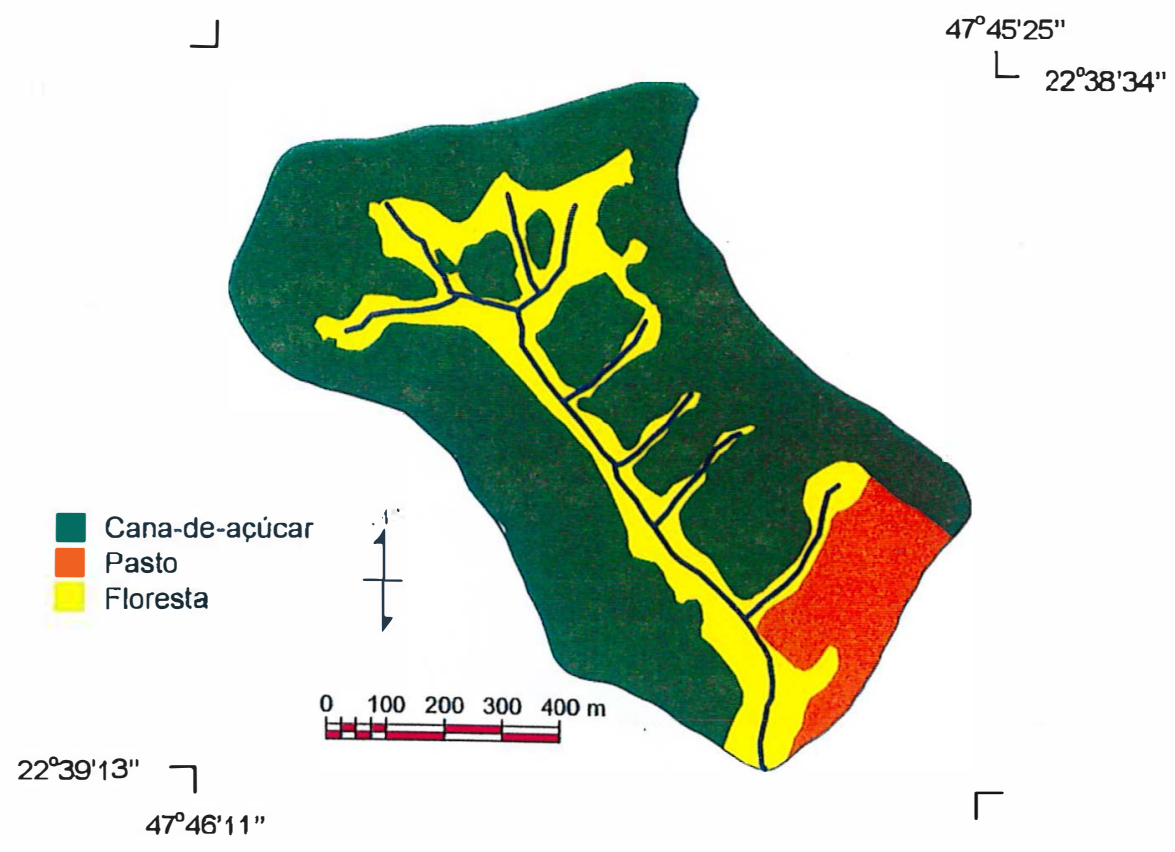

Figura 3. Mapa de uso da terra da bacia de estudo.

\subsubsection{Levantamento de dados, ajuste dos parâmetros para o modelo USLE e sua aplicação}

A USLE é apresentada da seguinte forma (Wischmeier \& Smith, 1978):

$$
A=\text { R.K.L.S.C.P }
$$

onde: $A=$ perda média anual de solo por unidade de área $\left(\mathrm{Mg} \mathrm{ha}^{-1}\right.$ ano); $R=$ erosividade das chuvas $\left(\mathrm{MJ} \mathrm{ha}^{-1} \mathrm{~mm} \mathrm{~h}^{-1}\right) ; K=$ erodibilidade do solo $\left(\mathrm{Mg} \mathrm{ha}^{-1}\left(\mathrm{MJ} \mathrm{ha}^{-1} \mathrm{~mm} \mathrm{~h}^{-1}\right)^{-1}\right)$ ano $^{-1} ; L S=$ fator comprimento da encosta e grau de declive; $C=$ fator uso e manejo; $P=$ fator práticas conservacionistas.

$\mathrm{O}$ fator $\mathrm{R}$ foi obtido através do cálculo dos valores mensais do Índice de Erosão (EI), seguindo a equação proposta por Lombardi Neto \& Moldenhauer (1980), para uma série de dados de 30 anos registrados pelo Posto Meteorológico da ESALQ/USP (Piracicaba - SP), localizado a $22^{\circ} 42^{\prime} 30^{\prime \prime}$ de latitude sul, $47^{\circ} 38^{\prime} 00^{\prime \prime}$ longitude oeste e 546 metros de altitude, distante $14,7 \mathrm{~km}$ da área de estudo. O valor utilizado para este parâmetro foi considerado único para toda a área e igual a $6235 \mathrm{MJ} \mathrm{mm} \mathrm{ha}^{-1} \mathrm{~h}^{-1}$. 
Para a determinação do fator $\mathrm{K}$ foram coletadas amostras de solo em 31 pontos ao longo da área (Figura 4), de 0,20 em $0,20 \mathrm{~m}$ de profundidade até a profundidade máxima de $1,2 \mathrm{~m}$ ou o contato com a rocha alterada.

As análises químicas do solo foram efetuadas seguindo os métodos descritos em Raij et al. (1987). Para a execução da análise granulométrica, as amostras de solo foram secas ao ar e passadas em peneira ASTM n. ${ }^{\circ} 10$ (malha $2 \mathrm{~mm}$ ), para a obtenção da terra fina seca ao ar (TFSA). A análise granulométrica dividiu as partículas de areia em 7 frações: areia muito grossa $(2-1 \mathrm{~mm})$, grossa $(1-0,5 \mathrm{~mm})$, média $(0,5-0,25 \mathrm{~mm})$, fina $(0,25-0,1 \mathrm{~mm})$ e muito fina $(0,1-0,05 \mathrm{~mm})$. As frações silte $(0,05-0,002 \mathrm{~mm})$ e argila $(<0,002 \mathrm{~mm})$ foram determinadas pelo método do densímetro de Bouyoucos (Kiehl, 1979).

$\mathrm{O}$ fator $\mathrm{K}$ foi determinado a partir dos resultados granulométricos e químicos das amostras de solo, seguindo a equação para solos brasileiros e americanos proposta por Denardin (1990), baseada no nomograma de Wischmeier et al. (1971) (Tabela 1). Os valores de $\mathrm{K}$ foram associados a cada unidade de mapeamento de solos no mapa digital no SIG.

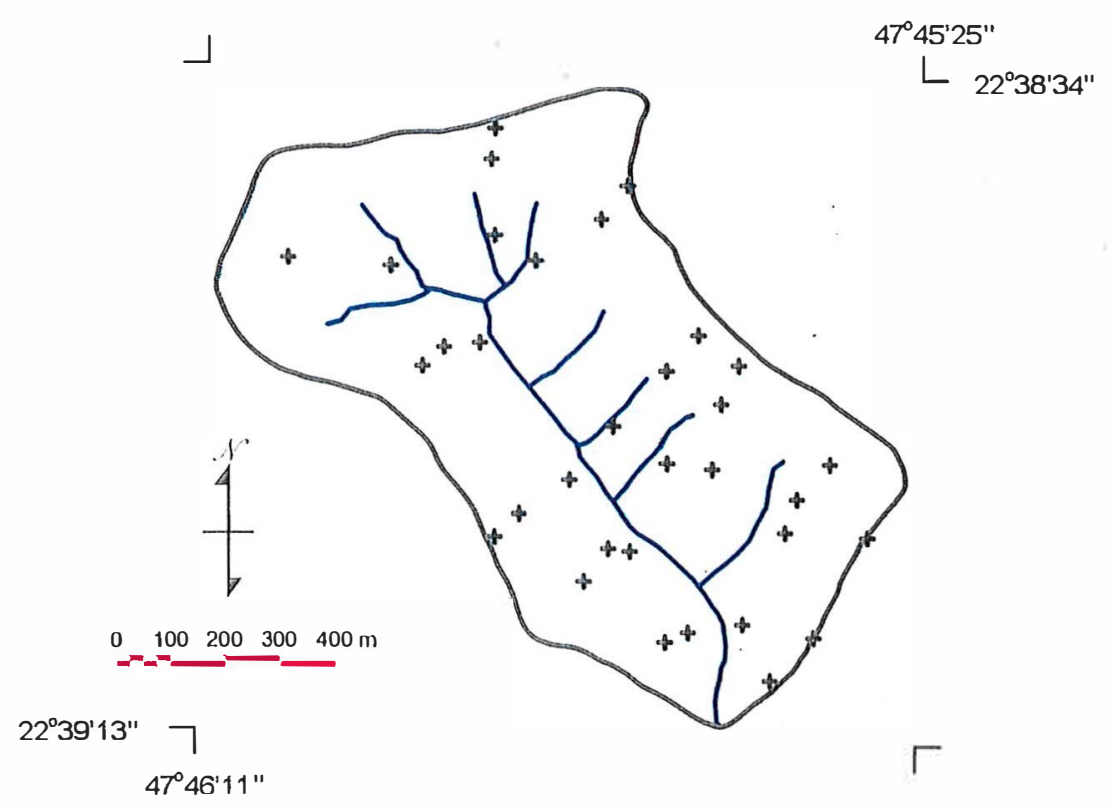

Figura 4. Pontos de amostragem de solos na bacia. 
Tabela 1. Fator $\mathrm{K}$ para os solos da bacia.

\begin{tabular}{cc}
\hline Solo & Fator $\mathbf{K}$ \\
\hline ACt & 0,028 \\
ACtq +PVAq & 0,028 \\
RLe & 0,037 \\
CXa & 0,025 \\
\hline
\end{tabular}

Os valores do fator uso-manejo foram obtidos em literatura (Menk, 1993; DeMaria (comunicação pessoal ${ }^{8}$ )) (Tabela 2). Para as áreas com cana-de-açúcar, onde o plantio em contorno é adotado, o fator $\mathrm{P}$ utilizado foi o de 0,5 . Para as áreas de pastagem e mata ciliar, o fator P foi considerado igual a 1,0 (Bertoni \& Lombardi Neto, 1990). Estes valores foram associados a cada unidade de uso da terra no mapa digital.

\begin{tabular}{cc} 
Tabela 2. Fator uso-manejo para as culturas encontradas na bacia \\
\hline Uso da terra & Fator C \\
\hline Cana-de-açúcar & 0,3066 \\
Pastagem & 0,0080 \\
Mata ciliar & 0,0001 \\
\hline
\end{tabular}

Para o cálculo do fator LS, um mapa de curvas de nível na escala de 1:10.000, com linhas a cada $5 \mathrm{~m}$ de diferença de cota, foi digitalizado no SIG. As curvas foram interpoladas para espaçamento vertical de 2 metros, através de ferramentas de triangulação no SIG. O cálculo do fator LS foi feito de forma vetorial, isto é, cada vertente onde seriam estimadas as perdas de solo foi desenhada no SIG, perpendicularmente às curvas de nível, seguindo a direção e sentido preferenciais do fluxo da enxurrada (Figura 5).

\footnotetext{
${ }^{8}$ Isabella C. DeMaria - Pesquisadora do Instituto Agronômico de Campinas, Seção de Conservação do Solo (Campinas - SP)
} 


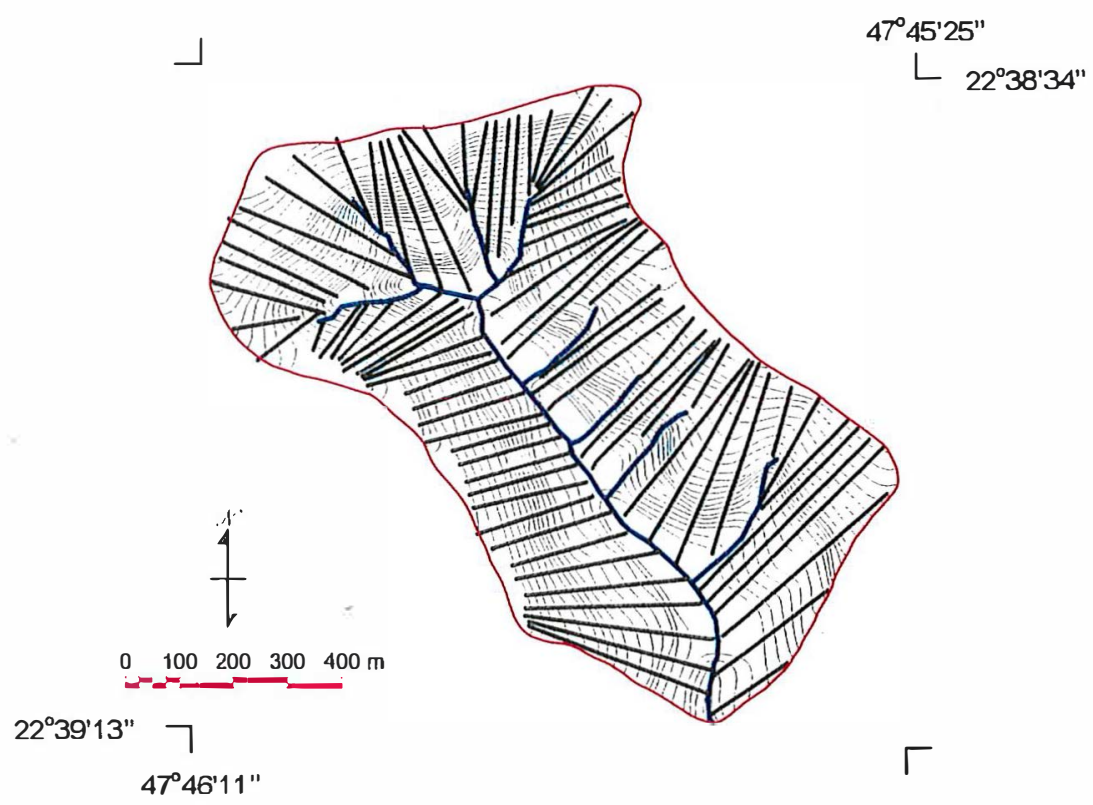

Figura 5. Vertentes desenhadas no SIG para a aplicação dos modelos.

No SIG os mapas de solos, uso da terra (com seus respectivos valores de $\mathrm{K}$ e $\mathrm{CP}$ ), curvas de nível e vertentes foram sobrepostos. Estas informações foram exportadas para um programa computacional de interface entre modelos de erosão e SIGs vetoriais desenvolvido para este estudo (descrição no capítulo 3). De posse destas informações o programa calculou o fator LS para cada metro linear ao longo de cada vertente através do método adaptado de Foster \& Wischmeier (1974) e Wischmeier \& Smith (1978) e as perdas de solo foram estimadas para pontos distantes de 20 em 20 metros ao longo de cada vertente, de acordo com Wischmeier \& Smith (1978). A descrição dos cálculos e procedimentos adotados pelo programa de interface estão descritos no capítulo 3 . Os 
valores pontuais de erosão foram georreferenciados, exportados para o SIG e interpolados pelo método do Inverso do Quadrado das Distâncias, gerando um mapa em formato matricial, com resolução espacial (pixel) de $5 \times 5 \mathrm{~m}$, contendo os valores de erosão para toda a área.

\subsubsection{Levantamento de dados, ajuste dos parâmetros para o modelo WEPP e sua aplicação}

A obtenção dos dados de erosão pelo modelo WEPP foi feita através de simulação contínua do clima por 98 anos, utilizando o modelo CLIGEN (Nicks et al. 1995). Os parâmetros climáticos foram extraídos de uma série de 30 anos da base de dados da Estação Meteorológica da ESALQ/USP. Os dados de solos para o modelo foram obtidos a partir dos resultados analíticos dos 31 pontos de amostragem descritos anteriormente. Foram construídos arquivos para cada solo da área de estudo, onde os parâmetros de entrada foram, para cada $0,20 \mathrm{~m}$ de profundidade: teor de areia total, teor de argila total, teor de areia muito fina, teor de matéria orgânica e capacidade de troca catiônica. $\mathrm{O}$ albedo do solo (\%), a erodibilidade entre-sulcos $\left(\mathrm{kg} \mathrm{s} \mathrm{m}^{-4}\right)$, a erodibilidade no sulco $\left(\mathrm{s} \mathrm{m}^{-1}\right)$, a tensão de cisalhamento crítico $\left(\mathrm{N} \mathrm{m}^{-2}\right)$ e a condutividade hidráulica efetiva $\left(\mathrm{mm} \mathrm{h}^{-1}\right)$ foram calculados pelo WEPP com base nos dados químicos $\mathrm{e}$ granulométricos do horizonte superficial dos solos.

Os dados necessários para a construção dos arquivos de uso/manejo do WEPP (Apêndices 1 e 2) foram obtidos em literatura ou por consulta a pesquisadores, a partir de dados da região ou a partir de adaptações de dados obtidos em locais e culturas semelhantes (Doorenbos \& Kassan, 1979; Berish, 1982; Machado et al., 1982; van Heemst, 1988; Zimmer et al., 1988; Casagrande, 1991; Szott et al., 1994; Australian Agronomy Conference, 1996; Castro \& Kauffman, 1998; Didham, 1998; Vasconcelos, 1998). Foram construídos arquivos de uso/manejo no WEPP (versão para vertentes), para as culturas da cana-de-açúcar, pastagem e mata ciliar.

A construção dos arquivos de vertentes para o WEPP foi feita de maneira semelhante à descrita para o cálculo do fator LS da USLE. O programa de interface 
(capítulo 3) construiu arquivos de vertentes e seus Elementos de Fluxo (combinação entre solo e uso da terra de cada parte da vertente), associando-os aos respectivos arquivos e de solos e uso/manejo construídos no WEPP. A estimativa da perda de solo e deposição foi feita no WEPP e os resultados foram georreferenciados novamente no programa de interface. Os resultados pontuais de perda de solo e deposição foram interpolados no SIG, obtendo-se um mapa de erosão para toda a bacia, em formato "raster".

\subsubsection{Comparação dos modelos}

Duas comparações foram feitas entre os resultados dos modelos de estimativa de erosão. A primeira comparação foi quanto aos valores absolutos de erosão e a segunda quanto à distribuição espacial destes valores na área. A fim de identificar possíveis efeitos dos fatores condicionantes da erosão relacionados ao meio fisico, a primeira comparação foi também dividida por uso da terra, por comprimento de vertente e por tipo de solo. Pelo fato de a USLE não estimar deposição de sedimentos ao longo das vertentes, dois tipos de análises foram consideradas nas comparações. Na primeira, a estimativa da erosão foi feita em área total (AT), considerando perdas e deposições, e na segunda em área parcial (AP), desconsiderando-se as áreas de deposição líquida estimadas pelo modelo WEPP. As comparações por uso da terra, comprimento da vertente e solo foram feitas somente nas APs. As comparações espaciais foram feitas para AT. 


\subsection{Resultados e Discussão}

\subsubsection{Comparação dos valores médios de erosão estimados pelos modelos}

Os resultados obtidos pelos dois modelos de estimativa de erosão mostraram que, quando considerada a área total da bacia (AT), a USLE estimou valores de erosão superiores ao WEPP para todos os usos da terra (Tabela 3). Quando descontadas as áreas de deposição líquida estimadas pelo modelo WEPP (AP), a USLE apresentou perdas de solo inferiores ao WEPP apenas nas áreas de mata ciliar (Tabela 3). Pode-se notar que, tanto em AT como em AP, as áreas com cana-de-açúcar apresentaram perdas de solo superiores aos outros usos para ambos os modelos, sendo que a média de perda da bacia foi grandemente influenciada por esta cultura, devido à sua predominância na área (69\%). As perdas de solo estimadas pelo modelo WEPP em áreas de pastagem e mata ciliar, quando consideradas em AP, mostraram-se com valores relativamente próximos. Quando considerada a AT, porém, observou-se que houve grande deposição de sedimentos em áreas de mata ciliar em relação às áreas de pastagens estimadas por este modelo.

Tabela 3. Erosão média (valores positivos) ou deposições (valores negativos) em área total (AT) e excluindo-se as áreas de deposição líquida estimadas pelo modelo WEPP (AP) para os diferentes usos da terra $\left(\mathrm{Mg} \mathrm{ha}^{-1} \mathrm{ano}^{-1}\right)$.

\begin{tabular}{ccccc}
\hline USO DA TERRA & \multicolumn{2}{c}{ USLE } & \multicolumn{2}{c}{ WEPP } \\
\cline { 2 - 5 } & AT & AP & AT & AP \\
\hline Cana-de-açúcar & 120,5 & 120,5 & 28,2 & 38,6 \\
Pastagem & 6,9 & 8,0 & $-1,0$ & 1,8 \\
Mata ciliar & 1,2 & 0,4 & $-80,1$ & 1,6 \\
Área total & 88,8 & 108,8 & 4,5 & 34,8 \\
\hline
\end{tabular}


Quando comparados os resultados dos modelos em AP, observa-se que a USLE estimou perdas superiores ao WEPP para todos os solos da bacia (Tabela 4). Nota-se que a perda média para o solo RLe apresentou-se inferior em relação aos outros solos, porém esta diferença pode ser explicada pela não ocorrência deste solo em áreas com cana-deaçúcar, uso que apresentou os maiores valores de perda para ambos os modelos. Mais uma vez pode-se notar pela Tabela 4 que o WEPP estimou perdas superiores à USLE apenas em áreas de mata ciliar.

Um dos fatores que contribuiu para este resultado é o fato de que, na USLE, o valor do fator $\mathbf{C}$ diminui abruptamente quando se atingem as áreas de mata, diminuindo também bruscamente as perdas de solo. $\mathrm{O}$ mesmo não ocorre utilizando o modelo WEPP: ao atingir as áreas de mata, e portanto, alterando o Elemento de Fluxo, o WEPP ainda considera a enxurrada advinda das áreas morro acima, o que faz com que as perdas no início nas áreas de mata não sejam reduzidas tão rapidamente como no caso da USLE, e fazendo com que os valores de perda média para o WEPP apareçam maiores que os estimados pela USLE (Tabela 4). Porém, os resultados obtidos pelos modelos para este uso da terra devem ser considerados com ressalvas. Isto porque o modelo WEPP não foi calibrado para condições de floresta (Flanagan \& Nearing, 1995), tendo sido feitas adaptações para o presente trabalho. No caso da USLE, poucas experimentações foram feitas em áreas de floresta e erros podem estar implícitos na obtenção do fator $\mathrm{C}$ devido à reduzida quantidade de sedimentos coletados nas parcelas.

Observa-se, no entanto, que em ambos os modelos este uso da terra apresentou perdas de solo inferiores aos demais usos. Nota-se também que as maiores diferenças entre perdas em pastagem e mata ciliar ocorreram na USLE (Tabela 4), devido à grande diferença dos fatores $\mathrm{C}$ e $\mathrm{P}$ entre estes dois usos (Tabela 2 ).

Demonstra-se que a USLE estimou valores de erosão superiores ao WEPP pelos valores dos coeficientes angulares das regressões entre os resultados dos dois modelos, em AP, para todas as combinações entre solo e uso existentes na bacia (Tabela 5). Com exceção das áreas de mata ciliar, não houve diferença significativa entre os coeficientes angulares entre os dois modelos, independentemente dos solos ou usos. 
Tabela 4. Perda de solo $\left(\mathrm{Mg} \mathrm{ha}^{-1}\right.$ ano $\left.^{-1}\right)$ em AP para os diferentes tipos de solo e usos da terra.

\begin{tabular}{|c|c|c|c|c|c|c|c|c|}
\hline & \multicolumn{2}{|c|}{$\begin{array}{l}\text { Solo } \\
\text { ACt }\end{array}$} & \multicolumn{2}{|c|}{$\begin{array}{c}\text { Solo } \\
\text { ACtg+PVAg }\end{array}$} & \multicolumn{2}{|c|}{$\begin{array}{l}\text { Solo } \\
\text { RLe }\end{array}$} & \multicolumn{2}{|c|}{$\begin{array}{l}\text { Solo } \\
\text { CXa }\end{array}$} \\
\hline & USLE & WEPP & USLE & WEPP & USLE & WEPP & USLE & WEPP \\
\hline Cana-de-açúcar & 141,1 & 40,9 & 90,9 & 31,7 & $\bar{I}$ & 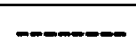 & 149,8 & 54,9 \\
\hline Pastagem & 14,3 & 3,9 & ---- & & 5,5 & 1,0 & & \\
\hline Mata ciliar & 0,7 & 2,3 & -.- & --.---.- & 0,04 & 0,8 & 0,1 & 1,0 \\
\hline Todos & 130,3 & 37,8 & 90,6 & 31,6 & 4,3 & 1,0 & 146,5 & 53,7 \\
\hline
\end{tabular}

Tabela 5. Coeficientes angulares (a) das regressões dos pontos de perda (AP) dos modelos USLE e WEPP (USLE $=$ a.WEPP). Valores seguidos pela mesma letra minúscula (linha) ou maiúscula (coluna) não diferem entre si ao nível de significância de $5 \%$.

\begin{tabular}{|c|c|c|c|c|c|}
\hline & Solo ACt & $\begin{array}{l}\text { Solo ACtq } \\
+ \text { PVAq }\end{array}$ & Solo RLe & Solo CXa & Todos \\
\hline Cana-de-açúcar & $\begin{array}{l}3,05 \text { a } \mathbf{A} \\
247 \text { A }\end{array}$ & 2,72 a A & & 2,73 a A & $\begin{array}{ll}2,91 & \mathbf{a} \\
261 & \mathbf{a}\end{array}$ \\
\hline Mata & 0,10 b B & -.-- & 0,05 & 0,10 b $\mathbf{~ B}$ & 0,09 b \\
\hline Todos & $3,05 \mathbf{A}$ & $2,72 \mathbf{A}$ & $3,62 \mathrm{~A}$ & $2,73 \mathbf{A}$ & 2,91 \\
\hline
\end{tabular}

A possível influência do comprimento das vertentes nas estimativas de perda foi verificada, dividindo-se as vertentes da bacia em quatro grupos: até 100, 100 a 200, 200 a 300 e 300 a 420 metros. Os resultados mostraram que a USLE estimou perdas superiores ao WEPP em todos os grupos, sem diferenciação entre eles ao nível de significância de $5 \%$.

Desta forma, através das comparações entre valores absolutos de perda de solo, pode-se observar que, embora existam diferentes usos da terra, solos e comprimentos de vertentes na bacia, a tendência geral foi a superestimativa da USLE em relação ao WEPP por 2,91 vezes, com exceção das áreas de mata ciliar. Este fato poderia levar a crer que, em condições como as da área de estudo, quando se desconsideram as áreas de deposição líquida, o ajuste de um modelo para o outro poderia ser feito utilizando-se este valor como fator de conversão. Estas observações, porém, tratam-se de médias, devendo também ser observada a distribuição espacial dos valores de perda ao longo da área. 


\subsubsection{Comparação da distribuição espacial dos valores de erosão estimados pelos modelos}

Os mapas de perda de solo obtidos pela USLE e pelo WEPP através da interpolação dos pontos de erosão são mostrados nas Figuras 6 e 7, respectivamente.

Comparando os dois modelos quanto à distribuição espacial, para AT, pode-se observar que a USLE concentrou seus valores de perda em até $10 \mathrm{Mg} \mathrm{ha}^{-1} \mathrm{ano}^{-1}(35 \% \mathrm{da}$ área) ou na faixa de 40 a $150 \mathrm{Mg} \mathrm{ha}^{-1} \mathrm{ano}^{-1}$ (35\% da área) (Figuras 8a e 9a). As áreas de menor perda pela USLE encontram-se nos topos de morros e no final das encostas, quando se atinge as áreas de mata ciliar (Figura 6), devido ao decréscimo brusco no valor do fator $\mathrm{C}$ para este uso da terra. O WEPP, por sua vez, apresentou uma distribuição diferenciada dos valores de perda, sendo que $27 \%$ da área foi estimada como deposição líquida e $70 \%$ da área teve perdas inferiores a $30 \mathrm{Mg} \mathrm{ha}^{-1} \mathrm{ano}^{-1}$ (Figuras $8 b$ e $9 b)$.

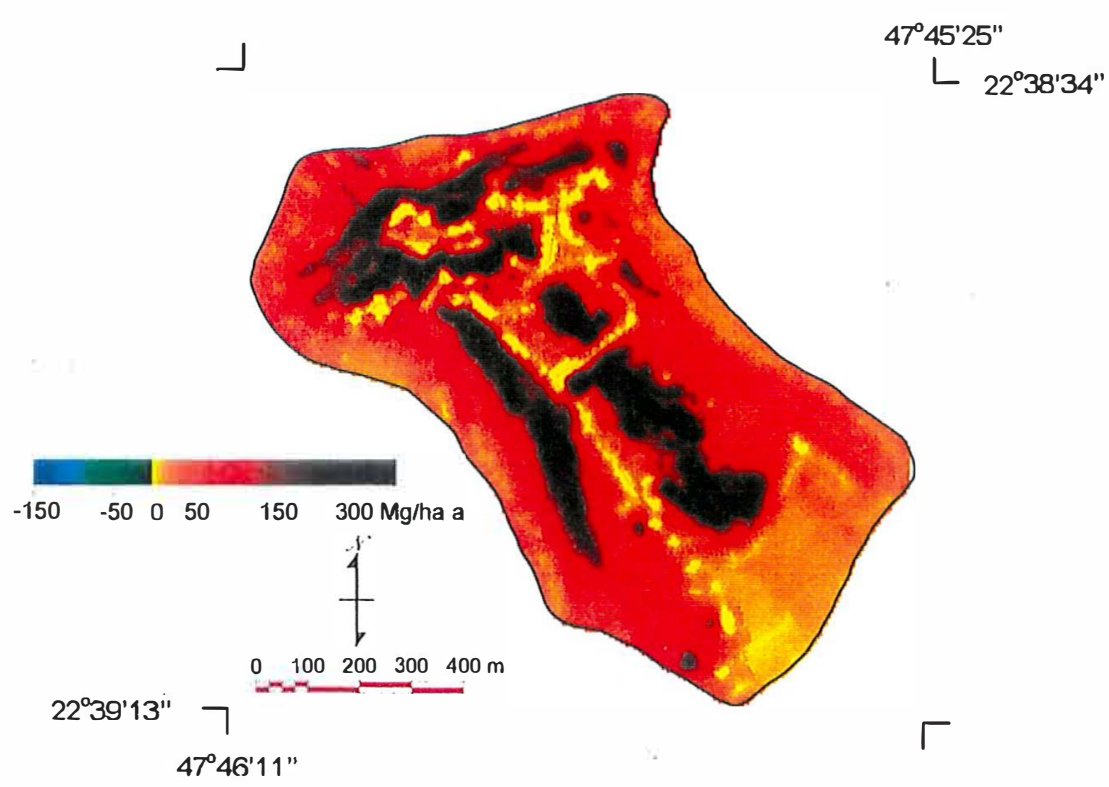

Figura 6. Distribuição espacial da erosão estimada pelo modelo USLE. 


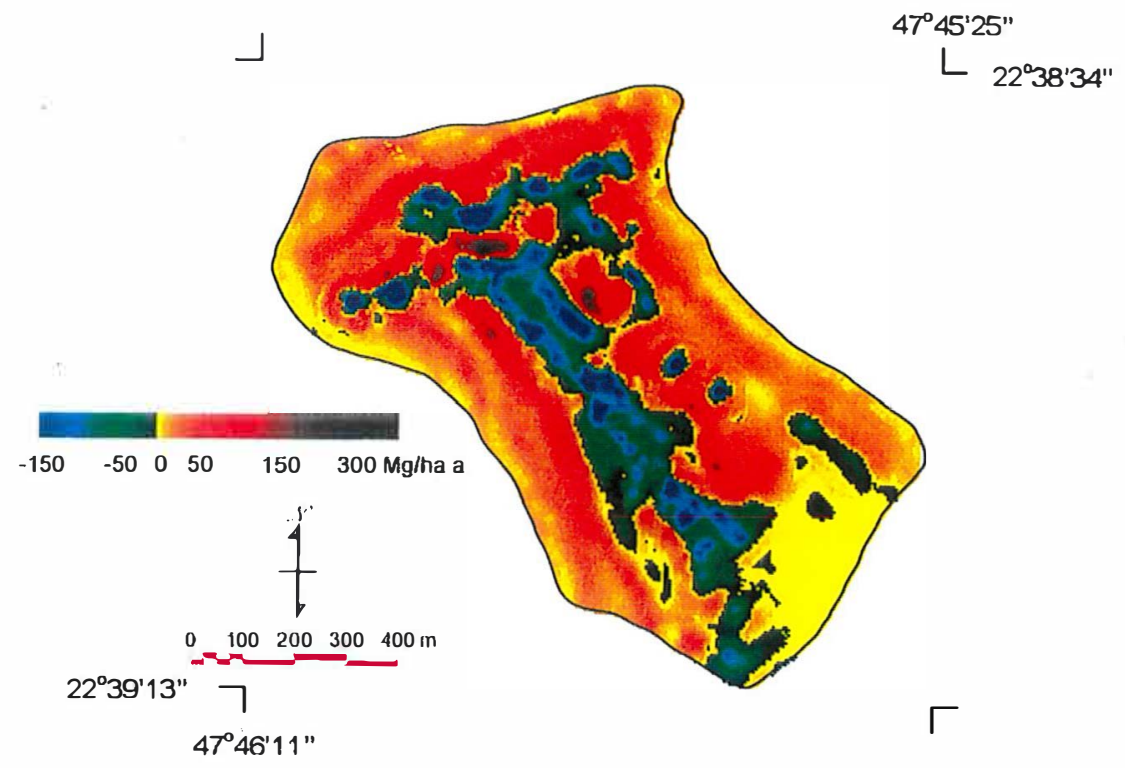

Figura 7. Distribuição espacial da erosão estimada pelo modelo WEPP.
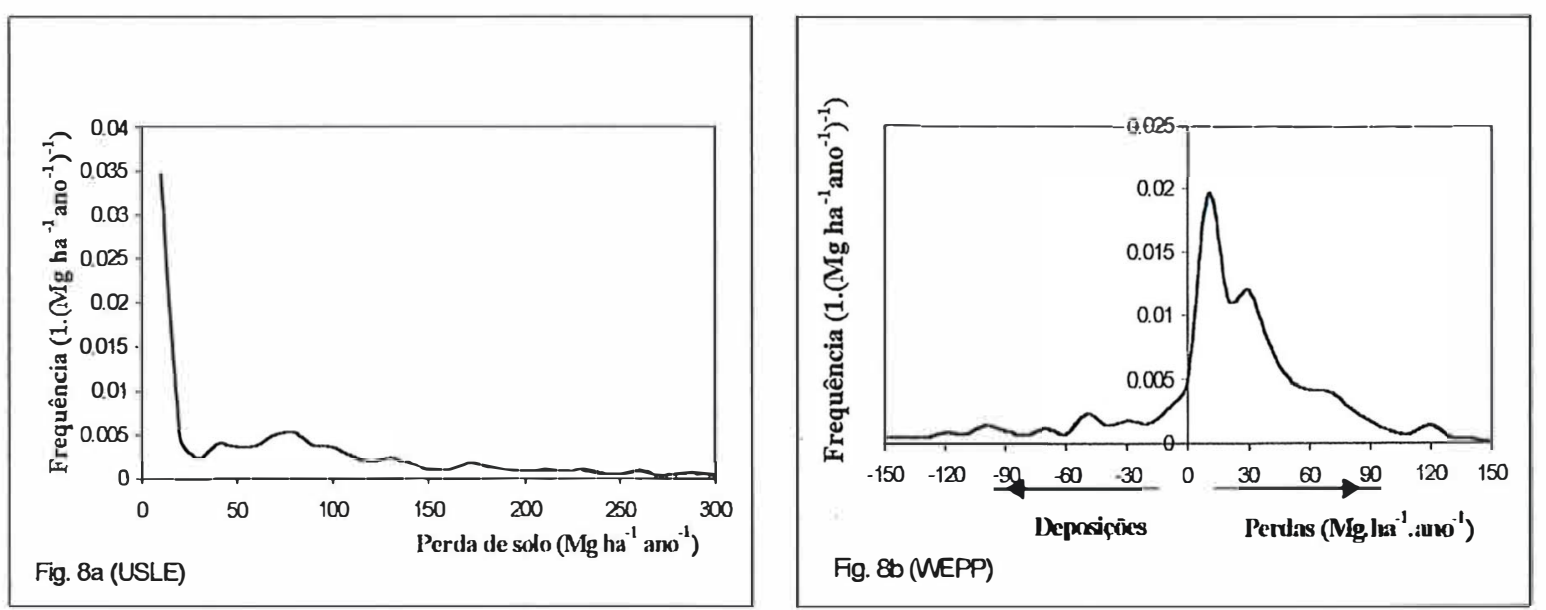

Figura 8. Distribuições de freqüência dos valores de erosão estimados pela USLE (8a) e pelo WEPP (8b). 

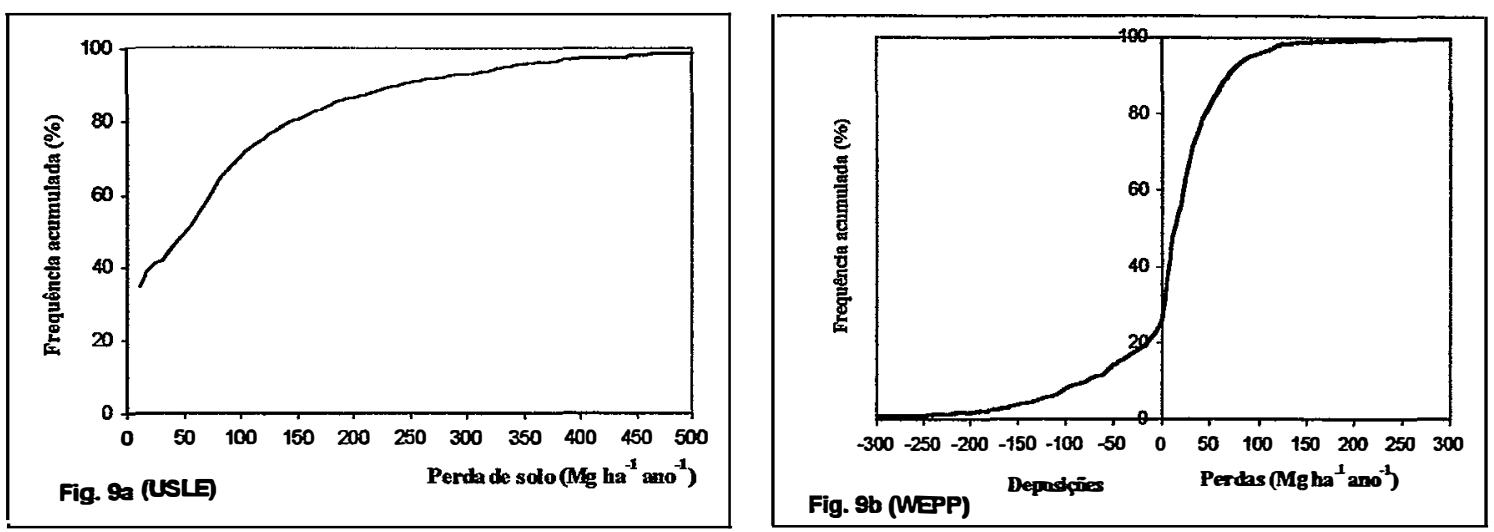

Figura 9. Freqüência acumulada dos valores de erosão estimados pela USLE (9a) e pelo WEPP (9b).

As Figuras 10 e 11 mostram a tendência crescente de maior diferenciação na estimativa das perdas entre USLE e WEPP indo da parte superior das vertentes para a inferior. Estas figuras utilizaram-se de um parâmetro $Q$ de comparação para descrever o comportamento da relação de estimativa de perda/deposição entre USLE e WEPP em função da distância do topo das vertentes:

$$
Q=\frac{[U S L E]+1000}{[W E P P]+1000}
$$

onde [USLE] $\left(\mathrm{Mg} \mathrm{ha}^{-1} \mathrm{ano}^{-1}\right)$ é a perda estimada pela USLE e [WEPP] $\left(\mathrm{Mg} \mathrm{ha}^{-1} \mathrm{ano}^{-1}\right)$ é a perda líquida (valores positivos) ou deposição líquida (valores negativos) estimadas pelo WEPP.

Somando-se o valor 1000 no numerador e denominador fez-se com que ambos ficassem sempre positivos pois, no caso do presente estudo, o maior valor negativo estimado pelo WEPP foi de $-632 \mathrm{Mg} \mathrm{ha}^{-1}$ ano $^{-1}$. Caso contrário, ou seja, utilizando apenas o quociente [USLE]/[WEPP], este se tornaria altamente variável em função de pequenas mudanças no valor de [WEPP] quando este se encontrasse próximo a zero, como demonstrado na Tabela 6. Mantendo, no exemplo desta tabela, o valor de [USLE] como $200 \mathrm{Mg} \mathrm{ha}^{-1} \mathrm{ano}^{-1}$, verifica-se, na primeira linha, que para [WEPP]=[USLE], 
obviamente $Q=1$. Nas linhas seguintes observa-se que, conforme [WEPP] vai diminuindo, $Q$ aumenta. No entanto, quando [WEPP] apresenta valores próximos a zero, $Q$ se mantém em torno de 1,20, enquanto o quociente [USLE]/[WEPP] está sujeito a grandes variações (de -2000 a +2000 no presente exemplo). Assim, o fator $Q$ permitiu uma comparação mais ponderada das estimativas de erosão da USLE e do WEPP.

As diferenças entre os modelos chegaram a ser de cerca de 200 vezes no final das encostas, antes de se alcançarem as áreas de deposição líquida, sendo, na média, de 2,65 vezes. Este fato pode ser explicado pelo fato de o WEPP considerar deposições ao longo das encostas à medida em que se avança morro abaixo, devido à sinuosidade do relevo, o que não é o caso para a USLE.

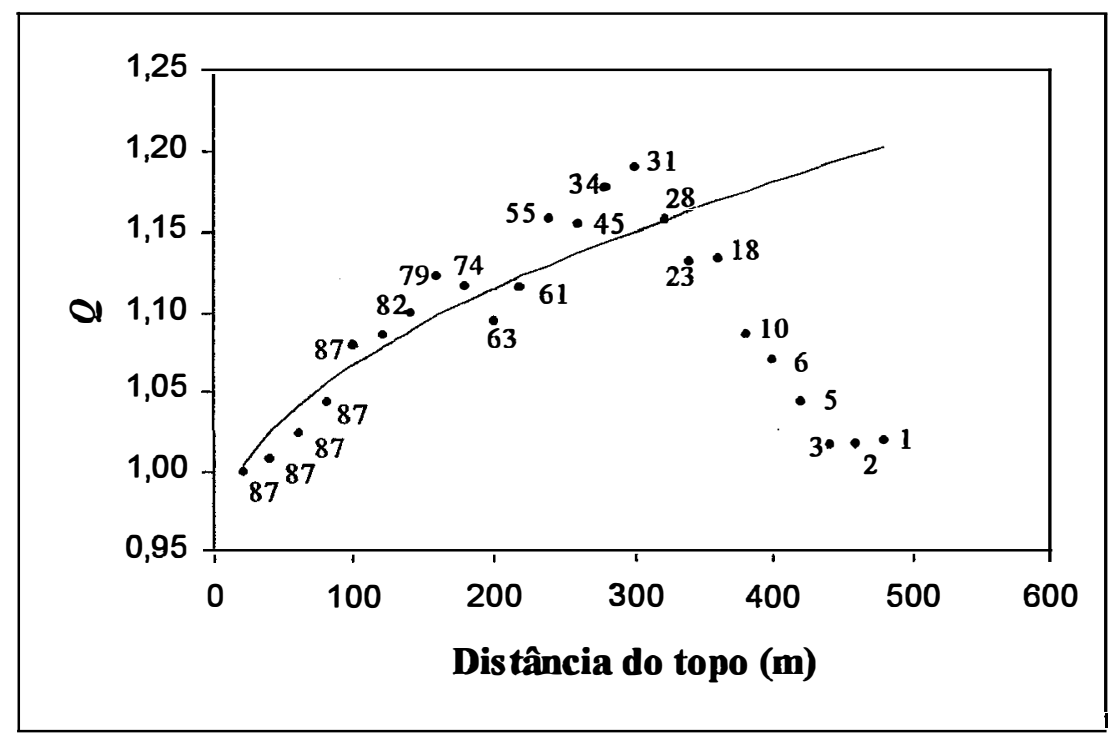

Figura 10. Aumento das diferenças entre as estimativas dos modelos USLE e WEPP em relação à distância do topo das vertentes. Os valores apresentados junto aos pontos significam o número de dados (vertentes) considerados na estimativa da erosão média ponderada para cada 20 metros de distância do topo. 
Tabela 6. Exemplo numérico do fator $Q$ de comparação entre as estimativas de erosão pelos modelos USLE e WEPP.

\begin{tabular}{cccc}
\hline $\begin{array}{c}\text { [USLE] } \\
\mathrm{Mg} \mathrm{ha}^{-1} \text { ano }^{-1}\end{array}$ & [USLE]/[WEPP] & $\boldsymbol{Q}$ \\
\hline 200 & 200 & 1 & 1,00 \\
200 & 100 & 2 & 1,09 \\
200 & 10 & 20 & 1,19 \\
200 & 1 & 200 & 1,20 \\
200 & 0,1 & 2000 & 1,20 \\
200 & $-0,1$ & -2000 & 1,20 \\
200 & -1 & -200 & 1,20 \\
200 & -100 & -2 & 1,33 \\
\hline
\end{tabular}

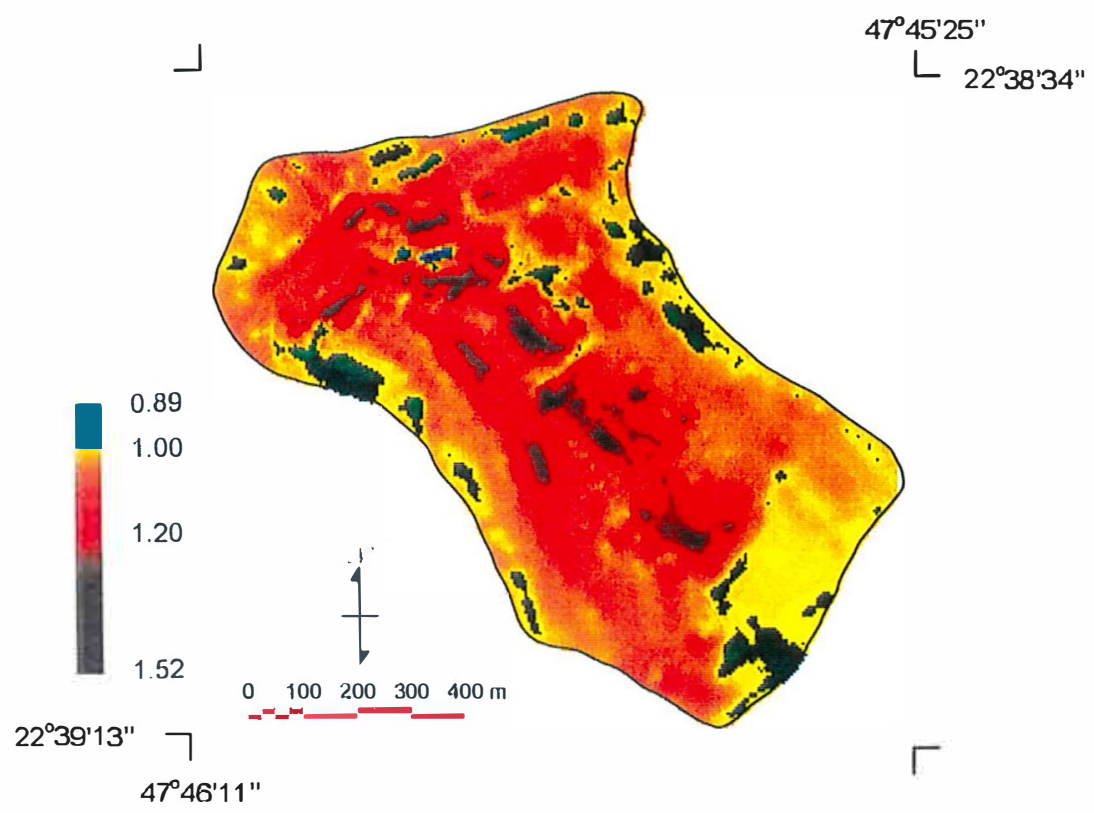

Figura 11. Mapa de comparação espacial dos valores de erosão obtidos pelos dois modelos $(Q)$. 
A desconsideração das deposições em áreas como bacias hidrográficas por parte da USLE é uma das limitações mais discutidas por diversos autores (Johnson, 1988; Castro, 1992; Hamlet et al., 1992), que enfatizam a problemática deste modelo nesta escala, devido ao fato de na maior parte das condições reais de campo em bacias a topografia do terreno ser irregular, o que causa grandes variações no volume e na velocidade da enxurrada. Neste sentido, Brown et al. (1981) e de Jong et al. (1983), estudando bacias fechadas, observaram que quando se consideram rampas desuniformes, quanto maior o comprimento de rampa maior a possibilidade de haver deposição de sedimentos ao longo dela. Embora não se disponha de valores de perda de solo medidos no presente trabalho, e portanto, de valores reais de erosão, os resultados da comparação espacial entre os modelos (Figura 10) permitem afirmar que o uso da USLE, nesta escala, não é recomendável. Neste sentido, Risse et al. (1993) apontam para o fato de a USLE ter sido concebida e avaliada para situações de declividade entre 3 a 20,7\% e para comprimentos de rampa entre 10,67 a 192,02 metros. Estes limites freqüentemente são extrapolados em condições de bacias hidrográficas, o que ocorreu no caso dos comprimentos de rampa para a área estudada. Deste modo, o autor afirma que quando métodos concebidos para pequenas parcelas são usados para bacias hidrográficas complexas, a aplicabilidade de equações como a USLE fica reduzida.

Mais uma vez, embora não tenha sido medida a erosão na bacia, e portanto, não seja possível a validação dos modelos utilizados, o WEPP mostrou-se como uma ferramenta promissora para a utilização na escala do presente trabalho. Entre as vantagens do uso deste modelo em relação à USLE estão a consideração das áreas de deposição ao longo das vertentes e a existência de rotinas de cálculo de perda e deposição conforme se altera o Elemento de Fluxo, levando em conta a enxurrada advinda das áreas morro acima (Flanagan \& Nearing, 1995). Isto faz com que não haja quedas ou aumentos abruptos dos valores de perda nas encostas como ocorre com a USLE. Por ser uma equação multiplicativa em que cada fator tem peso igual, na USLE qualquer mudança significativa em um dos fatores ao longo da vertente provocará alterações abruptas nos valores de perda estimada, como ocorreu no presente trabalho para o fator $\mathrm{C}$. 
Por outro lado, a confiabilidade na aplicação do modelo WEPP será possível após a adaptação de suas equações para as condições da área de estudo, não tendo sido este o foco do presente trabalho. Dentre os parâmetros aos quais o modelo se mostra mais sensível, Nearing et al. (1990b) apontam a erodibilidade no sulco, a tensão de cisalhamento crítico e porcentagem de cobertura do solo pela cultura no sulco (biomassa viva ou morta), sendo estes parâmetros alguns dos aos quais deve-se atentar para a determinação. Os autores também advertem para o número reduzido de dados existentes para validar o efeito da declividade em vertentes muito longas.

A condução de análises de sensibilidade deve direcionar as pesquisas e mostrar quais parâmetros do WEPP merecem maior cautela e precisão na determinação. Uma vez conhecidos estes parâmetros e tendo sido contornada a problemática da falta de georreferência intrínseca do modelo através do método utilizado no trabalho, o uso do WEPP associado a SIGs mostra-se com uma solução para trabalhos visando planejamento agrícola e ambiental em bacias hidrográficas da dimensão da área de estudo.

Para o momento, a extrapolação da aplicação do WEPP para uma área maior que a bacia estudada é possível, se esta apresentar características pedológicas, climáticas e de uso da terra semelhantes às levantadas para o presente trabalho. Salienta-se, porém, que devido ao grande número de parâmetros exigidos por este modelo, principalmente para os arquivos de uso/manejo, sua aplicação fica limitada para áreas extensas como, neste caso, para a Bacia do Rio Piracicaba $\left(12.400 \mathrm{~km}^{2}\right)$. O uso ou não do WEPP para fins de planejamento ou previsão de impactos ambientais em bacias desta escala deve ser avaliado em função da disponibilidade de dados e do nível de detalhamento exigido como resposta. Dados levantados de forma detalhada são freqüentemente agrupados e generalizados para áreas extensas. $O$ levantamento de um vasto número de parâmetros exigidos pelo modelo WEPP demandaria tempo e investimentos que dificultariam a execução do trabalho nesta escala. Diversos parâmetros relativos às culturas também não se encontram em literatura. Portanto, mais uma vez, a análise de sensibilidade do 
modelo aos seus parâmetros deverá direcionar as necessidades de pesquisa e vir a viabilizar a aplicação do mesmo em grandes áreas. 


\subsection{Conclusões}

1) A USLE estimou perdas de solo superiores ao WEPP para toda a área da bacia, independentemente do solo, uso da terra e comprimento da vertente, exceção feita para as áreas de mata ciliar. $\mathrm{Na}$ média, a erosão estimada pela USLE foi 2,91 vezes maior que a estimada pelo WEPP;

2) Na USLE, onde qualquer alteração abrupta em um dos seus fatores causa uma alteração igualmente abrupta na perda de solo estimada, a mudança do uso da terra de cana-de-açúcar para mata ciliar resultou em queda abrupta na perda de solo estimada por este modelo. $\mathrm{O}$ mesmo não aconteceu com o WEPP, por este levar em consideração os fenômenos que ocorrem na parte superior da vertente;

3) Quando comparados espacialmente, as diferenças entre os valores das perdas de solo estimados pela USLE e as perdas líquidas estimadas pelo WEPP se acentuaram à medida em que a distância do topo das vertentes aumentou, devido à consideração das deposições ao longo das encostas pelo modelo WEPP;

4) A não consideração das deposições de sedimentos nas encostas e as condições pelas quais a USLE foi desenvolvida permitem afirmar que esta não deve ser utilizada em áreas como bacias hidrográficas. As irregularidades no relevo e a complexidade de solos e usos da terra nesta escala limitam a utilização deste modelo;

5) $\mathrm{O}$ modelo WEPP, por estimar deposição de sedimentos e ajustar a estimativa das perdas e deposições a cada alteração de solo e/ou uso da terra mostrou-se como uma ferramenta promissora para a utilização na escala de bacia, como a utilizada no trabalho; 
6) $\mathrm{O}$ método de atribuição de georreferência aos resultados de erosão dos modelos utilizado no trabalho permitiu que a variabilidade espacial das perdas e deposições fosse mapeada. 


\section{CONCLUSÕES}

1) O programa de interface desenvolvido foi capaz de integrar de forma automatizada os modelos de erosão (USLE e WEPP) ao SIG, fazendo com que os resultados de erosão fossem georreferenciados, mostrando-se como uma ferramenta útil no auxílio do mapeamento da erosão do solo e no planejamento de áreas como bacias hidrográficas;

2) A utilização de um método vetorial de definição das vertentes e sua localização de forma manual ou assistida possibilitou o maior controle no detalhamento das informações espaciais de erosão;

3) A USLE estimou perdas de solo superiores ao WEPP para toda a área da bacia, independentemente do solo, uso da terra e comprimento da vertente, exceção feita para as áreas de mata ciliar. Na média, esta maior estimativa da USLE foi de 2,91 vezes;

4) A comparação espacial entre os modelos mostrou que as diferenças entre eles se acentuaram da parte superior para a inferior das encostas devido à consideração das deposições ao longo das mesmas pelo modelo WEPP;

5) A não consideração das deposições de sedimentos nas encostas e as condições pelas quais a USLE foi calibrada permitem afirmar que esta não deve ser utilizada em áreas como bacias hidrográficas. As irregularidades no relevo e a complexidade de solos e usos da terra nesta escala limitam a utilização deste modelo;

6) O modelo WEPP, por estimar deposição de sedimentos e ajustar a estimativa das perdas e deposições à cada alteração de solo e/ou uso da terra mostrou-se como uma ferramenta promissora para a utilização na escala de bacia, uma vez que o problema da variabilidade espacial das perdas e deposições foi contornado pela 
atribuição de georreferência. $O$ principal desafio para a utilização deste modelo é o levantamento dos fatores aos quais ele é mais sensível para as condições de estudo, com vistas a diminuir o número de experimentações necessárias para o levantamento dos parâmetros e tornar viável sua aplicação em planejamento agrícola e ambiental. 
ANEXOS 


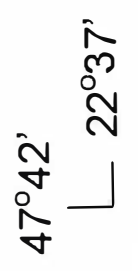
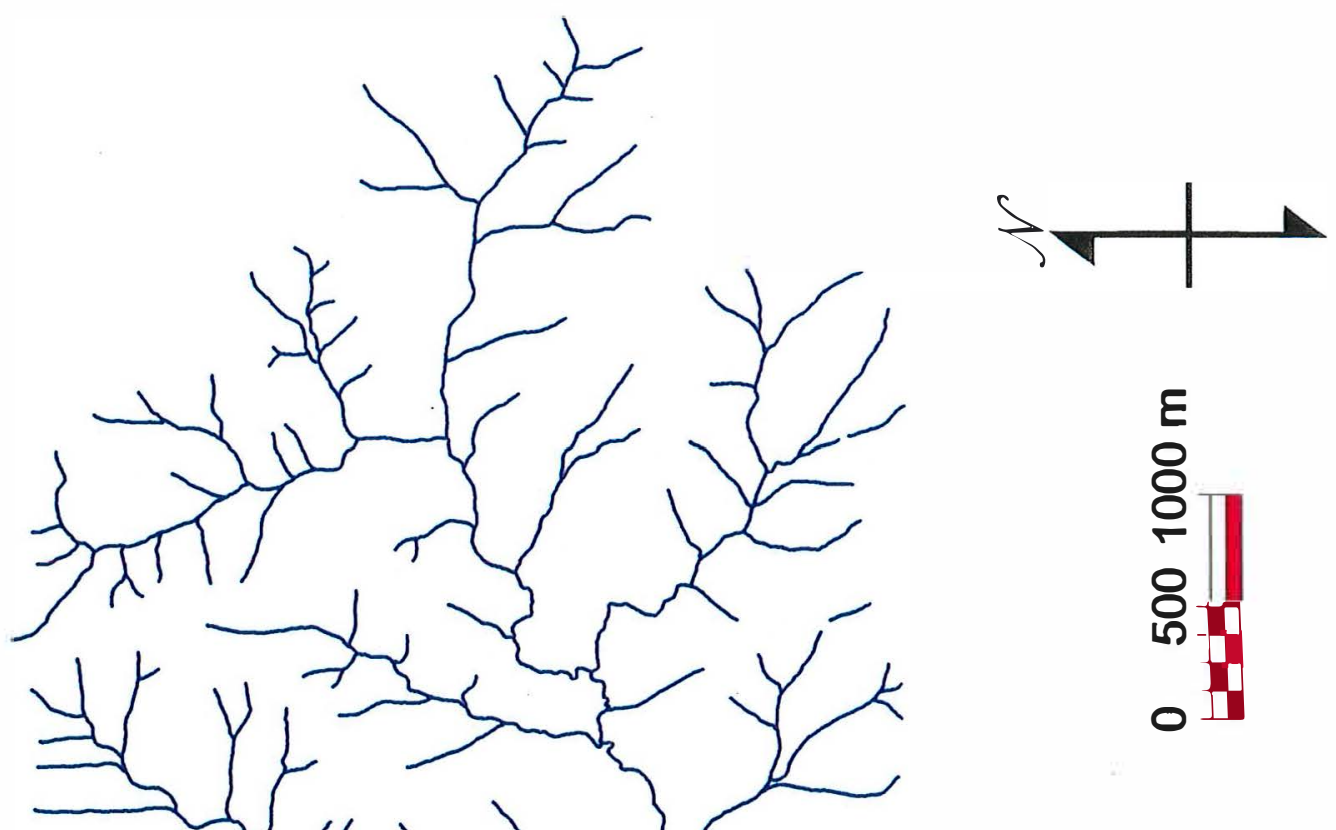


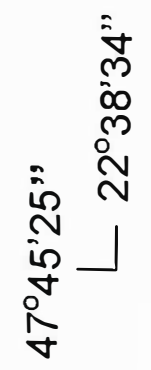

7

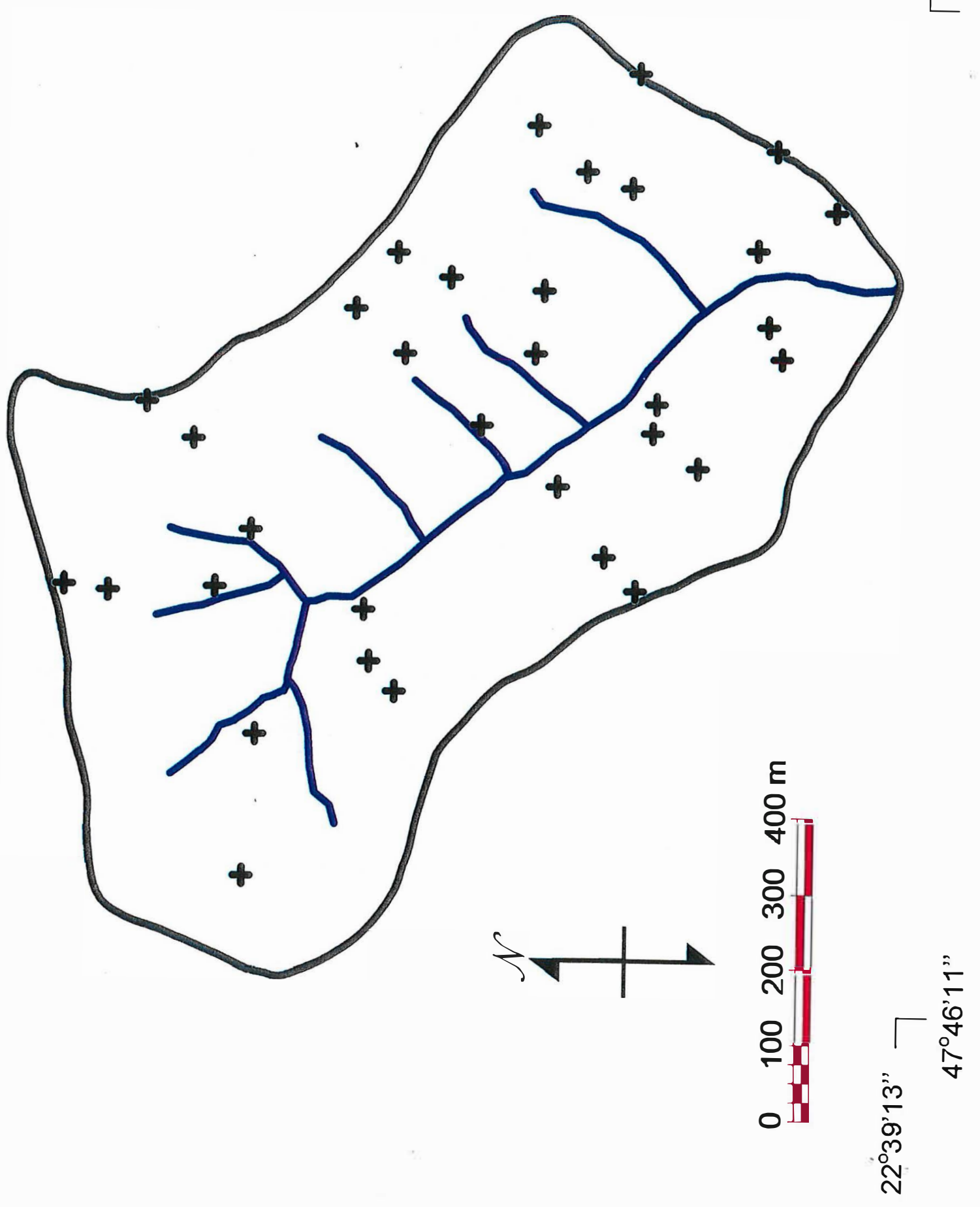




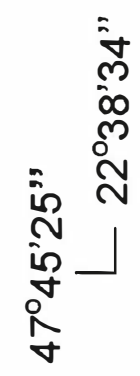

ᄀ

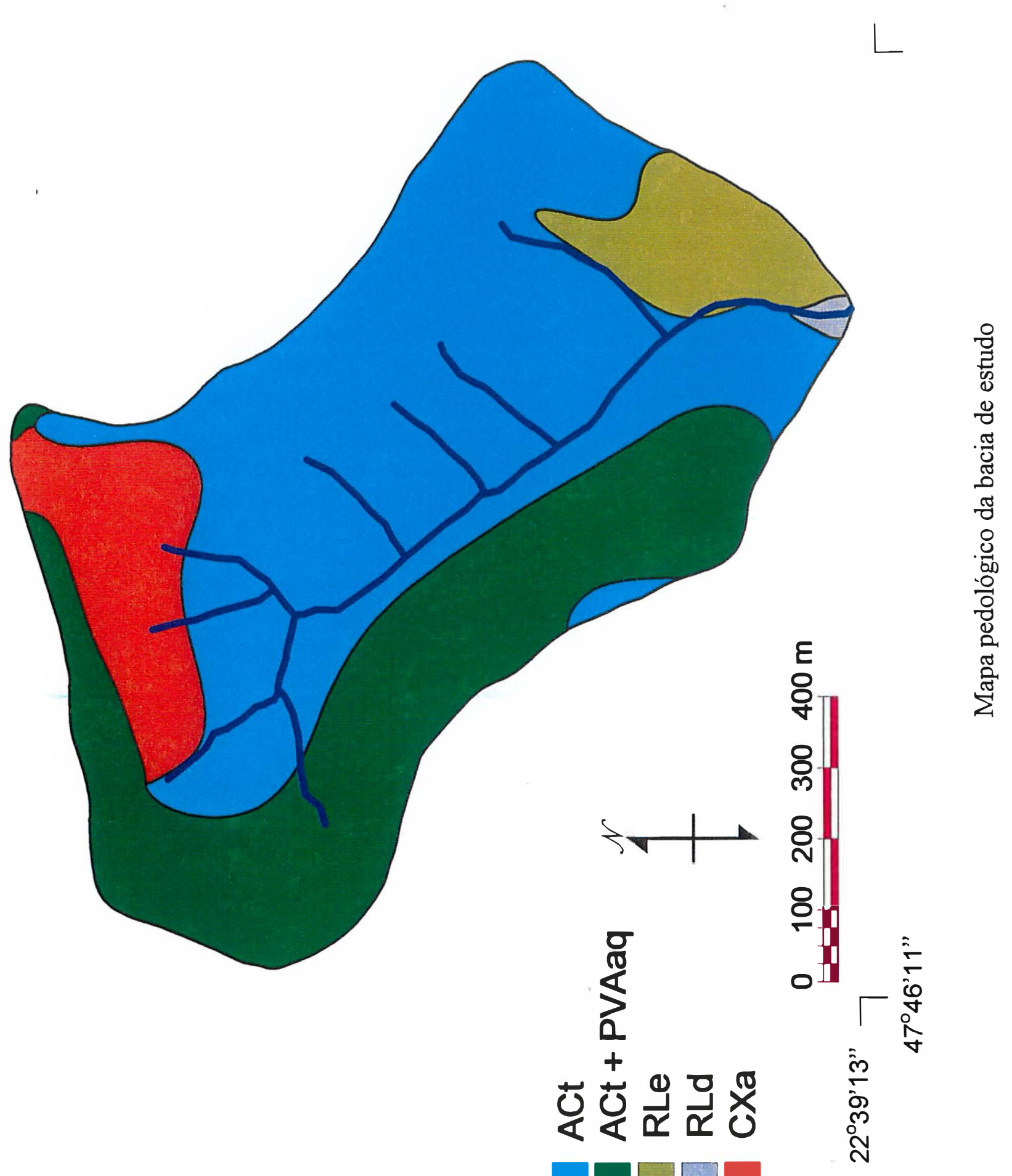




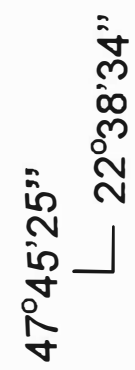

7

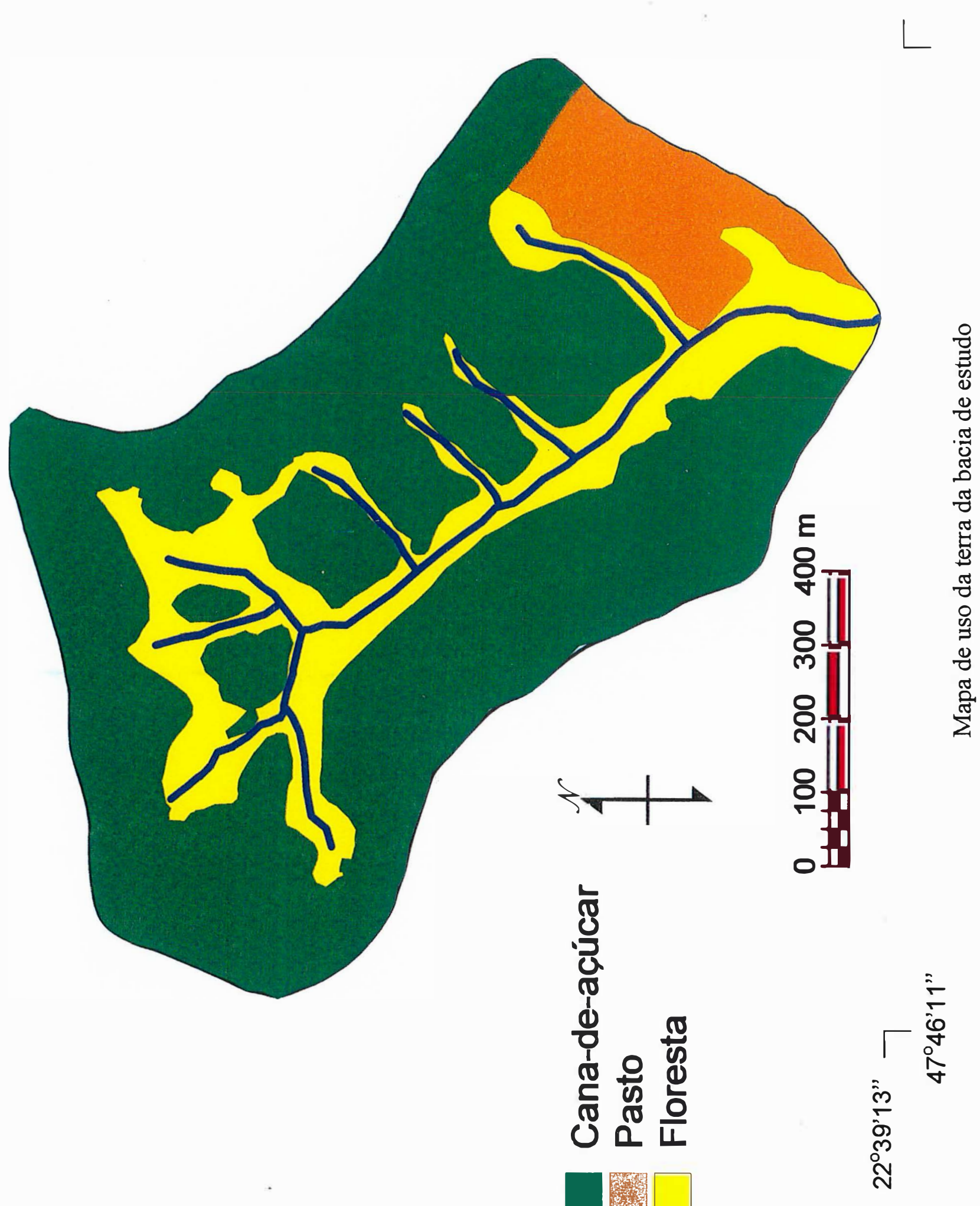



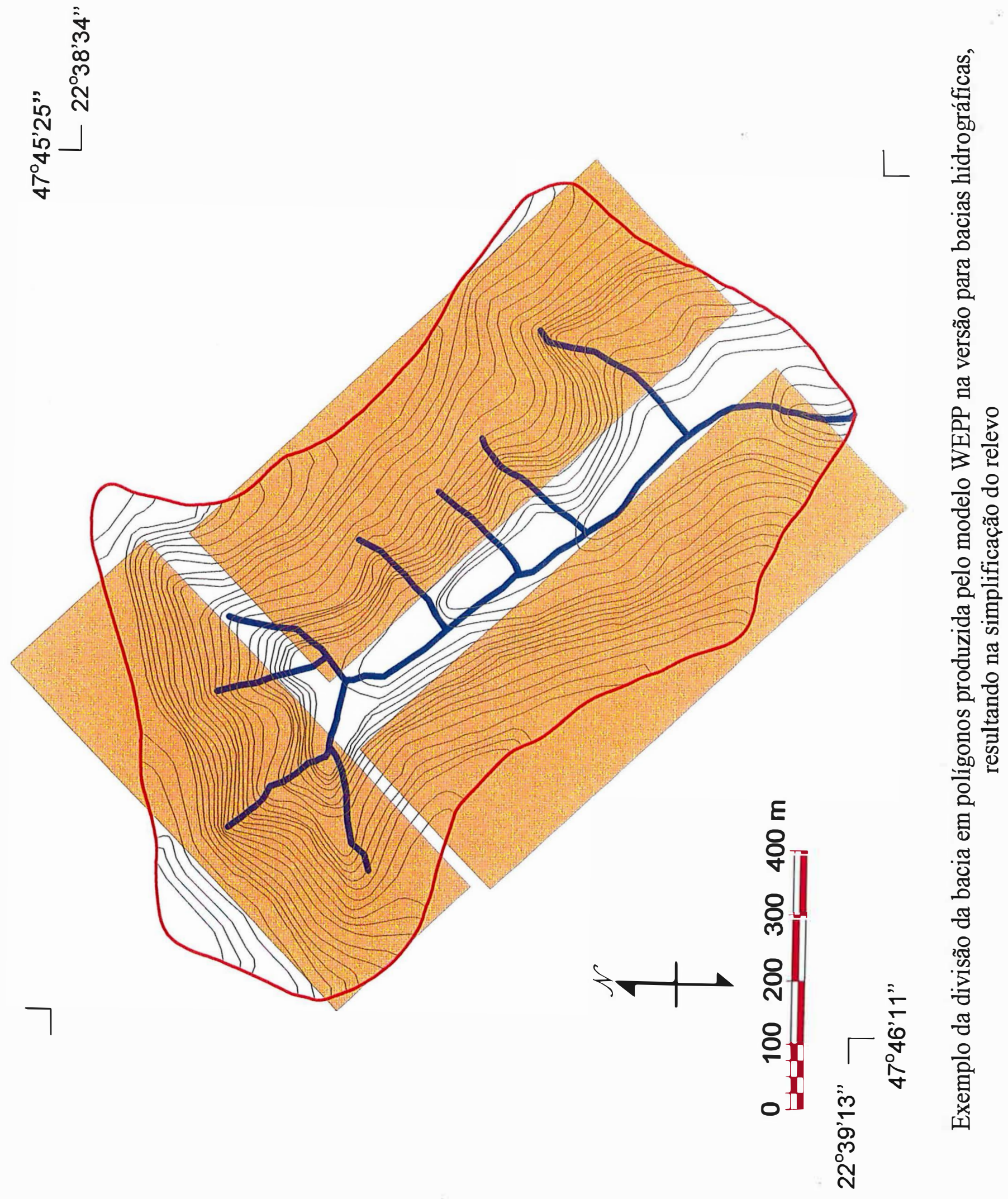


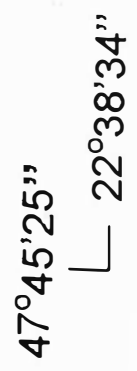

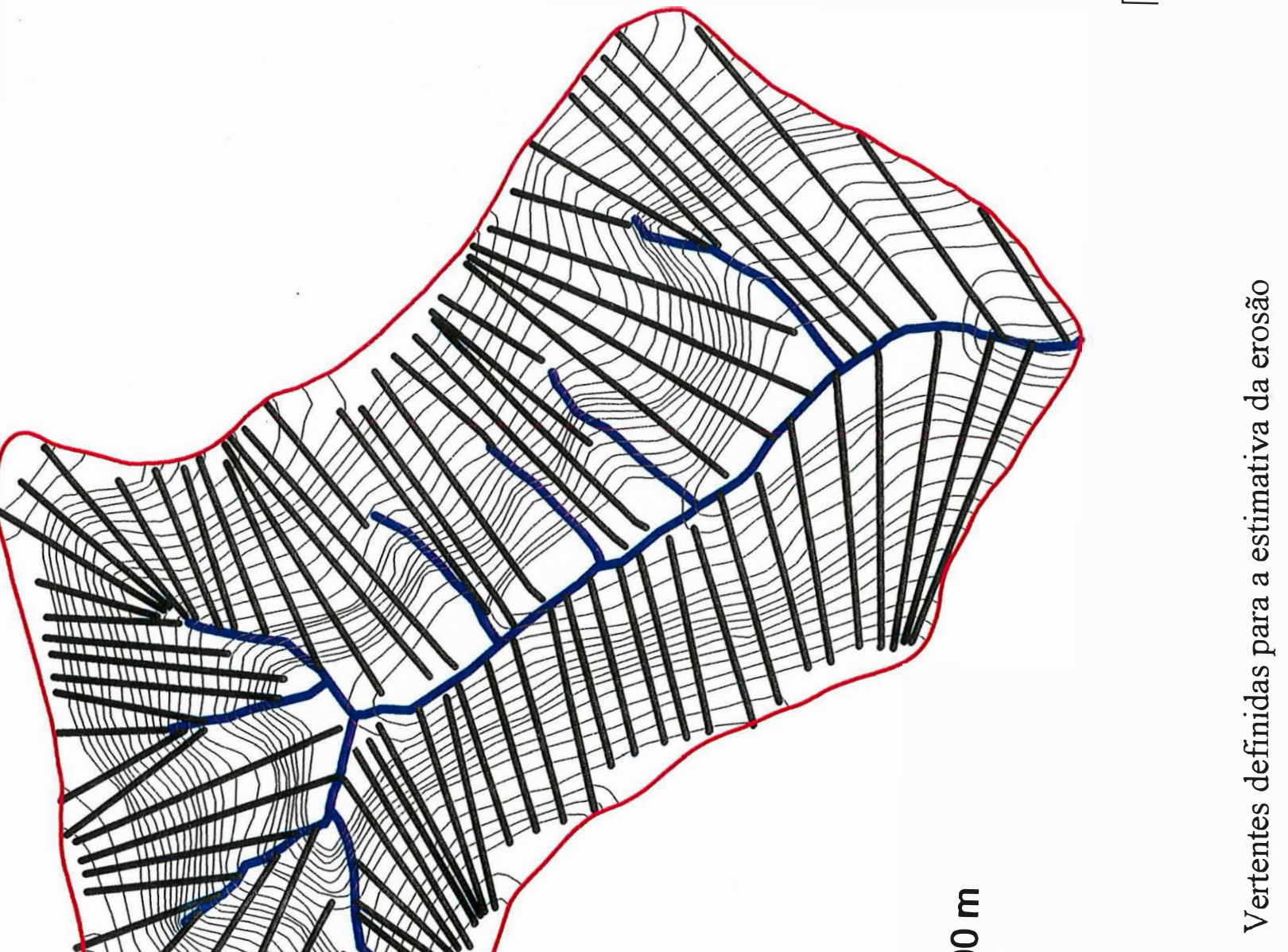

7

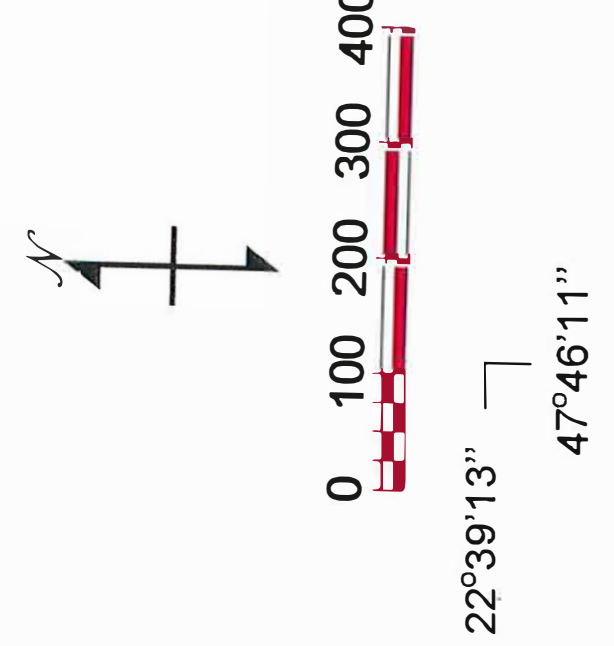



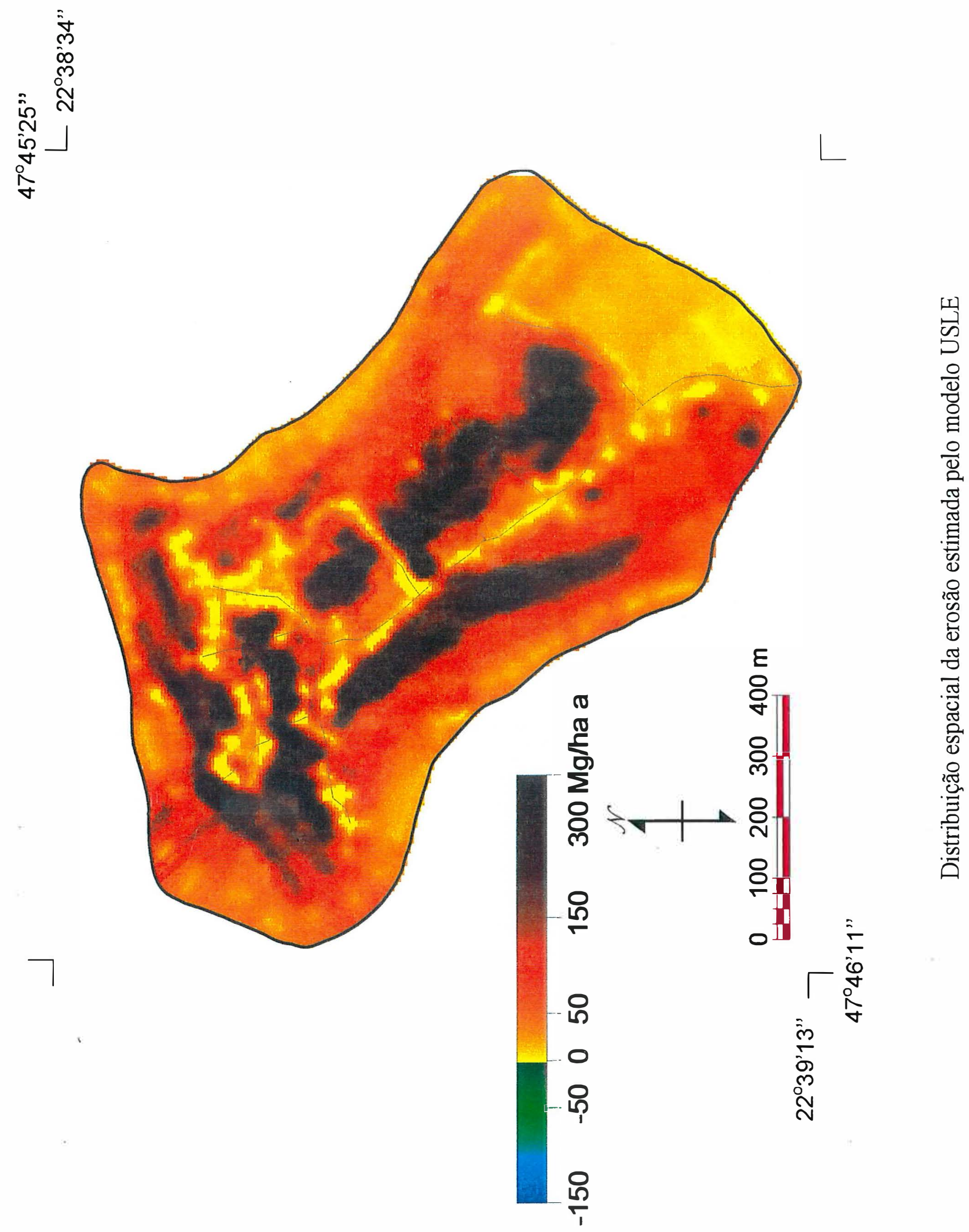
㐫

$\square$

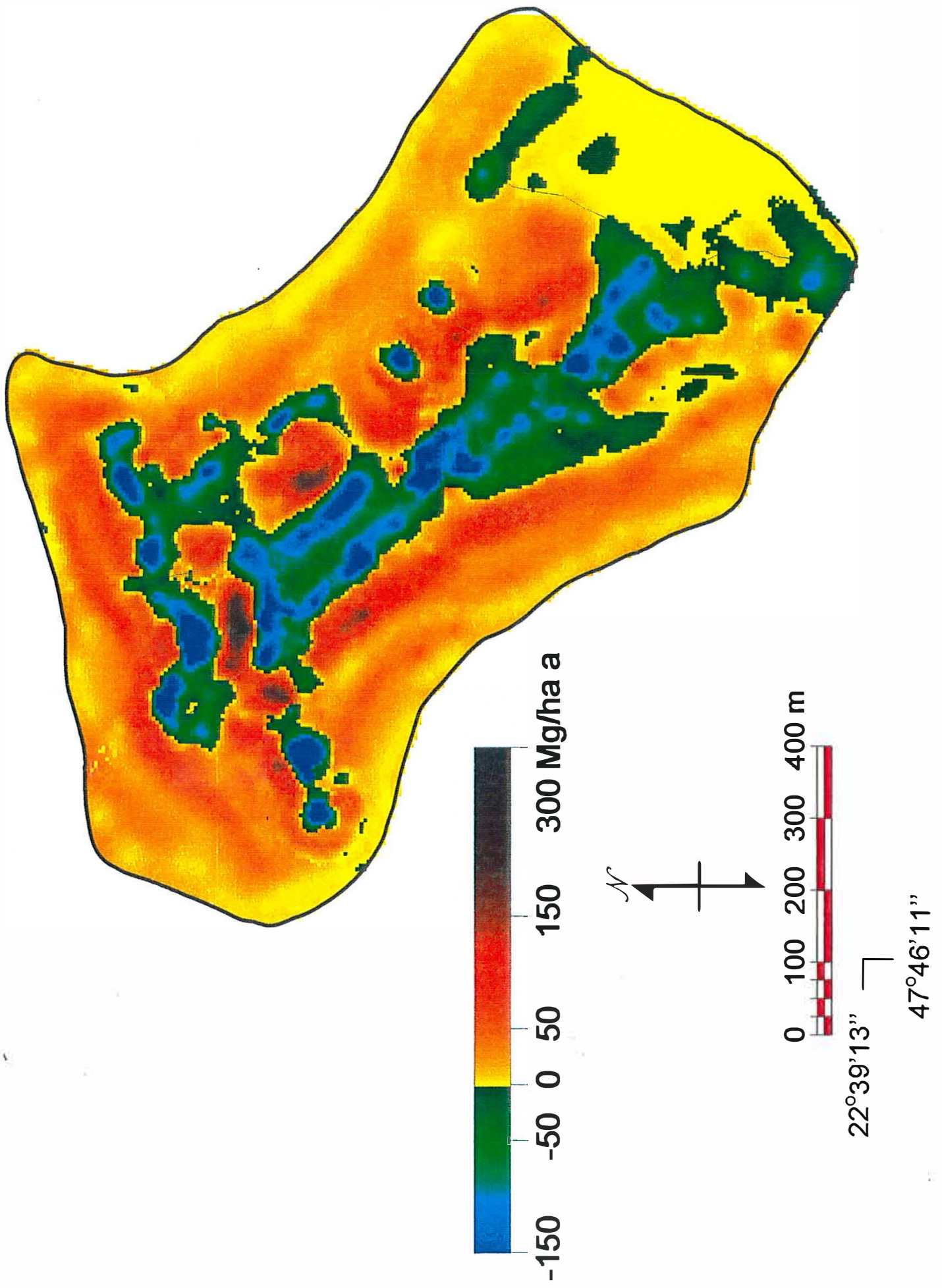

Ô) 

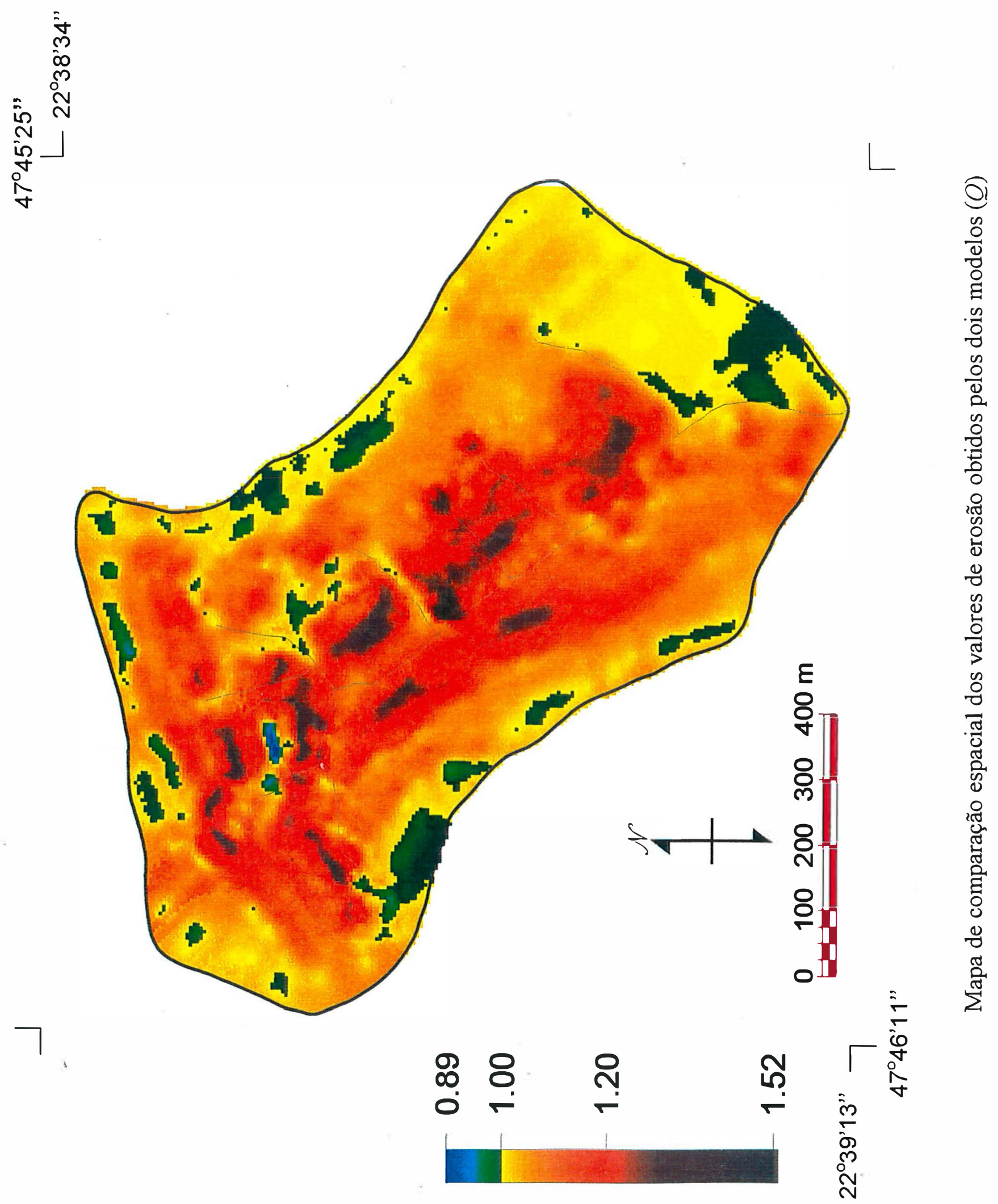


\section{REFERÊNCIAS BIBLIOGRÁFICAS}

ANGULO, R.J.; ROLOFF, G.; de SOUZA, M.L P. Aplicabilidade de nomograma de Wischmeier et. al. (1971) para a determinação da erodibilidade de solos brasileiros. Revista do Setor de Ciências Agrárias, v.7, n.2, p.145-153. 1985.

AUSTRAlian AGRONOMY CONFERENCE, 8. Toowoomba, 1996. Proceedings. Toowoomba. p. 172-175.

BERISH, C.W. Root biomass and surface area in three successional tropical forests. Canadian Journal of Forest Research. v. 12, p.699-704, 1982.

BERTONI, J.; LOMBARDI NETO, F. Conservação do Solo. São Paulo: Ícone, 1990. $355 p$.

BOUMA, J. Using soil survey data for quantitative land evaluation. In: STEWARRT, B.A. (Ed.) Advances in Soil Science. New York: Springer-Verlag, 1989. cap. 9. p.177-213.

BROWN, R.B. CUTSHALL, N.H.; KLING, G.F. Agricultural erosion indicated by ${ }^{137}$ Cs redistribution: I. levels and distribution of activity in soils. Soil Science Society of America Journal, v.45, n.5, p. 1184-1190. Sep./Oct. 1981.

CÂMARA, G. Anatomia de Sistemas de Informações Geográficas: Visão atual e perspectivas de evolução. In: ASSAD, E.D. \& SANO, E.E. (Coords.) Sistema de Informações Geográficas: Aplicações na Agricultura. Planaltina: EMBRAPACPAC, 1993. 274p.

CASAGRANDE, A.A. Tópicos em Morfologia e fisiologia da cana-de-açúcar. Jaboticabal: FUNEP, 1991. 157p.

CASTRO, A. G. de. Técnicas de sensoriamento remoto e Sistemas Geográficos de Informações no estudo integrado de bacias hidrográficas. São José dos Campos, 1992. Dissertação (Mestrado) - Instituto Nacional de Pesquisas Espaciais (INPE). 
CASTRO, E.A. de; KAUFFMAN, J.B. Ecosystem structure in the Brazilian Cerrado: a vegetation gradient of aboveground biomass, root and consumption by fire. Journal of Tropical Ecology. v. 11, p.263-283, 1998.

CENSI, A.L.C.; LADEIRA, M.C.; LIMA, C.C.N.A. de. Autocad 12: Guia Prático. 5. ed. São Paulo: Érica, 1994. 671p.

CHINNAMANI, S.; SAIRAM VENKATA, V. \& SAKTHIVADIVEL, R. Applicability of the Universal Soil Loss Equation in mountain watersheds in semiarid and humid regions. In: WALLING, D.E. (Ed.) Recent Developments in the Explanation and Prediction of Erosion and Sediment Yield. Proceedings of the Symposia by the First Scientific General Assembly of the International Association of Hidrological Sciences, Exceter: IAHS Publ., n.137, p.229-237, Jul. 1982.

COCHRANE, T.A.; FLANAGAN, D.C. Small watershed modeling with WEPP using grid-based DEMs and GIS. In: ASAE INTERNATIONAL MEETING, Toronto, 1999. Toronto: ASAE/CSAE-SCGR, 1999.

COGO, N.P. Erodibilidade de alguns solos do Rio Grande do Sul avaliada pelo método do nomograma. In: ENCONTRO NACIONAL DE PESQUISAS SOBRE CONSERVAÇÃO DO SOLO, 2., Passo Fundo, 1978. Anais. Passo Fundo:SBCS. 1978. p.215-217.

CRESTANA, S. Técnicas recentes de determinação de características do solo. In: REUNIÃO BRASILEIRA DE MANEJO E CONSERVAÇÃO DO SOLO E DA ÁGUA, 10. Florianópolis, 1994. Resumos. Florianópolis: SBCS, 1994. p. 86-97.

deJONG, E.; BEGG, C.B.M. KACHANOSKI, R.G. Estimates of soil erosion and deposition for some Saskatchewan soils. Canadian Journal of Soil Science, v. 63, p.607-617, 1983.

DeMARIA, I.C.; DECHEN, S.C.F. Comparação de modelos de predição de erosão utilizando dados obtidos em parcelas experimentais com cobertura artificial, em Latossolo Roxo. In: CONGRESSO BRASILEIRO DE CIÊNCIA DO SOLO, 26, Rio de Janeiro, 1997. Resumos. Rio de Janeiro: SBCS, 1997. p.401.

DENARDIN, J.E. Erodibilidade do solo estimada por meio de parâmetros físicos e químicos. Piracicaba, 1990. Tese (Doutorado) - Escola Superior de Agricultura Luiz de Queiroz (ESALQ), Universidade de São Paulo.

DESMET, P.J.J.; GOVERS, G. A GIS procedure for automatically calculating the USLE LS factor on topographically complex landscape units. Journal of Soil and Water Conservation. v.51, n. 5, p. 427-433, 1996. 
DIDHAM, R.K. Altered leaf-litter decomposition rates in tropical forests fragments. Oecologia. v. 116, p. 397-406, 1998.

DOORENBOS, J.; KASSAN, A.A. Yield response to water. Irrigation and Drainage paper 33: FAO. Rome: FAO. 1979.

EASTMAN, J. R. IDRISI - User's Guide. 2. Version. Worcester: Clark University, 1997.

EMBRAPA, Centro Nacional de Pesquisa de Solos (Rio de Janeiro, RJ). Sistema brasileiro de classificação de solos. Brasília: Embrapa Produção de Informação; Rio de Janeiro: Embrapa Solos, 1999. 412p.

FIGUEIREDO, A.G. Análise de produção e transporte de sedimentos nas Bacias do Rio do Peixe e Rio Aguapeí. São Paulo, 1988. Dissertação (Mestrado) - Escola Politécnica, Universidade de São Paulo.

FIORIO, P.R. Cronologia do uso da terra e seu impacto no ambiente da Microbacia do Córrego do Ceveiro na região de Piracicaba, SP. Piracicaba, 1998. 114p. Dissertação (Mestrado) - Escola Superior de Agricultura Luiz de Queiroz, Universidade de São Paulo.

FLANAGAN, D.C.; NEARING, M.A. (Ed.) USDA-Water Erosion Prediction Project: Hillslope profile and watershed model documentation. West Lafayette: USDA-ARS-MWA-SWCS. 1995. p.1.1-14.27.

FOSTER, G.R.; FLANAGAN, D.C.; NEARING, M.A.; LANE, L.J.; RISSE, L.M.; FINKNER, S.C. Hillslope erosion component. In: FLANAGAN, D.C.; NEARING, M.A. (Ed.) USDA-Water Erosion Prediction Project: Hillslope profile and watershed model documentation. West Lafayette: USDA-ARS-MWA-SWCS. 1995. cap. 11, p. 11.1-11.12.

FOSTER, G.R.; WISCHMEIER, W.H. Evaluating irregular slopes for soil loss prediction. Transations of American Society Agricultural Engineering, v.17, n. 1, p.305-309. Jan./Feb. 1974.

FREIRE, O.; PESSOTTI, J.E. Erodibilidade de alguns solos de Piracicaba. In: ENCONTRO NACIONAL DE PESQUISA SOBRE CONSERVAÇÃO DO SOLO, 2. Passo Fundo, 1978. Anais. Passo Fundo:SBCS, p. 185-192.

GILLEY, J.E.; WETLZ, M.A. Hydraulics of Overland Flow. In: FLANAGAN, D.C.; NEARING, M.A. (Ed.) USDA-Water Erosion Prediction Project: Hillslope 
profile and watershed model documentation. West Lafayette: USDA-ARSMWA-SWCS, 1995. cap. 10, p. 10.1-10.7.

HAMADA, E; CAVALIERI, A.; ROCHA, J.V.; KÜPPER, R de B. Estimativa de perdas de solo, através de Sistema de Informação Geográfica. In: SIMPÓSIO NACIONAL DE CONTROLE DE EROSÃO, 4., Bauru, 1995. Resumos. Bauru: Secretaria de Agricultura e Abastecimento de São Paulo, 1995. p. 233-234.

HAMLETT, J.M.; MILLER, D.A.; DAY, R.L.; PETERSON, G.W.; BAUMER, G.M.; RUSSO, J. Statewide GIS-based ranking of watersheds for agricultural pollution prevention. Journal of Soil and Water Conservation. v.47, n.5, p.399-404, Sept./Oct 1992.

HENKLAIN, J.C. \& FREIRE, O. Avaliação do método nomográfico para determinação da erodibilidade de Latossolos do Estado do Paraná. Revista Brasileira de Ciência do Solo, v.7, n.2, p.191-195, Maio/Ago. 1983.

HESSION, W.C.; SHANHOLTZ, V.O. A geographic information system for targeting nonpoint-source agricultural pollution. Journal of Soil and Water Conservation. v.43, n.3, p. 264-266, May/Jun 1988.

HILBORN, R.; MANGEL, M. The ecological detective: Confronting models with data. Princeton University Press, 1997. 334p.

JÄGER, S. Modelling regional soil erosion susceptibility using the Universal Soil Loss Equation and GIS. In: RICKSON, R.J. (Ed.) Conserving Soil Resources European Perspectives. Cambridge: Silsoe College, Cranfield University, 1994. cap. 17, p. 161-177.

JENKINS, A.; PETERS, N.E.; RODHE, A. Hydrology. In: MOLDAN, B.; CERNY, J. (Coords.) Biogeochemistry of small catchments: A tool for environmental research. Chichester: John Wiley \& Sons, 1994. Scope 51, p. 31-54.

JOHNSON, R. Putting soil movement into perspective. Journal of Production Agriculture, v.1, n.1, p. 5-12, 1988.

KIEHL, E.J. Manual de edafologia. São Paulo:Ceres, 1979. 264p.

KRESNOR, W.R.; OLSON, K.R. JOHNSON, D.L. Fiels evaluation of methods to estimate soil erosion. Soil Science, v.153, n. 1, p. 69-81, Jan 1992.

LAFLEN, J.M.; FLANAGAN, D.C. A powerful tool. Agricultural Engineering, v.73, n.4, p.18-19, Jul 1992. 
LAFLEN, J.M.; LANE, L.J. FOSTER, G.R. WEPP: a new generation of erosion prediction technology. Journal of Soil and water Conservation, v.46, n.1, p.3438, Jan./Feb. 1991.

LAL, R. Soil erosion by wind and water: Problems and prospects. In: LAL, R. (Ed.) Soil erosion and research methods. Wageningen: HL, SWCS, 1988. cap.1, p.1-8.

LANE, L.J.; NEARING, M.A. USDA-Water Erosion Prediction Project: Hillslope Profile Model Documentation. West Lafayette:NSERL Report n.2, 1989.

LANE, L.J.; RENARD, K.G.; FOSTER, G.R.; LAFLEN, J.M. Development and application of modern soil erosion prediction technology. Australian Journal of Soil Research, v.30, n.6, p. 893-912, 1992.

LIMA, E. R. V. de; KUX, H. J. H. \& SAUSEN, T. M. Sistema de Informações Geográficas e técnicas de sensoriamento remoto na elaboração de mapa de riscos de erosão no sertão da Paraíba. Revista Brasileira de Ciência do Solo. v.16, n.2, p.257-263, Maio/ Ago 1992.

LOMBARDI NETO, F.; MOLDENHAUER, W.C. Erosividade da chuva: sua distribuição e relação com perdas de solo em Campinas, SP. In: ENCONTRO NACIONAL DE PESQUISA SOBRE CONSERVAÇÃO DO SOLO, 3. Recife, 1980. Anais. Recife, 1980.

MACHADO, E.C.; PEREIRA, A.R.; FAHL, J.I.; ARRUDA, H.V.; CIONE, J. Índices biométricos de duas variedades de cana-de-açúcar. Pesquisa Agropecuária Brasileira, v.17, n.9, p. 1323-1329, 1982.

MARIANO, M.T. Uma análise da participação da sociedade civil na gestão dos recursos hídricos do Estado de São Paulo. São Carlos, 1996. Dissertação (Mestrado) - Escola de Engenharia de São Carlos, Universidade de São Paulo.

MATSON, P.A., PARTON, W.J., POWER, A.G., SWIFT, M.J. Agricultural intensification and ecosystem properties. Science. v.277, p.504-509. 1997.

MELLEROWICZ, K.T.; REES, H.W.; CHOW, T.L.; GHANEM, I. Soil conservation planning at watershed level using the Universal Soil Loss Equation with GIS and microcomputer technologies: A case study. Journal of Soil and Water Conservation, v.49, n.2, p. 194-199. Mar./Apr. 1994.

MENK, P.C.M. Avaliação econômica do controle da erosão na Microbacia do Ribeirão Iperó, em Araçoiaba da Serra, Estado de São Paulo. Piracicaba, 1993. Dissertação 
(Mestrado) - Escola Superior de Agricultura Luiz de Queiroz, Universidade de São Paulo.

MITRA, B.; SCOTT, H.D.; DIXON, J.C.; McKIMMEY, J.M. Applications of fuzzy logic to the prediction of soil erosion in a large watershed. Geoderma. v. 86, p. 183-209, Oct 1988.

NEARING, M.A.; DEER-ASCOUGH, L.; LAFLEN, J.M. Sensivity analysis of the WEPP Hillslope Profile Erosion Model. Transactions of the ASAE. v.33, n. 3, p.839-849, May/Jun 1990.

NEARING, M.A.; LANE, L.J.; ALBERTS, E.E.; LAFLEN, J.M. Prediction technology for soil erosion by water: status and research needs. Soil Science Society of America Journal, v.54, p. 1702-1711, Sep./Oct. 1990.

NICKS, A.D.; LANE, L.J.; GANDER, G.A. Weather Generator. In: FLANAGAN, D.C.; NEARING, M.A. (Ed.) USDA-Water Erosion Prediction Project: Hillslope profile and watershed model documentation. West Lafayette: USDA-ARSMWA-SWCS, 1995. p.2.1-2.22.

NICKS, A.D.; LOPES,. V.L.; NEARING, M.A.; LANE, L.J. Overview of WEPP hillslope profile erosion model. In: LANE, L.J. NEARING, M.A. USDA-Water Erision Prediction Project: Hillslope profile model documentation. West Lafayette:NSERL, 1989. cap.1, p.1.1-1.8.

PELLETIER, R.E. Evaluation nonpoint pollution using remotely sensed data in soil erosion models. Journal of Soil and Water Conservation, v.40, n. 4, p. 332-335. Jul/Aug 1985.

PINTO, S.dos A. F. Sensoriamento remoto e integração de dados aplicados no estudo da erosão dos solos: contribuição metodológica. São José dos Campos, 1991. Tese (Doutorado) - Instituto Nacional de Pesquisas Espaciais (INPE).

PROCHNOW, M.C.R. Recursos hídricos e metodologia de pesquisa. Geografia. v.10, n.19, 1985.

RAIJ, B van; QUAGGIO, J.A.; CANTARELLA, H.; FERREIRA, M.E.; LOPES, A.S.; BATAGLIA, O.C. Análise química de solos para fins de fertilidade. Campinas: Fundação Cargil, 1987. 170p.

RANIERI, S.B.L. Avaliação de métodos e escalas de trabalho para determinação de risco de erosão em bacia hidrográfica utilizando Sistema de Informações 
Geográficas (SIG). São Carlos, 1996. 128p. Dissertação (Mestrado) - Escola đe Engenharia de São Carlos, Universidade de São Paulo.

RENARD, K.G.; MAUSBACH; M.J. Tools for conservation. In: LARSON, W.E.; FOSTER, G.R.; ALlMARAS, R.R.; SMITH, C.M. (Ed.) Proceedings of Soil Erosion and Productivity Workshop. Minnesota:University of Minnesota, cap.4, 1990. p 55-64.

RISSE, L.M.; NEARING, M.A.; NICKS, A.D.; LAFLEN, J.M. Error assessment in the Universal Soil Loss Equation. Soil Science Society of America Journal. v. 57, p.825-833, May/Jun 1993.

ROCHA, J.V.; LOMBARDI NETO, F.; BACELLAR, A.A.A. Cálculo do fator comprimento de rampa (L): uma metodologia para uso em Sistema de Informação Geográfica. n: SIMPÓSIO NACIONAL DE CONTROLE DE EROSÃO, 4., Bauru, 1995. Resumos. Bauru: Secretaria de Agricultura e Abastecimento de São Paulo, 1995. p. 421-422.

SABAVI, M.R.; FLANAGAN, D.C.; HEBEL, B.; ENGEL, B.A. Application of WEPP and GIS-GRASS to a small watershed in Indiana. Journal of Soil and Water Conservation, v.50, n.5, p. 477-483, Sep/Oct 1995.

SABAVI, M.R.; WILLIAMS, J.R. Water balance and percolation. In: FLANAGAN, D.C.; NEARING, M.A. (Ed.) USDA-Water Erosion Prediction Project: Hillslope profile and watershed model documentation. West Lafayette: USDA-ARSMWA-SWCS, 1995. cap. 5, p. 5.1-5.14.

SANTOS, M. F. dos. Subsídios para o planejamento conservacionista da bacia hidrográfica do Ribeirão do Feijão (São Carlos, Itirapina e Analândia, SP). São Carlos, 1993. Dissertação (Mestrado) - Escola de Engenharia de São Carlos, Universidade de São Paulo.

SILVA, J.R.; FREIRE, O. Previsão de perdas de solo e estimativa de assoreamento em relação a características de uma bacia hidrográfica. Ciência Agronômica, v.17, n.1, p.13-27, Jun. 1986.

SOILEAU, J.M.; HAJEK, B.F.; TOUCHTON, J.T. Soil erosion and deposition evidence in a small watershed using Fallout Cesium-137. Soil Science Society of America Journal, v. 54, n.6, p. 1712-1719, Sep./Oct. 1990.

SPAROVEK, G. (coord.) Plano Diretor da Microbacia do Córrego do Ceveiro. Vol. I: Diagnóstico da situação, levantamento de problemas e propostas de solução. Piracicaba, Escola Superior de Agricultura "Luiz de Queiroz", 1991. 286p. (Mimeo) 
SPAROVEK, G.; WEILL, M. de A.M.; RANIERI, S.B.L.; SCHNUG, E.F.; SILVA, E.F. The life-time concept as a tool for erosion tolerance definition. Scientia Agricola, v.54, p. 130-135, Jun. 1997. Número especial.

SRINIVASAN, R.; ENGEL, B.A. Effect of slope prediction methods on slope and erosion estimates. Applied Engineering in Agriculture. v.7, n.6, p. 779-783, Nov. 1991.

STAR, J.; ESTES, J. Geographic Information Systems. New Jersey: Prentice-Hall, 1990. 331p.

STEIN, D.P.; DONZELI, P.L.; GIMENEZ, A.F;; PONÇANO, W.L.; LOMBARDI NETO, F. Potencial de erosão laminar, natural e antrópico, na bacia do PeixeParanapanema. São Paulo. Instituto de Pesquisas Tecnológicas do Estado de São Paulo (IPT), 1987.

SZOTT, L.T.; PALM, C.A.; DAVEY, C.B. Biomass and litter accumulation under managed and natural tropical fallows. Forest Ecology and Management. v.67, p.177-190, 1994.

van HEEMST, H.D.J. Plant data values required for simple crop growth simulation models: review and bibliography. In: Simulation Report CABO-TT, Wageningen: Center for Agrobiological Research (CABO) and Department of Theoretical Production Ecology, Agricultural University, 1988. n. 17, 100p.

VASCONCELOS, A.C.M. de. Comportamento de clones IAC e variedades de cana-deaçúcar (Saccharum spp.) nas condições edafoclimáticas da região do Vale do Paranapanema. Jaboticabal, 1998. 108p. Dissertação (M.S.) - Faculdade de Ciências Agrárias e Veterinárias, Universidade Estadual Paulista.

WEILL, M. de A.M. Estimativa da erosão do solo e avaliação do seu impacto na Microbacia do Ceveiro (Piracicaba, SP), através do Índice de Tempo de Vida. Piracicaba, 1999. 100p. Tese (Doutorado) - Escola Superior de Agricultura Luiz de Queiroz (ESALQ), Universidade de São Paulo.

WISCHMEIER, W.H.; JOHNSON, C.B. \& CROSS, B.W. A soil erodibility nomograph for farmland and construction sites. Journal of Soil and Water Conservation, v.26, n.5, p.189-193. Sept./Oct. 1971.

WISCHMEIER, W.H.; SMITH, D.D. Predicting rainfall erosion losses - a guide to conservation planning. Washington: USDA, 1978. 57p. (USDA: Agricultural Handbook, 537). 
WISCHMEIER, W.H.; SMITH, D.D. Predicting rainfall-erosion losses from cropland east of the Rocky Mountains: Guide for selection of practices for soil and water conservation. Washington: USDA, 1965. 47p. (USDA: Agricultural Handbook, 282).

YOUNG, R.A.; ONSTAD, C.A.; BOSCH, D.D.; ANDERSON, W.P. AGNPS: A nonpoint source pollution model for evaluating agricultural watersheds. Journal of Soil and Water Conservation, v.44, n.2, p.168-173, Mar/Apr. 1989.

ZIMMER, A.H.; EUCLIDES, V.P.B.; MACEDO, M.C.M. Manejo de plantas forrageiras do genero Brachiaria. In: SIMPÓSIO SOBRE MANEJO DA PASTAGEM, 9, Piracicaba, 1988. Anais. Piracicaba: FEALQ, 1988. p.141-183. 
Apêndice 1 
Entrada de dados de planta/manejo para o modelo WEPP

\begin{tabular}{|c|c|c|c|}
\hline Parâmetro & $\begin{array}{l}\text { Cana-de- } \\
\text { açúcar }\end{array}$ & Pastagem & $\begin{array}{l}\text { Vegetaçāo } \\
\text { ciliar }\end{array}$ \\
\hline Coeficiente de cobertura do dossel & $14^{(1)}$ & $14^{(1)}$ & $14^{(1)}$ \\
\hline Parâmetro para a equacião de altura do dossel & $23^{(1)}$ & $23^{(1)}$ & $23^{(1)}$ \\
\hline Taxa de energia de biomassa (kg MJ $)$ & $13^{(1)}$ & $13^{(1)}$ & $13^{(1)}$ \\
\hline Temperatura basal diária do ar $\left({ }^{\circ} \mathrm{C}\right)$ & $10^{(2)}$ & $12^{(12)}$ & 12 \\
\hline $\begin{array}{l}\text { Parâmetro para a equação de cobertura do resíduo na superficie do } \\
\text { solo }\left(\mathrm{m}^{2} \mathrm{Kg}^{-1}\right)\end{array}$ & $5^{(1)}$ & $5^{(1)}$ & $8^{(1)}$ \\
\hline Graus-dia para a emergência $\left({ }^{\circ} \mathrm{C}\right)$ & $10^{(2)}$ & $25^{(1)}$ & 25 \\
\hline Altura de corte da planta na colheita (m) & $0,08^{(3)}$ & $0,05^{(11)}$ & - \\
\hline Cobertura do dossel após a senescência (\%) & 90 & 80 & $100^{(13)}$ \\
\hline Diâmetro da planta quando adulta (m) & $0,03^{(4)}$ & $0,003^{(12)}$ & $0,3^{(14)}$ \\
\hline Índice de declínio de calor da folha (0-1) & $0,85^{(1)}$ & $0,85^{(1)}$ & $0,85^{(1)}$ \\
\hline Biomassa remanescente após a senescência (\%) & $95^{(1)}$ & $90^{(1)}$ & $98^{(1)}$ \\
\hline Coeficiente de extinção de radiação & $0,48^{(4)}$ & $0,65^{(1)}$ & $0,65^{(1)}$ \\
\hline Fator de conversão para o acamamento & $0,99^{(1)}$ & $0,99^{(1)}$ & $0,99^{(1)}$ \\
\hline Máximo fator de frioção para a planta viva & $12^{(1)}$ & $12^{(1)}$ & $12^{(1)}$ \\
\hline Índice de colheita & 0,9 & $0,95^{(12)}$ & 0 \\
\hline Altura máxima do dossel (m) & $2,5^{(4)}$ & $1^{(12)}$ & $\begin{array}{c}0,03^{(13)} \\
\text { (serrapilheira) } \\
\end{array}$ \\
\hline Constante de decomposição da biomassa acima do solo & $0,015^{(1)}$ & $0,015^{(1)}$ & $0,015^{(1)}$ \\
\hline Constante de decomposição da biomassa enterrada & $0,015^{(1)}$ & $0,015^{(1)}$ & $0,015^{(1)}$ \\
\hline Temperatura ótima para o crescimento da planta $\left({ }^{\circ} \mathrm{C}\right)$ & $27^{(2)(7)}$ & $30^{(11)(2)}$ & 25 \\
\hline Tolerância à seca & $0,25^{(1)}$ & $0,0025^{(1)}$ & $0,25^{(1)}$ \\
\hline Espaçamento entre plantas na linha (m) & $0,08^{(6)}$ & $0,002^{(2)}$ & $0,0025^{(1)}$ \\
\hline Profundidade máxima da raiz (m) & $2,5^{(7)}$ & $0,9^{(11)}$ & 1 \\
\hline Taxa de raiz a parte aérea & $0,71^{(7)}$ & $0,55^{(10)}$ & $0,1^{(13)}$ \\
\hline Máxima massa de raízes para uma planta perene $\left(\mathrm{kg} \mathrm{m}^{-2}\right)$ & $0,7^{(7)}$ & $0,6^{(1)}$ & 0,34 \\
\hline Período a partir do qual ocorre a senescência (dias) & 0 & 14 & 360 \\
\hline $\begin{array}{l}\text { Temperatura máxima a partir da qual o crescimento de uma planta } \\
\text { perene cessa }\left({ }^{\circ} \mathrm{C}\right)\end{array}$ & 40 & 38 & 38 \\
\hline Temperatura critica de congelamento $\left({ }^{\circ} \mathrm{C}\right)$ & $0,5^{(1)}$ & $5^{(1)}$ & 5 \\
\hline İndice de Área Foliar máximo & $3,7^{(8)}$ & $10^{(11)}$ & $5,2^{(13)}$ \\
\hline \multicolumn{4}{|l|}{$\begin{array}{l}\begin{array}{c}\text { Condições em } 1^{\circ} \text { de janeiro (inicio de qualquer simulação de } \\
\text { erosão) }\end{array} \\
\end{array}$} \\
\hline Densidade do solo $\left(\mathrm{g} \mathrm{cm}^{-3}\right)$ & 1,3 & 1,3 & 1,3 \\
\hline Cobertura oferecida pelo dossel (\%) & 100 & 100 & 100 \\
\hline Dias desde a ultima operação agrícola & 470 & - & -- \\
\hline Dias desde a ultima colheita & 180 & - & - \\
\hline Profundidade de congelamento do solo (m) & 0 & 0 & 0 \\
\hline Cobertura do solo entre-sulcos (\%) & $70^{(6)}$ & $60^{(\mathrm{II})}$ & 100 \\
\hline Total de chuva caído desde a ultima operação agrícola (mm) & 500 & 500 & 500 \\
\hline Altura da rugosidade após a ultima operação agrícola (m) & 0,15 & $0,02^{(I)}$ & $0,02^{(1)}$ \\
\hline Cobertura do solo no sulco (\%) & $80^{(6)}$ & 60 & 100 \\
\hline Rugosidade randômica após a ultima operação ag̣ícola (m) & 0,04 & $0,01^{(1)}$ & $0,04^{(1)}$ \\
\hline Tipo de sulco & Temporário & Temporário & Temporário \\
\hline Profundidade de neve (m) & 0 & 0 & 0 \\
\hline Massa de raizes mortas nos primeiros $10 \mathrm{~cm}$ do solo $\left(\mathrm{kg} \mathrm{m}^{-2}\right)$ & $0,1^{(7)}$ & $0,15^{(11)}$ & $0,06^{(16)}$ \\
\hline Massa de resíduos enterrados nos primeiros $10 \mathrm{~cm}$ do solo $\left(\mathrm{kg} \mathrm{m}^{-2}\right)$ & $0,1^{(7)}$ & 0 & 0 \\
\hline
\end{tabular}

Fonte: (1) adaptado do WEPP, para culturas e/ou situações semelhantes; (2) van Heemst (1988); (3) consulta a produtores; (4) Vasconcelos (1998); (5) Doorenbos \& Kassan (1979); (6) Pesquisadora Raffaella Rosseto, IAC / Centro de Pesquisa de Cana (comunicação pessoal); (7) Casagrande (1991); (8) Machado et al. (1982); (9) Eng. Agrônomo Roberto Carvalho - Dina Sementes (comunicação pessoal); (10) Proceedings of the $8^{\text {th }}$ Australian Agronomy Conference (1996); (11) Zimmer et al. (1988); (12) Eng. Agrônoma Patrícia Santos - Depto. Zootecnia - ESALQ (comunicação pessoal); (13) Szott et al. (1994); (14) Castro \& Kaufinan (1998); (15) Didham (1998); (16) Berish (1982). 
Apêndice 2 


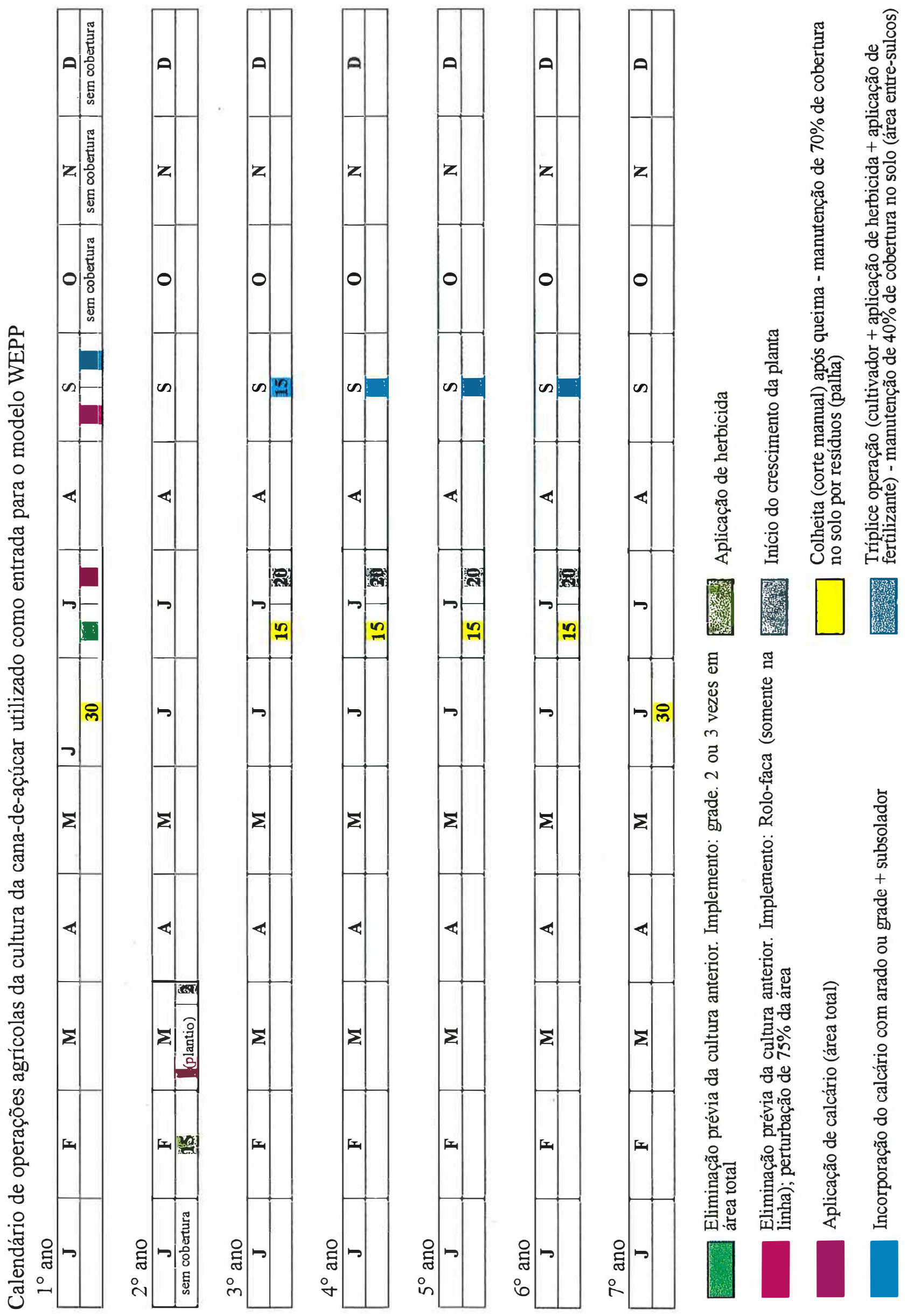

